\title{
Survey and Analysis of Federally Developed Technology
}

Nancy Moore, Project Manager

February 1983

Prepared for

Pacific Northwest Laboratory

by Energetics, Incorporated

under Contract B-96676-A-Z

Pacific Northwest Laboratory

Operated for the U.S. Department of Energy

by Battelle Memorial Institute 


\section{DISCLAIMER}

This report was prepared as an account of work sponsored by an agency of the United States Government. Neither the United States Government nor any agency thereof, nor any of their employees, makes any warranty, express or implied, or assumes any legal liability or responsibility for the accuracy, completeness, or usefulness of any information, apparatus, product, or process disclosed, or represents that its use would not infringe privately owned rights. Reference herein to any specific commercial product, process, or service by trade name, trademark, manufacturer, or otherwise, does not necessarily constitute or imply its endorsement, recommendation, or favoring by the United States Government or any agency thereof. The views and opinions of authors expressed herein do not necessarily state or reflect those of the United States Government or any agency thereof.

\section{PACIFIC NORTHWEST LABORATORY operated by \\ BATTELLE \\ for the \\ UNITED STATES DEPARTMENT OF ENERGY under Contract DE-AC06-76RLO 1830}

\begin{tabular}{|c|c|}
\hline \multicolumn{2}{|c|}{$\begin{array}{l}\text { Printed in the United States of America } \\
\text { Available from } \\
\text { National Technical Information Service } \\
\text { United States Department of Commerce } \\
5285 \text { Port Royal Road } \\
\text { Springfield, Virginia } 22161\end{array}$} \\
\hline \multicolumn{2}{|c|}{$\begin{array}{l}\text { NTIS Price Codes } \\
\text { Microfiche A01 }\end{array}$} \\
\hline \multicolumn{2}{|c|}{ Printed Copy } \\
\hline Pages & $\begin{array}{l}\text { Price } \\
\text { Codes }\end{array}$ \\
\hline $001-025$ & $\mathrm{~A} 02$ \\
\hline $026-050$ & $\mathrm{A03}$ \\
\hline $051-075$ & A04 \\
\hline $076-100$ & A05 \\
\hline $101-125$ & A06 \\
\hline $126-150$ & A07 \\
\hline 151.175 & $A 08$ \\
\hline $176-200$ & $A 09$ \\
\hline $201-225$ & $A 010$ \\
\hline $226-250$ & A011 \\
\hline $251-275$ & $\mathrm{~A} 012$ \\
\hline $276-300$ & $\mathrm{~A} 013$ \\
\hline
\end{tabular}


N. L. Moore, PNL Project Manager

J. E. Reed

J. L. Conrad, Energetics, Incorporated

February 1983

Prepared for

Pacific Northwest Laboratory by Energetics, Incorporated under Contract B-96676-A-Z

Pacific Northwest Laboratory

Richland, Washington 99352 
TABLE OF CONTENTS

Page

I. INTRODUCTION . . . . . . . . . . . . . . . . . . . . . 1

II. METHODOLOGY ....................... 2

III. SIGNIFICANT FEDERAL LABORATORY WORK APPLICABLE TO THE PULP AND PAPER INDUSTRY . . . . . . . . 5

IV. RESPONSE OF PULP AND PAPER INDUSTRY TO FEDERALLY DEVELOPED TECHNOLOGIES . . . . . . . . . . . . . 18

APPENDIX: FEDERALLY DEVELOPED TECHNOLOGIES WITH POTENTIAL APPLICATION IN THE PULP AND

PAPER INDUSTRY . . . . . . . . . . . . . . . . . . . 23 
$\bullet$ -

1 


\section{EXECUTIVE SUMMARY}

Federal laboratories represent collections of expertise and facilities unparalleled in the world. They conduct basic and applied research and development in numerous and diverse fields. Although the products of their efforts could be of considerable value to the private sector, they remain relatively unknown due to the time and resources required to identify and analyze them.

This document presents the methodology and results of a test effort to determine whether there exist unexpected opportunities for the direct transfer of technologies from federal laboratories to industry. Specifically, the latest results of six federal laboratories with potential application in the pulp and paper industry, particularly those results applicable to improving energy productivity, were evaluated, cataloged, and distributed to industry representatives to gauge their reaction.

The six laboratories surveyed include: Idaho National Engineering Laboratory (INEL), Jet Propulsion Laboratory (JPL), Lawrence Livermore National Laboratory (LLL), National Aeronautics and Space Administration Lewis Research Center (NASA Lewis), Oak Ridge National Laboratory (ORNL), and Sandia National Laboratory, Livermore (SNL).

The principal methodological steps in this effort were the development of a taxonomy of the pulp and paper industry, identification of industry needs and laboratory capabilities, laboratory visits, review of technology findings with industry, and evaluation and compilation of industry responses.

The initial step in this effort was to develop a taxonomy of the wood fiber forestry and paper and allied products industry, which describes the major processes and activities from tree seedling production to paper and paperboard coating and converting. The taxonomy provided a means of organizing industry needs and federally-developed technologies and for coupling the two. Furthermore, the taxonomy allows industry personnel to readily identify federally developed technologies applicable to particular sectors of the industry.

Preparation for the lab visits involved preliminary identification of major program effots, unique technical expertise, and existing technology transfer efforts for the selected federal labs. This step was aided by documents obtained from the laboratories Technology Utilization Officers, who have responsibility for federal laboratory compliance with the StevensonWydler Technology Innovation Act of 1980 (PL-96-480).

Also, prior to the lab visits, the project team convened a two-day brainstorming session during which industry needs and possible laboratory programs applicable to those needs were identified. The document from this session (a taxonomy on wich was overlaid the team's perceptions of federal laboratory work potentially applicable to individual elements) was sent to the laboratories to provide advanced insight into the scope and depth of the investigation.

The laboratory visits typically involved an initial presentation to a small group of senior technical managers selected by the Technology Utilization officers. Principal Investigators working in areas related to the taxonomy 
elements, identified in the initial presentation, were then interviewed. The resulting notes and technical documents became the information base for the project.

Follow-up activities included the cataloging of information gathered, additional communications with the Principal Investigators, and the development of formatted profiles for each technology. The technology profiles were compiled in notebook form, arranged by taxonomy element, and distributed to pulp and paper industry personnel for review comment. Also, oral presentations were made to corporate and industry-wide groups to introduce the projects intent and to familiarize industry representatives with the technologies uncovered. Finally, industry comments were compiled to develop a summary of industry reaction, and this final report was prepared on the effort.

Numerous federally-developed technologies were identified during the course of this test effort. Profiles for 38 technologies relevant to the PPI were prepared and are presented as an Appendix to this document. Those more significant and generally less known technologies are described in the text according to applicable taxonomy element. Several technologies were found to be relevant to more than one taxonomy element.

For example, in the development, management and utilization of forest resources, several key technologies were uncovered. ORNL, using enclosed tents and carbon 14 tagging techniques, is studying the impact of various atmospheric environments on seedling production of loblolly pine and white oak. Nutrient cycling is being studied on a 250-acre plot over which 15-year data is sought. INEL, in conjunction with a geothermal enery project, is searching for genetically superior tree species suitable for large areas of marginal, usually non-arable, land that could be irrigated with saline aquifers existing below such acreage. ORNL, with the USDA, is studying short rotation intensive culture forest production, emphasizing the development of hard woods capable of extremely intensive culture. Studies on the long-term effects of whole tree harvesting on forest parameters and the development of a county-level geoecology data base are other ORNL activities. JPL is working on global ecology monitoring using the Landsat satellite, and NASA Lewis has developed a series of photovoltaic systems with a variety of potential uses including insect survey/kill traps, power supply for lookout towers, and refrigeration and space conditioning systems for remote areas.

In the area of pulp and paper production, federally-developed technologies could conceivably lead to basic changes in conventional industry processes in addition to resolving many outstanding problems faced by the PPI. These technologies apply to a wide range of processes from $\log$ debarking to final paper and paperboard manufacture.

ORNL has expressed interest in an experimental evaluation of a debarking technique employing a high voltage discharge to strip bark from logs using less energy than conventional techniques. Several concepts might promote development of chippers that are capable of maintaining their sharpness under adverse conditions. JPL is examining techniques for sputtering amorphous metal onto conventional metal substrates. Coating alloys, such as titanium diboride, on conventional chipper blades can make the blades extremely hard and impart a high thermal conductivity, prolonging their life. LLL is concentrating on coating techniques employing cubic boron nitride, an extremely 
hard ceramic material, and the fabrication of tools capable of high temperature operation. Such techniques for surface treating conventional metals with high strength, high thermal conductivity amorphous metals could represent major breakthroughs in thermo-mechanical pulping processes.

Also relevant to mechanical pulping and similar processes is work by NASA Lewis in the area of high-speed, high-temperature bearings and lubricants. NASA Lewis is investigating lubricants capable of prolonged operation at temperatures in excess of $425 \mathrm{~F}$, specifically polyvinyl ethers, fluorocarbons, and parafinic lubricants; they have also developed a commercially available three micron filter capable of improving bearing life. They have also developed alloys for the raceways of highly loaded bearings that reduce the failure mode (usually spallation), two detectors to indicate failure before it actually occurs, and traction drives capable of transforming the output of a gas turbine to the drive speeds required for helicopter blades.

Numerous technologies were uncovered that are potentially applicable to chemical pulping and especially to the black liquor cycle. For example, NASA Lewis and INEL are examining the use of bi-phase engines for liquid concentration. Bi-phase engines could replace the first flash drying stage of black liquor concentration, achieving large energy savings.

JPL is working on a photoacoustic spectrometer that may be capable of evaluating the degree of cooking achieved in the digester by detecting the ratio of lignin to pulp in the effluent stream. A second instrument being developed by JPL involving laser-induced flurescence and a light pipe system could also be used to determine the free lignin in digester effluent and might also be used to determine the lignin concentration in the recovery boiler feed. Some other technologies that could promote more efficient operation of the recovery boiler include a pinhole imaging system developed at INEL, allowing more efficient inspection of the boiler; work on the acoustic control of fuel droplet size by NASA Lewis; and work on the acoustic signature of turbulent flame by JPL. Finally, use of amorphous metals (as boiler tube sheathing) could drastically lessen recovery boiler tube corrosion. Novel explosive forming, bonding and welding techniques developed by LLL could potentially be used to fabricate such composite tubes which would otherwise be impossible with conventional techniques.

Technologies relevant to paper and paperboard production were also uncovered. Amorphous metals, high-speed lubricants, and other technologies previously mentioned could be useful to the pulp refining process. A laser thermal lensing technique under developement by JPL has potential for use as an on-line consistency meter for pulp entering the head box of the paper machine. Another device developed by JPL, an electrolytic polymeric hygrometer, detects moisture levels from a few parts per million to saturation. This device could be used at various locations within a hooded papermaking machine, permitting more efficient operation and lower steam demand; or to determine moisture content of sheet or felt, reducing production interruptions due to web breakage.

Auxillary systems found at integrated pulp and paper mills.can also benefit from federally-developed work. For power and chemical recovery systems, the same technologies applicable to the black liquor recovery boiler would apply here as well. In addition, INEL has been developing organic 
Rankine systems for the extraction of electrical energy from low-temperature, geothermal fluids which could conceivably recover energy from thermal mechanical pulping and other high-volume, low-quality waste energy streams. SNL has extensive experience and facilities in the area of combustion research and operates a Combustion Research Facility open to use by qualified researchers.

Federal laboratories are also active in the area of health, safety and pollution control. SNL has developed a real time dust monitoring system capable of monitoring and control of a high range of particulates. JPL is investigating enzymatic hydrolysis of cellulose and hemi-cellulose to produce fuels and feedstocks through anaerobic digestion. ORNL is investigating the use of waste stream products, such as lignosulfanate and sodium sacchrinate, as surfactants for increasing tertiary oil recovery. ORNL has also developed a series of multimedia models to investigate the environmental movement of pollutants. Finally, in this area, INEL has developed a Management Oversight and Risk Tree (MORT) system for evaluating, and managing environment, health, and safety information.

Finally, several laboratories are working in areas that could lead to more efficient process control. INEL has developed a system for validating the signals received from a multiple number of sensors in an integrated process stream. NASA Lewis is developing a series of hybrid computer technologies and models to successfully simulate real time operation of highspeed processes. LLL is developing a local area network information system for rapid transmission of experimental and control data within the laboratory. This fiber optics based system is designed to rapidly transport analog and digital signals from sensors located throughout a complex process stream.

The reaction of the pulp and paper industry to the federally-developed technologies and to the effort itself was unanimously favorable. It was evident from industry reaction that a great deal of work underway at federal labs (much of which the industry was unaware of) has relevance to pulp and paper industry needs. Some technologies uncovered were perceived as being useful to the industry and others, as useful to specific companies. While some technologies were consistently mentioned as being useful, virtually all were mentioned at least once.

Other features of the compilation of federally-developed technologies of value to the pulp and paper industry were: the familiarization with overall laboratory capabilities and test facilities, the inclusion of names and telephone numbers of people to contact at the labs and elsewhere for follow-up information, and organization of the technologies according to taxonomy elements which facilitated distribution and use of the information. 


\section{INTRODUCTION}

Federal laboratories conduct basic and applied research and development in numerous and diverse fields. Although the products of these efforts, individually or in combination, could be of considerable value to the private sector, they often remain relatively unknown due to the time and resources required to identify and analyze them.

The objective of this report was to evaluate the potential application of work underway at federal laboratories to technical problems in U.S. industry. More specifically, the latest results of six selected federal laboratories applicable to the pulp and paper industry, particularly those results applicable to improving energy productivity, were evaluated and catalogued. This effort was viewed as a test case for determining whether there exist unexpected opportunities for the direct transfer of technologies from federal laboratories to industry.

The six laboratories surveyed include: Idaho National Engineering Laboratory (INEL), Jet Propulsion Laboratory (JPL), Lawrence Livermore National Laboratory (LLL), National Aeronautics and Space Administration Lewis Research Center (NASA Lewis), Oak Ridge National Laboratory (ORNL), and Sandia National Laboratory, Livermore (SNL).

Topics discussed in subsequent sections of this report are as follows: Section II of the report outlines the methodology employed in identifying and evaluating federal laboratory capabilities and work currently underway at federal laboratories with potential application to the pulp and paper industry (PPI). In Section III those findings that have significant applicability and that are believed to be less well known to the PPI are described. Section IV discusses the reaction of the PPI to the federally developed technologies with respect to the perceived value of the information presented and with respect to receptivity to the direct transfer of such results to industry. Finally, the Appendix provides summary descriptions of all of the federally developed technologies uncovered having potential application in the PPI. As such, the Appendix is not a mere afterthought to the report; it is perhaps that portion of the report of greatest use and value to industry representatives. 


\section{I . METHODOLOGY}

As a first step in this program, a taxonomy of the wood fiber forestry industry and paper and applied products industry was developed. This taxonomy described the major processes and activities from tree seedling production and genetic development to paper and paperboard product coating and converting. The basic elements of this taxonomy are shown in Figure 1. The taxonomy provides a means of organizing industry needs (opportunities for federal labs) and the federally developed technologies, as well as providing a means for coupling the two. More importantly, the taxonomy allows the pulp and paper industry to readily identify federally developed technologies applicable to particular sectors of the industry.

At the same time the taxonomy was being developed, the major program areas, unique technical expertise, and existing technology transfer activities were identified for the selected federal laboratories. In this review process, appropriate documents were obtained from each laboratory using their respective Technology Utilization Officers as points of contact. These Officers have responsibility for federal laboratory compliance with the Stevenson-Wydler Technology Innovation Act of 1980 (PL 96-480).

Using the taxonomy as a guide the project team convened a two-day brainstorming session during which problems in the industry and possible laboratory programs which may bear on those problems were identified. During this session, emphasis was placed on "open-mindedness," i.e., no idea was considered too outlandish. The document resulting from this session was a taxonomy on which was overlaid the project team's perception of work underway in laboratories which could have bearing on problems within each element. This document was then sent to each laboratory prior to the project team visit to provide advanced insight into the scope and depth of the investigation.

The laboratory visits were extremely interesting and gratifying. It was interesting to observe the change from an initial attitude of bored and unconvinced compliance to one of enthusiastic interest and constructive participation after the discussions had been underway a short time. The visits typically began with an Energetics' presentation to a small group of senior technical managers selected by the Technology Utilization Officer. The result of this presentation was a list of names of Principal Investigators working in technology areas related to elements of the taxonomy. These Principal Investigators were then each interviewed, and the resulting notes and technical documents became the information base for the project.

Follow-up activities included the cataloguing of all information gathered, additional communication with the Principal Investigators, and the development of formatted profiles for each technology. These profiles listed the Principal Investigator, his telephone number, title, and organization code, the technology name, applicable taxonomy elements, and reference material, in addition to a narrative description.

The next methodological step was to review the technology findings with industry representatives. Summary technology descriptions were prepared in notebook form, arranged according to the taxonomy elements, and distributed to pulp and paper industry personnel for review comments. Presentations 


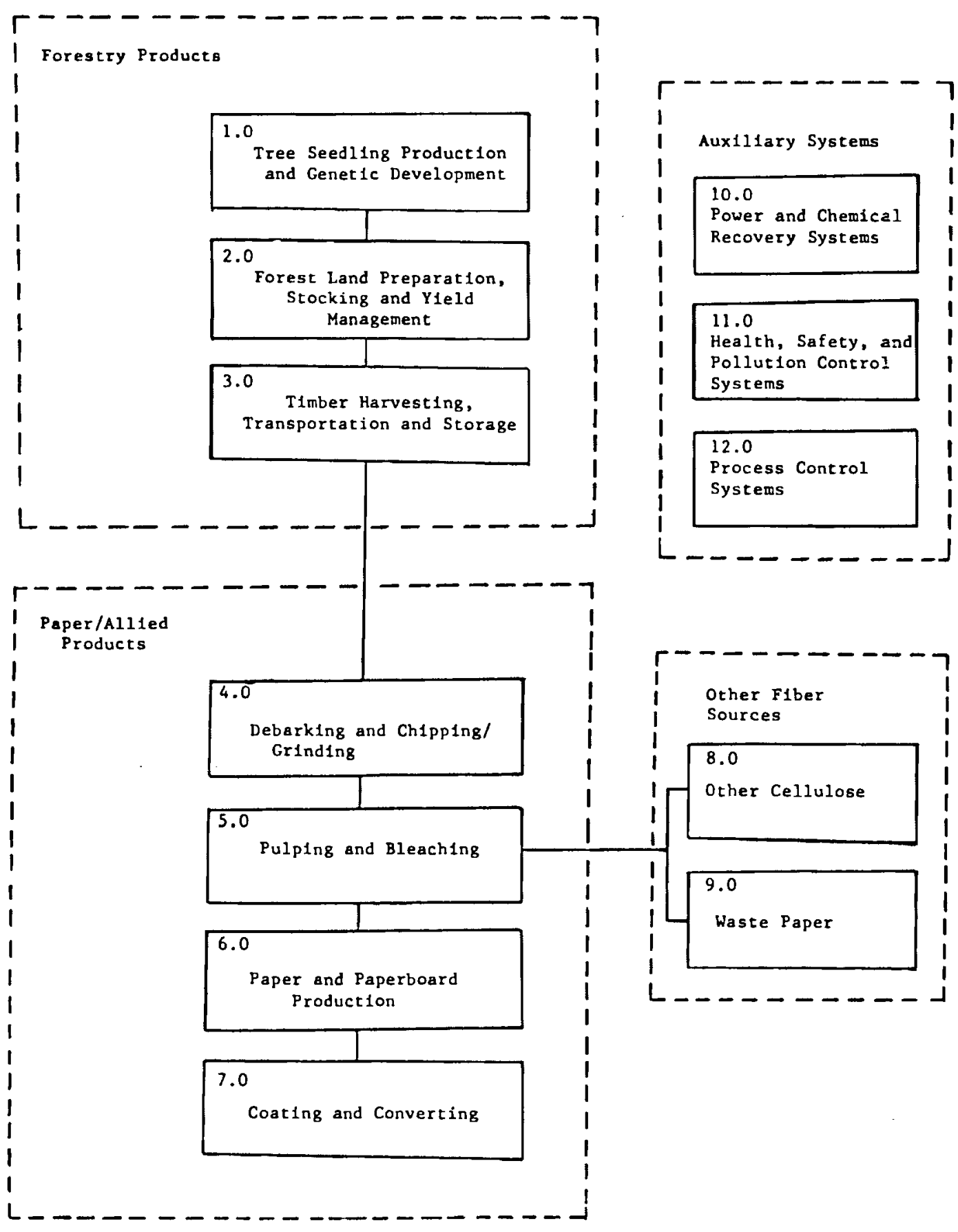

Figure 1. A Taxonomy of Wood Fiber Forestry Products and Paper/Allied Products Manufacturing Industries 
were given to corporate and industry-wide groups to introduce the project's intent and familiarize key, high-level industry representatives with the federal laboratory technologies found. Presentations were given to the following two industry-wide groups:

- The Annual Papermakers Conference, Technical Association of the Pulp and Paper Industry, April 5, 1982 (Keynote Address by Douglas G. Harvey).

- The June 11, 1982 Meeting of the NBS/DOE sponsored, Sensor Development Steering Committee.

The interest expressed by the industry at these meetings and in meetings with individual corporate $R \& D$ groups was extremely enthusiastic and, hopefully, portends industry interest in further pursuit of this concept.

Finally, the industry responses received in presentation settings and in the form of review comments were compiled to develop a summary of industry reaction. One fact has become clear. The national laboratories represent collections of expertise and facilities unparalleled in the world, and this capability represents a resource which, if brought to bear on industry problems, would enable significant improvement in productivity not only in Pulp and Paper but throughout the industrial sector. The mechanism through which this relationship is consumated has yet to be defined. 
III. SIGNIFICANT FEDERAL LABORATORY WORK

APPLICABLE TO THE PULP AND PAPER INDUST:

This Chapter discusses those technologies that are being developed in federal laboratories that may have significant applicability to problems within the pulp and paper industry. The Chapter is organized in accordance with the taxonomy elements previously discussed. In cases where a specific technology may be applicable to more than one taxonomy element, such technology is discussed in both places.

\subsection{Tree Seedling Production and Genetic Development}

\subsection{Tree Seedling Nurseries}

This activity in the pulp and paper industry involves the development of genetically superior trees for the production of seed capable of fide-spread nursery application. In addition, the actual nursery operations are included. This involves optimizing seed germination, development of containerization systems for seedlings, watering, nutrient feeding, bulk handling, packaging and chemical control of insects and disease organisms.

Oak Ridge National Laboratory, under the direction of D. S. Shriner, has a field facility that specifically looks at the seedling production of loblolly pine and white oak. They have developed a technique for surrounding test trees with tents which permits control of the atmosphere to which the seedling is exposed. By this means an air exchange rate of 2,000 cu. ft. per minute can be maintained. Such studies as carbon 14 tagging for determination of $\mathrm{CO}_{2}$ stimulation of growth are being conducted. Micromorbidity from toxic substances associated with various types of activity including acid rain and other atmospheric environments presumably adverse to seed propagation can be studied. The ORNL group is studying nutrient cycling on a 250 acre plot over which fifteen year data is being generated. This activity is directly applicable to the pulp and paper industry; it is believed that the National Council of the Pulp and Paper Industry for Air and Stream Improvement is well informed on this research.

\subsection{Tree Seed Gathering}

The current technique for gathering seeds from selected pulp and paper nursery trees involves shaking equipment that drops the seed into collection sheets below the tree. Although there has been industry expression to the effect that this is a somewhat archaic gathering technique, no activity within the laboratory was found which would improve upon the current practice.

\subsection{Genetic Selection and Improvement}

The industry is always interested in finding genetically superior trees for maximum growth and to thereby generate a greater pulp production per unit acreage planted. Idaho National Engineering Laboratory is currently investigating the ability of certain species of trees capable of saline water irrigation. This work is being done in conjunction with the Raft River geothermal energy project where large quantities of saline water are brought 
to the surface for power production. They have planted large acreage with twenty promising species of trees that could be tolerant to such irrigation. This work is being done in anticipation of using the very large areas of marginal land, normally non-arable, that could be irrigated with saline aquifers existing below the surface. Were this program successful, a significant quantity of additional acreage could be brought into production.

\subsection{Forest Land Preparation, Stocking and Yield Management}

\subsection{Forest Land Preparation}

Normally in the industry this activity includes the clearing, grading, fertilizing, tilling, watering and erosion control systems involved in preparing forest soils for seedling introduction. Recognizing that reforestization of hilly terrain is generally not attempted by the industry because of the cost of reforestization of such terrains, the initial study group concluded that there may be activities within the laboratories that could directly address this problem. Such activities could include the laser clearing of land and use of articulated heavy machinery that would be able to traverse the hilly terrains involved.

Discussions with NASA Lewis indicate that laser clearing may indeed be a very possible technological solution to large area forest clearing. Work at the Jet Propulsion Laboratory on articulated machinery capable of remote manipulation has indeed been performed on Mars lander vehicles and the like. It was our impression, however, that such articulated machinery would indeed be extremely expensive for this activity within the pulp and paper industry and probably would not be directly applicable.

Another thought was the use of aircraft for the actual planting of seedlings in remote terrain. The development of satellite landing systems indicated that it would be possible to set a seedling with an arrangement such that when dropped from an airplane, the seedling would plant itself. Subsequent discussions with the industry however, indicate that such techniques were already in practice and no further work needed to be done in this area.

\subsection{Stocking}

Includes the equipment and operation involved in planting seedlings. No technologies were found that directly relate to the stocking operation.

\subsection{Yield Management}

This activity includes the equipment and operations used to enhance and protect the fiber yield for the acreage planted. It includes such activities as insect and pest management, fire control, supplemental irrigation and fertilization, inventory and growth measurement, timber evaluations and harvest scheduling.

Oak Ridge National Laboratory, under the direction of $\mathrm{J}$. W. Ranney, is conducting a program in conjunction with the USDA on short rotation intensive culture forest production (SRIC). The SRIC activity focuses on the development of hard woods that are capable of extremely intensive culture. The Department 
of Energy's activities in this area supplemented on-going USDA work. This work has been in progress for a number of years now and is probably well-known throughout the pulp and paper industry. More details on this activity can be found in the Appendix.

Oak Ridge is also conducting a long-term study on the effects of whole tree harvesting on erosion, water quality, nutrients and forest productivity. This activity has been in progress for two years, and the second year progress report is referred to in the Appendix. Again, it is probable that the pulp and paper industry is well-acquainted with this work.

Oak Ridge is also developing a county-level data base for the conterminous United States. This activity may not be known by officials in the pulp and paper industry. This geoecology data base contains selected data on terrain and soils, water resources, forestry, vegetation, agriculture, land use, wildlife, air quality, climate, natural areas and endangered species on a county-wide basis throughout the United States. The data base is fully documented, and a comprehensive user's guide is available. It can be accessed in either batch jobs or interactive modes. It uses the statistical analysis system for data storage, retrieval, and analysis. Maps and graphics are generated from the data base by using independent programs. This data base could have significant impact on monitoring pests associated with specific pulp and paper activities, such as the gypsy moth. But it also could be used to determine the potential yield from various forested areas not currently being used by the pulp and paper industry. Another possible application of the data base would be to study forest fire history, such as acreage burned by county and year, and correlating this with rainfall, water table or snow cover for subsequent planning for deployment of firefighting resources by the industry. Although the tapes of the data base and the computer program that is used for its generation can be made available to potential users, the personnel that developed this technology are soliciting problems on which to work and indeed could provide a valuable, independent asset to the industry.

The Jet Propulsion Laboratory, under the direction of Dr. Dastoor, is working on global ecology monitoring using the Landsat satellite. They are attempting to determine the rate limiting parameters of the nitrogen and carbon cycles on a global basis. It is their opinion, however, that satellite and aircraft monitoring of specific forests on a regional basis may be a more fruitful pursuit. Ground-based instrumentation of soil moisture, soil nitrogen and gaseous components will be simultaneously used to evaluate the health of a forest. Once background data were obtained, forest yield optimization would be attempted by application of rate changing reactants such as the enzymatic catalysis of organic nitrogen. At least one paper company, the St. Regis Paper Company, is using Landsat data for forest management. An interesting extension of this activity, however, would be to look at specific forest rate measures through combined satellite-land instrumentation.

NASA Lewis, under the direction of Anthony Ratachek, has developed a series of photo-voltaic systems that may be applicable to yield management. For example, they have developed a photo-voltaic powered insect survey/kill trap. This highly reliable system has no moving parts and would be ideal for determining insect populations in remote sites. The system is now commercially available. A second photo-voltaic system has to do with the powering of look-out towers for forest fire control. These are 300 watt photo-voltaic 
systems with ancillary storage and control components. For a period of several years they have been shown to have $100 \%$ availability and have saved the U.S. Forest Service considerable costs in relationship to alternative powering of these forest towers. A third photo-voltaic system has been used to supply remote field crews with the amenities of life including a refrigerator and space conditioning systems. This work was funded in cooperation with the National Park Service and has proven to be quite satisfactory. Although the initial capital cost of the photo-voltaic systems are somewhat higher than conventionally powered systems, their applicability to remote areas would probably provide the economics required when one considers the cost of fuel supply.

\subsection{Timber Harvesting, Transportation and Storage}

\subsection{Harvesting}

This activity includes the equipment and operations used to cut, process and yard standing timber. It was originally perceived that laser cutting of timber might indeed be applicable technology under development by the laboratories. Subsequent discussion with the industry however, indicated that the harvesting equipment currently used is quite sophisticated and probably would not be improved by laser cutting. One activity being developed by Oak Ridge National Laboratory is a portable fluidized bed system capable of burning forest slash and generating electricity. Were the system sufficiently portable to transport to the field, a great portion of the waste wood (approximately $50 \%$ of the total timber value harvested) could be used to generate power on-site for the powering of the harvesting machinery. Such a concept although quite advanced compared to today's technology, could represent an activity of cooperative pursuit.

\subsection{Transportation}

This activity includes the equipment and operations used to transport pulp wood or pulp wood products from the forest lands to the pulp mill. Currently trucks, waterways and rail transport are used. We investigated the potential of lighter-than-air devices and ground-effect machines for the transportation of large quantities of pulp wood from remote forest regions to staging centers. NASA Lewis was interested in such a concept but had no work underway which potentially could provide such a capability.

\subsection{Storage}

This activity includes the equipment and operations involved in the weighing or scaling of pulp wood or pulp wood products in the storage of pulp wood at the mill site. It was perceived that the determination of moisture content of pulp wood logs, as they are being received, would be a substantial benefit to the log purchaser. The industry would like to be able to accurately determine the value of the pulp contained in the contract logs delivered based on the dry weight of the logs as received.

Several concepts were discussed with the laboratories including the development of a gamma ray activated gauging technique for determining the 
pulp or cellulose density of each $\log$ on a dry basis. It was concluded that, for specific grades of wood, such a system would be feasible; no work, however, has been underway that would be directly applicable to this problem.

\subsection{Debarking and Chipping/Grinding}

\subsection{Debarking}

The current method of debarking logs in an integrated paper mill involves either direct machine abraiding of the bark from the log or the use of high pressure hydrodynamic jets that remove the bark. Both techniques are extremely energy intensive. It was the perception of the project team that it would be possible to use a high voltage discharge for debarking logs. Such a concept would be analogous to those phenomena which occur when lightning strikes a tree and strips the bark from it. Most of the ionic species in a tree are in the cambium layer near the surface and would represent the primary current carrying capability of the $10 \mathrm{~g}$. Thus, if high voltage from a capacitive discharge bank were applied, presumably the bark would easily strip off. Although no direct work has been done in laboratories related to this problem, Oak Ridge National Laboratories expressed significant interest in attempting to perform such work. They have large capacitors sufficient to deliver the voltage to strip the bark. Mr. Eugene $\mathrm{C}$. Hise of the Engineering Technology Division, expressed interest in conducting an experimental evaluation of this proposed debarking technique.

\subsection{Chipping and Grinding}

Converting round wood to chips suitable for introduction into the digestor is an extremely energy intensive step and one which involves large chipping machinery with very high power input, typically on the order of $15,000 \mathrm{hp}$.

Obviously tool life in equipment of this type is extremely important. Indeed the development of chippers which are capable of maintaining their sharpness under extremely adverse conditions would be a great advantage to the industry. Several concepts emerged that might be applicable to this problem. The first of these involved technology being developed at the Jet Propulsion Laboratory under the direction of Dr. Suttish Khanna. They have been examining techniques for the sputtering of amorphous metal onto conventional metal substrates. Amorphous metal manufacture is a technology developed over the last decade or so. It requires the rapid cooling or quenching of the metal alloy as it is being deposited. It is possible by this means to develop a surface that has no grain structure and no boundary layers. Such a deposition, depending on the alloy composition, can be made extremely hard and also to have high thermal conductivity, two major assets for any machine tool required to perform under the high heating conditions associated with this activity. It is conceivable that such a coating could be laid down upon conventional chipper blades that could significantly prolong their 1 ife in the chipping operation. Unique alloys such as titanium diboride, under development by JPL, could be used for this type of tool coating. The applicability of amorphous metals to other potential problems will be discussed in paragraph 5.1 .

A second possible coating material for chippers and other high-powered tools in the industry involves technology developed by Lawrence Livermore 
Laboratory. In the need to develop tools that were capable of firish turning hard, tough, high temperature alloy materials, LLL has concentrated on tool coating surfaces of cubic boron nitride. Cubic boron nitride is an extremely hard ceramic material that can be deposited on conventional substrates and provide a tool surface that is capable of high temperature operation. In the work at LLL, these characteristics have been used for the machining of very high accuracy bearing surfaces on stainless and other high temperature alloys. Machine bearings of high purity can now be produced in a quasi-production line operation. But this same technology if applied to such surfaces as chipper blades, could significantly prolong their life. Cubic boron nitride is commercially available from multiple sources and a reference can be found in the Appendix.

\subsection{Pulping and Bleaching}

\subsection{Mechanical Pulping}

Mechanical pulping is an activity within the pulp and paper industry used for the preparation of pulp primarily for newsprint although better grades of paper can be made through the addition of various additives in the final sheet. A major advantage to mechanical pulping is a high pulp yield. There are several types of mechanical pulping techniques--all of which involve some form of physically grinding the wood chips down to pulp size. This may be done with large stone grinding wheels powered by very high horsepower motors or by refining, a thermomechanical means that combines both thermal and mechanical energy to reduce the wood chips to pulp. In both cases the amount of energy consumed in the pulping operation in the form of electricity is large. In the case of thermomechanical pulping, two 6,000 hp motors operating very carefully machined, close tolerance wheels which rotate in opposite directions, are used to reduce the chips to the pulp. Again, the hardness of the surface of these metallic wheels is extremely important in terms of useful life. The applicability of amorphous metals to these surfaces could be a significant improvement in the state of the art.

The Jet Propulsion Laboratory techniques for surface treating conventional metals with high strength, high thermal conductivity amorphous metal surfaces could represent a major breakthrough in the technology of thermomechanical pulping equipment.

Also, very significant in the operation of this equipment, is the ability of the bearing to maintain lubricity to the systems involved. High-speed, highly-loaded bearings are used. NASA Lewis has developed a sophisticated bearing system for both aircraft and helicopters. They have worked in areas of high temperature lubricant development which involved lubricants capable of prolonged operation in temperatures in excess of $425^{\circ} \mathrm{F}$. Three types of lubricants have been investigated, including polyvinyl ethers, fluorocarbons and parafinic lubricants. This latter type has demonstrated fifteen times the catalog bearing life under extremely high speed and high load conditions. A problem with parafinic fluids for aircraft operation is their low temperature pour point (high viscosity). This problem, however, would not be a deterrent to use in the pulp and paper industry. NASA Lewis also has been looking at entire bearing systems and has developed a three micron filter that has been 
shown to improve bearing life significantly. This filter is now commercially available and reference is given in the Appendix as to suppliers.

Spallation is considered to be a normal failure mode for high speed, highly loaded bearings. The development of alloys for the raceways of such bearings has significantly reduced the failure mode and heavily loaded bearings at $425^{\circ} \mathrm{F}$ have been operated as much as fifty thousand hours before failure. NASA Lewis researchers also have developed two detectors which can indicate bearing failure in advance of the actual failure. The first of these is a piezo-electric transducer that detects the initiation of spallation and the second is a magnetic spark ignition device called a chip burn-off detector which detects the amount of spallation that has actually occurred over the life of the bearing. This latter detector can be placed downstream of a bearing, and with the data obtained it is possible to predict when a bearing is going to fail via the spallation failure mode.

NASA has developed a computer capability which simulates the loads, the D.N. (an emperical operating parameter) and temperature as input and provides the bearing and lubrication systems designed to minimize cost and maintenance and to maximize the life of the integrated lubrication system. Although this system was developed for the analysis of bearing systems in aircraft and helicopters, they feel it is directly applicable to analyze any type of bearing system and expressed an interest in using this capability to analyze integrated paper mills.

In addition, NASA Lewis workers have developed traction drive mechanisms for transforming the output of a gas turbine to the drive speeds required for helicopter blades. In this technology they have achieved transmissions of 500 $\mathrm{hp}$ at speed reductions or speed increase ranging from 3:1 to 300:1. The 500 hp unit is about $6^{\prime \prime}$ in diameter and is $3^{\prime \prime}$ wide and has demonstrated a life of 47,000 hours with 97 percent efficiency. For very large drive systems, a hybrid drive mechanism capable of 30,000 hp transmission is being developed. This group also is directing an effort toward variable speed drives but these are not as yet commercially available.

\subsection{Chemical Pulping}

This activity in the pulp and paper industry involves the production of Kraft pulp primarily. In this activity wood chips are introduced into a digestor simultaneously with sodium sulfide and sodium hydroxide. The chips are cooked in this mixture such that the lignin is separated from the cellulosic pulp. There are two output streams from the digestor--the pulp rich stream which is subsequently washed, refined, bleached and enters the paper machine, and the black liquor stream which contains the lignin and soluble acids associated with the residue from pulp production. Considering first this black liquor stream, it emerges from the digestor at a temperature of about $350^{\circ} \mathrm{F}$. This mixture is flashed to evaporate water and then enters into a multiple effect evaporator in which its concentration is increased from about 15 percent solids to $50 \%$ solids. A subsequent concentration step is a direct contact evaporator which increases the solid content to 62 to 66 percent. This material is then burned in a recovery boiler in two stages. In the lower region it is burned substoiciometrically and produces a smelt containing sodium and sulfur primarily in sodium carbonate and sodium sulfide 
form. This smelt is drained from the digestor, diluted with wate=, and causticized with lime such that the original constituents of sodium sulfide and sodium hydroxide are regenerated for the digestion step. In the upper regions of the recovery boiler, additional air is added to completely burn the pyrolysis fumes arriving from the first stage. In this upper stage steam is raised in boiler tubes around the periphery of the recovery boiler.

Many problems exist in this black liquor cycle. The first of these is the fact that significant energy is used in the concentration of black liquor to the $62^{+}$percent solids. required for entry as a fuel of the recovery boiler. NASA Lewis and INEL have been looking at the application of bi-phase engines for liquid concentration. It appears to be feasible that the bi-phase engine could be used as a replacement for the first flash drying phase of black liquor concentration. Were this feasible, it would be possible to obtain significant electrical energy or mechanical energy from the flash evaporation stage.

A second major problem has to do with determination as to when sufficient digestion has taken place to separate the lignin from the cellulosic pulp. The Jet Propulsion Laboratory has been working on a photo-acoustic spectrometer that may be capable of evaluating the degree of cooking that has been achieved by detecting the ratio of lignin to pulp in the effluent stream.

A second intrument being developed by JPI involves laser induced fluorescence. They have observed that dilute black liquor exhibits several fluorescent peaks. And by using a multi-stage laser to induce fluorescence and a light pipe system to detect it, it may be possible to determine the amount of free lignin in the digestion effluent. This instrument may also be capable of determining the lignin concentration in the recovery boiler feed. This would be an extremely valuable determination in that the Btu content of that fuel could be determined on-line, thereby increasing the degree to which the substoichiometric phase of combustion could be controlled.

The boiler tubes in the recovery boiler are subjected to an extremely hostile corrosive environment. Both sodium and sulfur carry-over from the combustion processes in the form of sodium oxide and $\mathrm{SO}_{2}$ comprise this extremely corrosive atmosphere. As a consequence, the rècovery boiler is generally operated in a mode such that twenty hours of inspection are required each month to assure that the boiler tubes are not excessively corroded. It should be pointed out that catastrophic failure of a boiler tube leaks water directly into the base of the digestor which contains molten sodium carbonate and sodium sulfide and represents a significant explosion hazard. Thus the integrity of the boiler tubes and ability to determine their future life is extremely important.

Two major technologies were uncovered which potentially could be applied to this problem. The first of these has again to do with amorphous metals. As previously discussed, one of the characteristics of amorphous metals is that they have no grain boundary and no crystal structure. As a consequence, they are extremely resistant to corrosion at temperatures below $800^{\circ} \mathrm{K}$. This represents both a blessing and a curse. If it were possible to develop a boiler tube sheathing of such amorphous metals integral with the tube, high corrosion resistance could indeed be achieved. On the other hand, it is obviously impossible to use brazing or welding techniques for creating such a 
composite structure. Lawrence Livermore Laboratory, under the direction of Richard Landrigham, has developed techniques for explosive bonding, welding and fabrication of composite materials. When asked if LLL could use this technology for forming a composite boiler tube using the 2 " wide amorphous metal ribbon currently under production by Allied Corporation, spirally winding such ribbon to the tube and explosively joining the surface to the boiler tube substrate, they felt indeed that such a composite structure was amenable to their techniques. The potential of very high corrosion resistance for boiler tubes fabricated in this manner is promising and could significantly increase the life of the boiler tubes currently used in the recovery boiler.

A second technology, being developed at Idaho National Engineering Laboratory, involves the concept of a pinhole camera for inspection of highly adverse ambient environments. This pinhole imaging system is currently being used for investigating the integrity of reactor fuel elements under very high temperature conditions $\left(3,000^{\circ} \mathrm{C}\right)$. It is possible that such a system could be adapted for periodic inspection of the tube surfaces in a recovery boiler, thereby potentially eliminating the need for inspection shut down and/or extending the time between shutdowns for boiler tube surface cleaning.

Further work applicable to the recovery boiler is being done by NASA Lewis regarding the acoustic control of fuel droplet size. In conventional burners it is desirable to have droplets on the order of 50-200 microns. In a recovery boiler, however, an optimum droplet size for black liquor is on the order of one-quarter of an inch. Acoustic systems have been developed which maintain uniform droplet size in this first range and potentially could be developed to control droplet size in the spray nozzle used for fuel introduction in the recovery boiler at the much larger diameter. No work, however, has been done on this latter problem.

The Jet Propulsion Laboratory is examining the acoustic signature of turbulent flames. They have determined that indeed a burner nozzle, has an acoustic signature characteristic of that specific burner, and when such burner is operating off-optimum it can be detected by the change in its sound signature. Control of the air-fuel ratio of the recovery boiler nozzle has traditionally been a significant problem. It is possible that this acoustic signature could be used as a sensor to improve boiler control.

\subsection{Paper and Paperboard Production}

\subsection{Primary Paper Mills}

The principal stream coming from a Kraft digestor, as well as the pulp arising from mechanical pulping, enters into several operations that are relatively common across the industry. The pulp is first washed and then refined using, again, extremely high powered, closely spaced disks to at least two things, reduce the pulp to optimum fiber length for papermaking, and, by abraiding, dramatically extend the surface area of individual fibers and thereby provide added sites for hydrogen bonding in the papermaking step. This refiner again could use the development of amorphous metal coatings, high speed lubrication and other technologies previously discussed. The pulp is then bleached and adjusted in consistency to about $0.3-0.5$ percent solids 
where it enters the head box of the paper machine. The flow characteristics, wire speed and paper quality are all highly dependent on consistency of this pulp entering the system. There is no on-line consistency meter currently available to the industry. One of the instrument technologies in development at the Jet Propulsion Laboratory involves a laser thermal lensing technique that has the potential of providing such an on-line consistency meter. In this technology, a thermal lens is induced in a flowing stream by the use of an excitation laser. The persistence of this lens as a function of time is then determined by a second laser beam. The thermal lens dissipates into the liquid environment by both convection and conduction. In a system such as a suspension of pulp fibers in water, the rate at which the lens dissipates would be a function of the solids content of the cellulosic material. It is possible therefore, that this technology would be directly applicable to an on-line consistency meter.

Jet Propulsion Laboratory has developed an electrolytic polymeric hygrometer for the accurate detection of moisture levels ranging from a few parts per million to saturation. This is a device wherein a tube of nation polymer is contacted by wide area electrodes. Moisture is absorbed by the polymer and electrolyzed into hydrogen and oxygen. The current flow between the electrodes then is a direct measure of the moisture content of the ambient environment. It is anticipated that this type of instrument could be used at various locations throughout a hooded papermaking machine, thereby determining the optimum conditions for fresh air make-up from the heat requirements of the machine and, thereby, reduce steam demand for drying. It is also possible that this device could be used to determine the moisture content of the sheet and/or the felt by examining the moisture content in the region immediately above these two elements; this could possibly lead to reduced instances of production interruption due to paper web breakage.

\subsection{Coating and Converting}

No technology was found in the laboratories that directly related to this area.

\subsection{Other Cellulose Fiber Sources}

No technology was found in the laboratories that directly related to this area.

\subsection{Waste Paper}

No technology was found in the laboratories that directly related to the this area.

\subsection{Power and Chemical Recovery Systems}

The paper industry is a major consumer of both electrical and thermal power. About 50 percent of their energy needs are derived from wood as by-product power from the pulpmaking operation or the direct burning of wood products such as bark. There is still ample opportunity to improve, however, the internal power generation of an integrated paper mill. Previous discussion under Section 5 of the taxonomy has discussed the Kraft recovery boiler operation. 
An additional element of possible technology under developmer: in the laboratories, however, is the advent of bottoming cycles. Idaho National Engineering Lab has been developing organic Rankine systems for the extraction of electrical energy from low temperature geothermal fluids. A 5 negawatt plant is operating in the Raft River geothermal site. A 60 kilowatt plant is available for a variety of experimental programs. These types of cycles are able to convert thermal energy in relatively low temperature gas or liquid streams into useful electric or mechanical energy. In this regard, it is possible to perceive a system that could recover thermal energy from thermal mechanical pulping, round wood pulping and other high volume, relatively low quality waste energy streams.

INEL has also developed the concept of mixed fluid, organic Rankine bottoming cycles wherein the boiling characteristic of the fluid is matched to the cooling curve of the incoming waste stream thus eliminating the potential for multiple boilers and the problems associated with pinch point in such heating ranges. This is a powerful new concept and reference to this system design approach can be found in the Appendix.

\subsection{Health, Safety and Pollution Control}

As is the case with all industry, the pulp and paper industry must assume responsibility for the health and safety of its workers and for the control of potentially harmful air emissions and liquid and solid effluents generated from their operations.

Sandia National Laboratories has developed a real time dust monitoring system capable of a very high range of particulates monitoring and control. A tapered element oscillating microbalance is capable of isokinetic sampling of stack particulate emissions and integrating these over time. This instrument will be installed in a Tennessee Valley Authority power plant in the near future and has been used in the past for determining the particulate emissions in diesel exhaust. The instrument seems to have high accuracy over a very wide range of particulate concentration.

On the liquid effluent side, Jet Propulsion Laboratory has been investigating enzymatic hydrolysis of both cellulose and hemicellulose. They have evaluated anaerobic microorganisms that convert $\mathrm{C}_{6}$ cellulose to methane and $\mathrm{C}_{5}$ hemi-cellulose to furfurol alcohol. This work has been primarily directed toward production of useful fuels or feedstock from waste cellulosic materials. Waste streams from both non-wood and Kraft processes have high fiber content and potentially represent a feedstock for such reaction. JPL has also developed a technique for the quantitative recovery of lignin from waste streams using a quaternary ammonium compound as the extraction mechanism. The compound can be regenerated relatively easily in the cycle stream.

Oak Ridge National Laboratory has been investigating the use of lignosulfanate, sodium sacchrinate, and other potential waste stream products as surfactants for increasing tertiary oil recovery. Although lignosulfanate is not considered to be a major waste product from most paper production, the content of sodium sacchrinate in black liquor may be capable of extraction and use in such activity. Similar research has focused on use of bleach plant effluent in tertiary oil recovery. 
Oak Ridge has also developed a series of multi-media models to investigate the environmental movement of toxicants and pollutants. These models evaluate the numerous mechanisms which are operative in moving toxic materials away from the point of origin to locations where other activities would be exposed. This system, called the Uniform Transport Model for Toxicants, combines physical and chemical data on toxicants, mechanisms of dispersion and accumulation, and environmental data for typical or specific sites. The models can be used to estimate likely exposure for new chemicals or for new processes using existing chemicals prior to initiation of the activity so that potential risks can be managed.

The Idaho National Energy Laboratory has developed a system known as Management Oversight and Risk Tree (MORT) system for evaluating and managing environment, safety, and health information. This system was originally developed under INEL's lead laboratory position for implementing and coordinating all safety programs throughout the federal government. Although it started out as a technique for evaluating the cost versus benefits of reducing risks associated with any industrial activity, it has become more than that. It is clear that the expenditure of an infinite amount of money can bring about a level of risk in any industrial activity that is equal to zero. Any lesser expenditure permits some level of risk and hence hazard to exist. The MORT system permits the systematic analysis of these risks and the consequences of the hazards that might evolve in terms of the amount of money that must be spent to reduce such risks to an acceptable level. In this sense, then, the MORT system has become more of a management tool than a risk hazard analysis tool. The system is being adopted by a number of different industrial organizations, both in the United States and abroad. INEL conducts a series of seminars each year describing this activity.

\subsection{Process Control Systems}

The potential of pulp process control in an integrated pulp and paper mill is being investigated directly by the Department of Energy under several different programs including the development of new sensor technology at the National Bureau of Standards as well as the development of integrated systems using several contractors.

There are a number of technologies under development in the laboratories that could directly apply to such development. The Idaho National Engineering Lab has developed a system for validating the signals received from a multiple number of sensors in an integrated process stream. This technology compares individual sensor signals on a real time system with empirical data established in the memory bank and determines the quality of information that is received from the multiple sensors used in the process stream. Using a hierarchy of these information quality functions, it is then possible to determine the reliability of all the data received from the process stream systems. Using this automated system it is possible to evaluate the level of confidence and the quality of information about the physical system required.

The need for rapid real time simulation and control in a high speed process stream often exceeds the capability of a digital control system. NASA Lewis is developing a series of hybrid computer technologies and models to successfully simulate real time operation of high speed processes. Although 
the work is being developed for real time operation of aircraft tLrbine engines, the hybrid computer model allows achievement of steady state and dynamic accuracies with reasonable solution times for any complex process train. As such, this model capability may indeed be directly applicable to the pulp and paper industry.

In like fashion, Lawrence Livermore Laboratory is developing a local area network information system for rapid transmission of experimental and control data within Lawrence Livermore Laboratory. This system, using fiber optics, is designed to rapidly transport analog and digital signals from sensors located throughout a complex process stream. Such local a rea netrorks, known as Camacs, are now available commercially. The laboratory is a leader in the design and manufacture of fiber optic connectors and may be able to directly assist the implementation of a local area network system to an integrated pulp and paper mill.

This concludes the summary of the more significant technologies that were discovered existing in the laboratories with potential application in the pulp and paper industry. Several other activities, however, should be mentioned as potential areas in which the laboratories might contribute. The whole concept of moisture sensing both in logs and chips is one in which the laboratories may be able to develop instrumentation that would permit rapid, on-line capability. The applicability of lasers to the wood industry, although not directly applicable to the harvesting of pulp wood, could be considered for the dimensioning of structural lumber. If indeed sufficient power could be put into a laser and the beam could be provided with a relatively small diameter, significant energy could be saved in production of dimension lumber. This would provide the accurate cutting of such lumber with minimum kerf size and perhaps even eliminate the need for final planing; thus potential energy savings in the lumber industry are quite high. 
IV. RESPONSE OF PULP AND PAPER INDUSTRY

TO FEDERALLY DEVELOPED TECHNOLOGIES

As mentioned in Section 2, Methodology, the technology findings were presented to representatives of the pulp and paper industry to assess the value of the information and the receptivity (and concerns) of the industry relating to the transfer of such information from the federal laboratories. Formal oral presentations were made to corporate and industry-wide groups; and narrative technology descriptions were prepared, arranged in notebook form, and distributed to pulp and paper industry personnel. The intent of this section is to summarize industry reaction to the technologies uncovered and to the exercise itself. Typical industry responses are characterized and discussed, and actual responses are provided.

The response of the PPI to the federally developed technologies was unanimously favorable. That the information was of value to the PPI and that many of the technologies were previously unknown was unmistakable. Furthermore, that such an effort was undertaken in the first place, while considered surprising to some, was lauded.

The general reaction was that a significant amount of activity (much of which the PPI was unaware of) underway at federal laboratories has relevance to the PPI. Some activities uncovered were perceived as being very useful to the industry; others, as useful to specific companies. Several companies in the PPI have already followed up with the applicable laboratory(s) on specific technologies of interest. Additional characteristic responses and comments concerning the technologies are outlined below.

- In addition to identification of specific technologies, familiarization with the overall capabilities and test facilities at federal labs was of value to the PPI.

- Beyond merely relating the technologies to the laboratory of origin, inclusion of the names and numbers of people to contact at the labs and elsewhere was of utility and greatly increased the value of the report.

- Organization of the technologies according to the taxonomy elements provided a means of distributing the different technologies to individuals/departments having the appropriate responsibilities.

o While some technologies were consistently mentioned as being useful to individual companies, virtually all of the technologies were mentioned at least once as being useful.

The following are actual PPI responses to the oral presentations and written descriptions of federally developed technologies with potential application within the industry. 
Dr. Peter Ariessohn

Sensor Development Engineering

Weyerhaeuser Company

Tacoma, WA 94877

(206) 924-6559

Robert A. Bareiss

Director, Process Control

Technology

St. Regis Paper Company

Technical Research Center

West Nyack, NY 10994

(914) 578-7105

Dr. Nallan C.S. Chari

Manager, Process Engineering and Control

Owens-Illinois, Inc.

P.0. Box 1035

Toledo, OH 43666

(419) 247-9514

C. Peter Donofrio

Director, Planning \&

Surveillance

Champion Papers

Knightsbridge

Hamilton, OH 45020

(513) $868-4625$
"The laboratory visits were a $\varepsilon$ od investment; I can confirm from Weyeri $\equiv$ euser experience the cooperativeness of Sandia Livermore in providing for industrial use of their combustion test facilities."

"A very useful thing you have done. We will be following up immediately on bearings and lubricants with NASA Lewis and on the Management Oversight and Risk Tree System developed by EG\&G at INEL."

"The report was circulated to responsbile department heads. Two observations are made; one, we were suprised so much of relevance to PPI was on-going at the labs, two, our immediate follow-up will be limited due to the impact of the current econowy."

"I found that your Doug Harvey surfaced a lot of interesting ideas, for example, correlation of cohesive energy density of a substance and the solubility parameter for that substance; polymer chemistry and solubility parameters have long been factors in the industry. These other topics, discussed by the report, were of specific interest to various people at Champion:

(1) Tree seedling production and genetic developments;

(2) Microbiology, biocatalysis and bioengineering as they pertain to forest land yield management;

(3) High temperature, high speed bearings and lubricants;

(4) The three laser activated techniques researched by JPL for possible on-line analysis of complex mixtures;

(5) Amorphous metals for possible treatment of some of the industry's very serious corrosion problems, for example, stress corrosion, also welds;

(6) The Bi-Phase engine and any other technology for solids concentration/liquid evaporation; and

(7) Usefulness of weak black liquor and bleach plant effluents in enhanced oil recovery." 
Ole K. Fadum

Manager, Corporate Marketing

The Foxboro Company

Foxboro, MA 02035

(617) 543-8750 (x3956)

Robert J. Pfeifer

Manager, Systems Technology

Division

Accuray Corporation

P.0. Box 02248

650 Ackerman Road

Columbus, $\mathrm{OH} 43202$

(614) 261-2000
Dr. Del R. Raymond

Manager, Energy Dept.

Fiber Products R\&D

Weyerhaeuser Company

Tacoma, WA 98477

(206) $924-6850$
"The laboratory visits, for the purposes made, were an excellent exercise. It has been important and useful to learn of the capabilities there, also, the identify of the people to confer with. Another aspect, at every company somebody is responsible for determining and acquiring test facilities. Dr. Peter McCrea has that responsibility here and it will be useful to him to know some of these needs can perhaps be met at labs like ORNL and Sandia Livermore."

". . I would like to identify several areas from your compilation of Federal Laboratory Developed Technologies which we would be interested in exploring, possibly in some joint fashion.

1. Technology: High Temperature, High Speed Bearings and Lubricants (NASA Lewis)

While our needs are less demanding than many high speed, high temperature applications, we have a requirement for long, unattended operation in demanding envi ronments.

2. Technology: Three Laser Activated Detectors for Determining Composition of Complex Mixtures (JPL)

These seem far from being ready for serious consideration in application, but are promising conceptually.

3. Technology: Optical Scanners and Image Processing (INEL)

This inspection technology is important and commercially available, but stateof-the-art developments are important to us.

4. Technology: Polymeric Electrolytic Hygrometer (JPL)

"The visits you report on will be very helpful to us. I broke up your report into the various subjects and forwarded them to people having appropriate responsibilities; each has subsequently reported favorably on the material he received. We will doubtless be following up with the various labs." 
Dr. W. Cy Rutledge

Central Research

Mead Corporation

8 th and Hickory Streets

Chillicothe, $\mathrm{OH} \quad 45601$

(614) $722-3503$

\section{Craig Stansbury}

Director, Technology,

Standards and Metrics

American Paper Institute, Inc.

260 Madison Avenue

New York, NY 10016

(212) $340-0600$

Heinz Walbaum

Manager, Process Instruments

Development

International Paper Company

Corporate Resource Center

P.0. Box 797

Tuxedo Park, NY

(914) 351-2101 (x225)

Dale Raymond

Union Campe R\&D

P.0. Box 412

Princeton, NJ 08540

(609) 896-1200

Gary A. Baum

Institute of Paper Chemistry

P.0. Box 1039

Appleton, Wisconsin 54912

(414) 734-9251

An industry representative requesting anonimity:
"What Battelle and Energetics have done for the government on behalf of the pulp and paper industry could prove very valuable to us; the presentation by Mr. Harvey was very good."

Thought the report good and useful to the API Instrumentation Committee and endorsed Energetics distribution to same for comment; subsequently called Energetics and requested permission to inform API Recovery Boiler Committee, via newsletter, of pending availability of report via TIC, ORNL.

"What you have done is good; you have indeed identified advanced research products and capabilities, also places, people and telephone numbers. In the industry we are a little more down to earth in our research, more application oriented. We don't reject the quantum jumps type of research finding but are better able to handle incremental progress. I have circulated the report to the other IPC people who should know about it with the expectation they will call the laboratories on matters of interest to them."

"You have produced a very interesting report; we will be following up on several of the technologies, including capacitive discharge bark removal, . . . Staff members I asked to comment on the report have asked for it back."

"In my opinion, the compilation is a very worthwhile and potentially valuable undertaking. A number of people at the IPC have reviewed (it)."

"The report was very interesting: it is a resource we in the industry can use. Items of particular interest to us include:

(1) The data on ORNL activities in tree seedlings and hardwood.

(2) The solubility parameter work at JPL; it pertains to paper making chemistry and may bring something new to the subject.

(3) The combustion and corrosion research at Sandia. 
(4) The instrument validation work at INEL/ EG\&G; it could well assist our millwide process control efforts.

(5) The annular chromatograph at ORNL might have utility; it was interesting to read about anyway." 


\title{
APPENDIX: FEDERALLY DEVELOPED TECHNOLOGY \\ WITH POTENTIAL APPLICATION IN THE \\ PULP AND PAPER INDUSTRY
}

\begin{abstract}
Presented in this Appendix are summary descriptions of the federally developed technologies uncovered in this effort. The technologies are arranged according to the most directly applicable taxonomy element and include technology name; a listing of all potentially applicable taxonomy elements; laboratory of origin; the name, telephone number, and title of principal contact(s); a narrative description; and reference material. To aid in their identification, the technologies are listed according to: (1) the taxonomy elements under which only the most directly applicable technologies are listed and by which the technologies are presented, serving as a table of contents, (2) the taxonomy elements under which all potentially applicable technologies are listed and (3) the laboratory of origin.
\end{abstract}


FEDERALLY DEVELOPED TECHNOLOGIES

ACCORDING TO MOST APPLICABLE

TAXONOMY ELEMENT

$\underline{\text { Page }}$

1.0 TREE SEEDLING PRODUCTION AND GENETIC DEVELOPMENT

o Controlled Environment Forest Growth . . . . . . . . 33

o Genetic Selection of Trees for

Marginal Land Use .. . . . . . . . . . . . 34

2.0 FOREST LAND PREPARATION, STOCKING AND YIELD MANAGEMENT

- Microbiology, Biocatalysis and Bioengineering . . . . 35

o Short Rotation Intensive Culture . . . . . . . . . . . 36

- Whole Tree Harvesting: Impact Study on Forest

Nutrient and Carbon Dynamics . . . . . . . . . . . . 42

- Geoecology: A County Level Data Base for

the Conterminous United States... . . . . . . . 43

3.0 TIMBER HARVESTING, TRANSPORTATION, AND STORAGE

o Laser Application Research . . . . . . . . . . . 45

4.0 DEBARKING AND CHIPPING AND GRINDING

- Ultrasonic and Eddy Current Sensors . . . . . . . 46

o Capacitor Discharge Bark Removal . . . . . . . . . . 47

5.0 PULPING AND BLEACHING

- High Temperature, High Speed Bearings

and Lubricants. . . . . . . . . . . . . . . . . . . . 48

- Three Laser Activated Detectors for Determining

Composition of Complex Mixtures . . . . . . . . . 53

- Solubility Parameter Concept and

Cohesive Energy Density . . . . . . . . . . . . 59

6.0 PAPER AND PAPERBOARD PRODUCTION

o Optical Scanners and Image Processing . . . . . . 60

o Polymeric Electrolytic Hygrometer . . . . . . . . 61

7.0 COATING AND CONVERTING

o Precision Machining . . . . . . . . . . . . . 62

8.0 OTHER CELLULOSE FIBER SOURCES

(No directly applicable technologies)

\subsection{WASTE PAPER}

(No directly applicable technologies) 
(Continued)

$\underline{\text { Page }}$

\subsection{POWER AND CHEMICAL RECOVERY SYSTEMS}

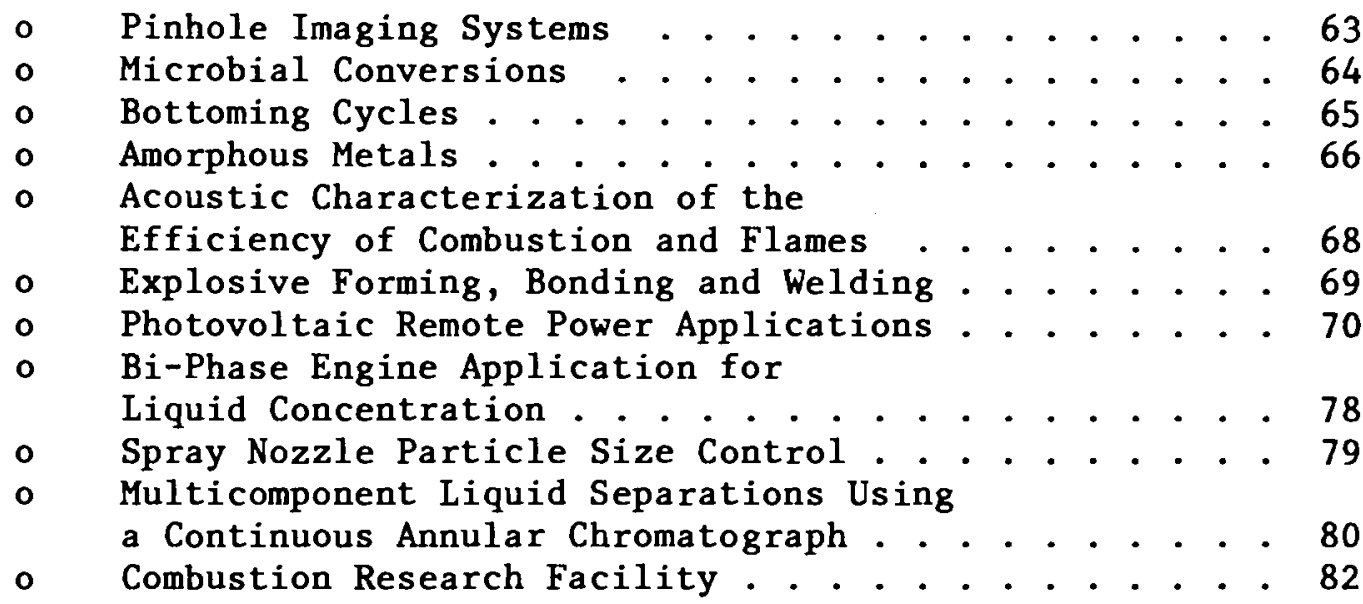

11.0 HEALTH, SAFETY, AND POLLUTION CONTROL SYSTEMS

- Management Oversight and Risk Tree (MORT) System

for Evaluating and Managing Environment, Safety

and Health Information. . . . . . . . . . . . . 85

- Enzymatic Hydrolysis of Cellulose $\left(\mathrm{C}_{6}\right)$ and

Hemicellulose $\left(C_{5}\right)$. . . . . . . . . . . . 87

- Estimating Environmental Movement of

Toxicants with Multimedia Models . . . . . . . . . . 88

- Waste Water Treatment (Anaerobic Digestion) . . . . 89

o Enhanced Oil Recovery Using Weak Black Liquor

or Bleach Plant Effluent .. . . . . . . . . . . . . 90

o Real Time Dust Mass Monitoring System . . . . . . . 92

\subsection{PROCESS CONTROL SYSTEMS}

- Economic Evaluation and Sensitivity Analysis . . . . . 94

o Sensors and Controls Signal Validation. . . . . . . . 95

- Failure Modes and Effects Analysis and Statistical Analysis . . . . . . . . . . . . . . . 97

o Fiber Optic Information Network . . . . . . . . . . . 98

- Complex, Multivariable Real Time

Simulation and Control . . . . . . . . . . . . . 99

- Process Control Engineering and

Software Development . . . . . . . . . . . . . 101 
FEDERALLY DEVELOPED TECHNOLOGIES ACCORDING

TO ALL POTENTIALLY APPLICABLE

TAXONOMY ELEMENTS

Page

\subsection{TREE SEEDLING PRODUCTION AND GENETIC DEVELOPMENT}

\subsection{Tree Seeding Nurseries}

- Genetic Selection of Trees for Marginal Land Use . . . . . . . . . . . . . 34

- Photovoltaic Remote Power Applications... . . . . 70

o Controlled Environment Forest Growth . . . . . . . . . 33

o Short Rotation Intensive Culture. . . . . . . . . . . 36

1.2 Tree Seed Gathering

\subsection{Genetic Selection and Improvement}

- Genetic Selection of Trees for Marginal Land Use . . . . . . . . . . . . 34

- Short Rotation Intensive Culture. . . . . . . . . . 36

2.0 FOREST LAND PREPARATION, STOCKING AND YIELD MANAGEMENT

\subsection{Forest Land Preparation}

- Genetic Selection of Trees for Marginal Land Use . . . . . . . . . . . . . . 34

o Laser Application Research . . . . . . . . . . . . 45

- Photovoltaic Remote Power Applications . . . . . . . 70

o Short Rotation Intensive Culture . . . . . . . . . . . 36

- Whole Tree Harvesting: Impact Study on Forest Nutrient and Carbon Dynamics . . . . . . . 42

\subsection{Stocking}

- Photovoltaic Remote Power Applications . . . . . . 70

\subsection{Yield Management}

- Genetic Selection of Trees for Marginal Land Use . . . . . . . . . . . . 34

- Microbiology, Biocatalysis and Bioengineering . . . . . . . . . . . . . . . . 35

o Photovoltaic Remote Power Applications . . . . . . 70

- Complex, Multivariable Real Time Simulation and Control . . . . . . . . . . . . . 99

o Controlled Environment Forest Growth . . . . . . . . . 33

o Short Rotation Intensive Culture . . . . . . . . . . . 36

- Whole Tree Harvesting: Impact Study on
Forest Nutrient and Carbon Dynamics . . . . . . . 42

- Geoecology: A County Level Data Base
for the Conterminous United States . . . . . . . . 43 
(Continued)

Page

\subsection{HARVESTING, TRANSPORTATION AND STORAGE}

\subsection{Harvesting}

- Amorphous Metals . . . . . . . . . . . . . . 66

- Precision Machining . . . . . . . . . . . . . . 62

- Laser Application Research . . . . . . . . . . . . . . 45

- Photovoltaic Remote Power Applications . . . . . . . . 70

- Whole Tree Harvesting: Impact Study on

Forest Nutrient and Carbon Dynamics . . . . . . . 42

\subsection{Transportation}

\subsection{Storage}

\subsection{DEBARKING AND CHIPPING/GRINDING}

4.1 Debarking

o Ultrasonic and Eddy Current Sensors . . . . . . . . . 46

- High Temperature, High Speed Bearings and Lubricants . . . . . . . . . . . . . . . . . . 48

o Capacitor Discharge Bark Removal . . . . . . . . 47

\subsection{Chipping/Grinding}

o Optical Scanners and Image Processing . . . . . . . 60

o Amorphous Metals................... 66

o Precision Machining . . . . . . . . . . . . . . 62

- High Temperature, High Speed Bearings and Lubricants... . . . . . . . . . . . 48

\subsection{PULPING AND BLEACHING}

\subsection{Mechanical Pulping}

○ Pinhole Imaging Systems . . . . . . . . . . . 63

○ Bottoming Cycles... . . . . . . . . . . . . . 65

- Three Laser Activated Detectors for Determining Composition of Complex Mixtures . . . . . . . . . . . . . . . . . 53

o Amorphous Metals... . . . . . . . . . . . . . 66

- Precision Machining . . . . . . . . . . . . . . . 62

- Explosive Forming, Bonding, and Welding . . . . . . . . . . . . . . . . 69

- High Temperature, High Speed Bearings and Lubricants. . . . . . . . . . . . . . . 48 
(Continued)

$\underline{\text { Page }}$

5.2 Chemical Pulping

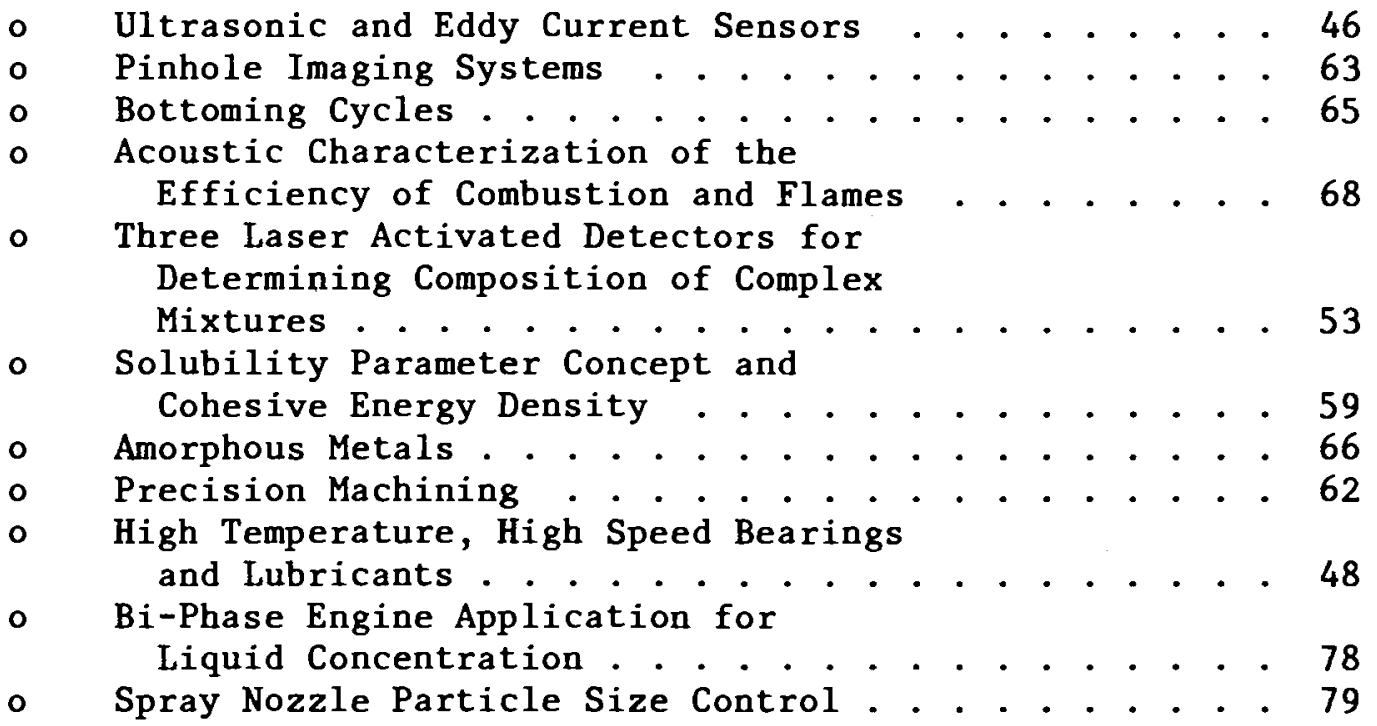

\subsection{Bleaching}

- Optical Scanners and Image Processing . . . . . . 60

\subsection{PAPER AND PAPERBOARD PRODUCTION}

\subsection{Primary Paper Mills}

- Ultrasonic and Eddy Current Sensors . . . . . . . . 46

- Optical Scanners and Image Processing . . . . . . . . 60

○ Bottoming Cycles . . . . . . . . . . . . . . . . 65

- Failure Modes and Effects Analysis and Statistical Analysis... . . . . . . . . . . 97

o Polymeric Electrolytic Hygrometer . . . . . . . . . 61

- Amorphous Metals .. . . . . . . . . . . . . . 66

- Three Laser Activated Detectors for Determining Composition of Complex Mixtures . . . . . . . . . . . . . . 53

- High Temperature, High Speed Bearings and Lubricants... . . . . . . . . . . . . 48

\subsection{Paperboard Mills}

- Ultrasonic and Eddy Current Sensors . . . . . . . . . 46

- Optical Scanners and Image Processing . . . . . . . . 60

- Bottoming Cycles . . . . . . . . . . . . . . . . . . 65

- Failure Modes and Effects Analysis and Statisical Analysis . . . . . . . . . . . 97

o Polymeric Electrolytic Hygrometer . . . . . . . . . . 61 
(Continued)

Page

o Amorphous Metals . . . . . . . . . . . . . . 66

- Three Laser Activated Techniques for Determining Composition of Complex Mixtures . . . . . . . . . . . . . . 53

- High Temperature, High Speed Bearings and Lubricants... . . . . . . . . . . . 48

7.0 COATING AND CONVERTING

\section{1-7.9 Al1 Taxonomy Elements}

- Solubility Parameter Concept and Cohesive Energy Density . . . . . . . . . . . . . . . . 59

o Precision Machining . . . . . . . . . . . . . . . . . 62

- High Temperature, High Speed Bearings and Lubricants... . . . . . . . . . . . . 48

\subsection{OTHER CELLULOSE FIBER SOURCES}

9.0 WASTE PAPER

- Solubility Parameter Concept and Cohesive Energy Density . . . . . . . . . . . . 59

- Multicomponent Liquid Separations Using

a Continuous Annular Chromatograph . . . . . . . . 80

10.0 POWER AND CHEMICAL RECOVERY SYSTEMS

o Pinhole Imaging Systems . . . . . . . . . . . . 63

o Microbial Conversions . . . . . . . . . . . . . . 64

o Bottoming Cycles . . . . . . . . . . . . . . . . 65

o Three Laser Activated Techniques for Determining Composition of Complex Mixtures . . . . . . . . . . . . . . 53

o Amorphous Metals...................... 66

- Acoustic Characterization of the Efficiency of Combustion and Flames . . . . . . 68

- Enzymatic Hydrolysis of Cellulose $\left(C_{6}\right)$ and Hemicellulose $\left(C_{5}\right)$. . . . . . . . . . 87

o Explosive Forming, Bonding, and Welding . . . . . 69

o Photovoltaic Remote Power Applications . . . . . . . . 70

- Bi-Phase Engine Application for Liquid Concentration . . . . . . . . . . . . . 78

- Multicomponent Liquid Separations Using a Continous Annular Chromatograph . . . . . . . 80

o Combustion Research Facility . . . . . . . . . . . 82 
(Continued)

$\underline{\text { Page }}$

11.0 HEALTH SAFETY AND POLLUTION CONTROL SYSTEMS

- Management Oversight and Risk Tree (MORT)

System for Evaluating and Managing

Environment, Safety and Health Information . . . . 85

- Enzymatic Hydrolys is of Cellulose $\left(C_{6}\right)$ and Hemicellulose $\left(C_{5}\right)$............. . 87

- Laser Application Research . . . . . . . . . . . 45

- Estimating Environmental Movement of

Toxicants with Multi-media Models . . . . . . . 88

- Wastewater Treatment

(Anaerobic Digestion) ............. . 89

- Enhanced Oil Recovery Using Weak Black

Liquor or Bleach Plant Effluent . . . . . . . . . 90

- Real Time Dust Mass Monitoring System . . . . . . . 92

\subsection{PROCESS CONTROL SYSTEMS}

- Economic Evaluation and Sensitivity

Analysis . . . . . . . . . . . . . . . 94

- Sensors and Controls Signal

Validation... . . . . . . . . . . . . 95

o Fiber Optic Information Network . . . . . . . . . 98

- Complex, Multivariable Real Time

Simulation and Control... . . . . . . . . . . 99

- Process Control Engineering and

Software Development ............. 101 
FEDERALLY DEVELOPED TECHNOLOGIES

ACCORDING TO LABORATORIES

IDAHO NATIONAL ENGINEERING LABORATORY (INEL)

- Genetic Selection of Trees for Marginal

Land Use . . . . . . . . . . . . . . . . . . 34

Ultrasonic and Eddy Current Sensors . . . . . . . . . . . 46

Optical Scanners and Image Processing . . . . . . . . . 60

Pinhole Imaging Systems. . . . . . . . . . . . . . . 63

Microbial Conversions . . . . . . . . . . . . . . . . . 64

Bottoming Cycles .. . . . . . . . . . . . . . 65

Management Oversight and Risk Tree (MORT)

System for Evaluating and Managing

Environment, Safety and Health . . . . . . . . . . 85

Economic Evaluation and Sensitivity Analysis . . . . . . . 94

Sensors and Controls Signal Validation . . . . . . . . . 95

Failure Modes and Effects Analysis and

Statistical Analysis . . . . . . . . . . . . . 97

JET PROPULSION LABORATORY (JPL)

- Microbiology, Biocatalysis and

Bioengineering . . . . . . . . . . . . . . . . . . . . . 35

- Three Laser Activated Detectors for

Determining Composition of Complex

Mixtures . . . . . . . . . . . . . . . 53

- Solubility Parameter Concept and

Cohesive Energy Density . . . . . . . . . . . . 59

o Polymeric Electrolytic Hygrometer. . . . . . . . . . 61

o Amorphous Metals . . . . . . . . . . . . . . 66

- Acoustic Characterization of the

Efficiency of Combustion and Flames . . . . . . . . 68

o Enzymatic Hydrolysis of Cellulose $\left(\mathrm{C}_{6}\right)$

and Hemicellulose $\left(C_{5}\right)$. . . . . . . . . . . . 87

LAWRENCE LIVERMORE NATIONAL LABORATORY (LLL)

o Precision Machining . . . . . . . . . . . . . . . . . . 62

o Explosive Forming, Bonding and Welding . . . . . . . . 69

- Fiber Optic Information Network . . . . . . . . . . 98

NASA Lewis Research Center (NASA LEWIS)

- Laser Application Research . . . . . . . . . . . . . 45

- High Temperature, High Speed Bearings and Lubricants . . . . . . . . . . . . . . . . . . 48

o Photovoltaic Remote Power Applications . . . . . . . . 70

- Bi-Phase Engine Application for

Liquid Concentration . . . . . . . . . . . . . . 78

- Spray Nozzle Particle Size Control . . . . . . . . . . 79

C Complex Multivariable Real Time
Simulation and Control . . . . . . . . . . . . . 99 
FEDERALLY DEVELOPED TECHNOLOGIES

ACCORDING TO LABORATORY

(Continued)

$\underline{\text { Page }}$

OAK RIDGE NATIONAL LABORATORY (ORNL)

o Controlled Environment Forest Growth . . . . . . . . . . 33

o Short Rotation Intensive Culture . . . . . . . . . . . . 36

- Whole Tree Harvesting: Impact Study on

Forest Nutrient and Carbon Dynamics . . . . . . . . . . 42

- Geoecology: A Country Level Data Base

for the Conterminous United States . . . . . . . . . . . 43

- Capacitor Discharge Bark Removal . . . . . . . . . . . . . 47

- Multicomponent Liquid Separations Using

a Continuous Annular Chromotograph . . . . . . . . . 80

- Estimating Environmental Movement of

Toxicants with Multi-media Models . . . . . . . . . 88

- Waste Water Treatment (Anaerobic Digestion) . . . . . . . 89

o Enhanced Oil Recovery Using Weak Black

Liquor or Bleach Plant Effluent . . . . . . . . . . . 90

- Process Control Engineering and

Software Development . . . . . . . . . . . . . 101

SANDIA NATIONAL LABORATORY, LIVERMORE (SNL)

o Combution Research Facility . . . . . . . . . . . . . . . 82

o Real Time Dust Mass Monitoring System . . . . . . . . . 92 
Technology: Controlled Environment Forest Growth

Applicable Taxonomy Element(s):

1.1 Tree Seedling Nurseries*

2.3 Yield Management

Laboratory: ORNL

Contact: $\quad$ D.S. Shriner

Environmental Sciences Division

(615) $574-7356$

A field facility, five years old, is in use. Species under study include loblolly pine and white oak. Test parameters include acid rain, elevated $\mathrm{CO}_{2}$ levels, and air pollution stress. Tents permit 2,000 cuft/micute of doctered and filtered air to be flowed over seedlings. Nutrient cycling, $\mathrm{C}-\mathrm{N}-\mathrm{S}$, is occurring on 250 acres; 15 year data is sought. $\mathrm{C}_{14} \mathrm{O}_{2}$ tagging is used in experiments where $\mathrm{CO}_{2}$ stimulation of growth is being studied. Studies are on-going of potential microbe morbidity from toxics associated with synfuels production. Respecting acid rain, somewhat surprisingly, at a five acre seed propagation site in acid rain affected soil, no adverse impact on seed propagation was found. The National Council of the PPI for Air and Stream Improvement is believed by ORNL to be informed on the foregoing research.

* Most applicable taxonomy element. 
Technology: Genetic Selection of Trees for Marginal Land Use

Applicable Taxonomy Element(s):

1.1 Tree Seedling Nurseries

1.3 Genetic Selection and Improvement*

2.1 Forest Land Preparation

2.3 Yield Management

Laboratory: INEL

Contact: Thomas L. Thuron

Scientist

(208) 522-3547

INEL's Earth and Life Sciences Group has experience in determining species survival of trees grown in an arid environment using saline water for irrigation. Results of previous studies have led to a project now underway to determine the biomass production potential of 20 promising species in a cold desert climate with saline irrigation water. This could lead to the identification of superior species of fiber producing plants that could be grown in adverse environments. If biomass yields are high enough, this concept could be applied in areas where normally non-arable land overlies saline aquifers. A quarter-million square miles of the United States (one-twelfth of the continential land area) overlie aquifers with a salinity near $3,000 \mathrm{mg} / 1$ that could be economically developed.

Reference(s):

(1) Alternate Energy Technical Development Project No. 907 Task Force, "Assessment of Biomass as an Alternate Energy Source - Vol. 1: Summary, "Internal Technical Report No. PGA81.049, EG\&G Idaho, Inc., September 1981.

(2) T.L. Thurow, "Terrestrial Biomass Production Research FY 1981 Results and FY 1982 Test Plan," Internal Technical Report No. SO-E-82-001, EG\&G Idaho, Inc., January 1982.*-่n

$\therefore$ Most applicable taxonomy element.

$*$ Document contained in project file. 
Technology: Microbiology, Biocatalysis, and Bioengineering

Applicable Taxonomy Element(s):

\subsection{Yield Management}

Laboratory; JPL

Contact: Dr. Minoo Dastoor

Chemical and Biological Processes Section (213) 354-7429

Dr. Dastoor of JPL, in cooperation with Richard Waring of the Corvalis Laboratory, is working on global ecology monitoring. Using the Land Sat they have accumulated vast amounts of data. They are attempting to determine the rate limiting parameters of the nitrogen and carbon cycles on a global basis. They feel, however, that satellite and aircraft monitoring of specific forests on a regional basis may be a more fruitful pursuit. Ground-based instrumentation on soil moisture, soil nitrogen and gaseous components would be simultaneously used to evaluate the health of a forest. Once background data were obtained, forest yield optimization would be attempted by application of rate changing reactants, e.g., enzymatic catalysis of organic nitrogen. 
Technology: Short Rotation Intensive Culture (SRIC)

Applicable Taxonomy Element(s):

1.1 Tree Seedling Nurseries

1.3 Genetic Selection and Improvement

2.1 Forest Land Preparation

2.3 Yield Management*

Laboratory: ORNL

Contact: J.W. Ranney

Field Program Manager

(216) $574-7364$

The SRIC concept is that biomass yields can be greatly increased by using genetically superior stock and optimized field management. Focus is on hardwoods because of their rapid juvenile growth and ability to sprout from the stump; biomass use focus is fuel and petrochemical substitutes. Research is on-going in all major wood producing regions of the country; focus is on species selection, stand management and economics. Research is prosecuted by approximately 30 universities and 5 industrial firms. Figure 1 describes the program. Table 1 lists test results from some first generation genetic selection studies; the best individuals grew almost 50 percent more than the average. Objectives of the stand management task are:

1. Develop procedures which permit a high degree of genetic control for the mass propagation of planting material.

2. Develop and improve techniques for assuring high survival and rapid early growth of newly planted seedlings and cuttings.

3. Identify the most efficient means for controlling competing vegetation in SRIC.

4. Determine the most cost-effective systems for using fertilizers in SRIC.

5. Determine the costs and benefits of using irrigation in SRIC.

6. Determine the relationships among species, spacing, rotation length, and production in SRIC.

7. Determine the major pests and diseases in SRIC systems, and develop ways to control them.

Weed control and fertilizer have proven essential for high productivity; tree spacing and timing of harvest have also proven important; disease and pests have proven relatively unimportant except in special instances, e.g., sycamore. Figures 2 and 3 compare current productivity and that which is believed attainable. 
Sensitivity analyses in the economic area are the most valid cost-type finding to date; the project is too young to provide absolute cos:/ benefit-type results. Sensitivity analyses show:

1. The costs of the SRIC system are most sensitive to land costs, harvesting costs and productivity rates.

2. The total cost of site preparation, planting, and management is significant; however, changes possible in any one (except irrigation) generally make little difference to the total.

Reference(s):

(1) Environmental Sciences Division, ORNL, "Project Summaries: Short Rotation Woody Crops Program," to Biomass Energy Technology Division, DOE, October 1981.

(2) North Central Forest Experiment Station, Forest Service - USDA, "Energy and Wood from Intensively Cultured Plantations: Research and Development Program," General Technical Report NC-58, 1980. (Available from U.S. GPO.) $\div * *$

(3) J.W. Raney and J.H. Cushman, "Short Rotation Woody Crops Program: Quarterly Progress Report for the Period Ending November 30, 1981," ORNL, 1981.*t*

(4) J.W. Raney, J.H. Cushman and J.L. Trimble, "The Short Rotation Woody Crops Program: A Summary of Research Sponsored by the Biomass Energy Technology Division," ORNL, March 1982. :-

* Most applicable taxonomy element.

**: Document contained in project file. 


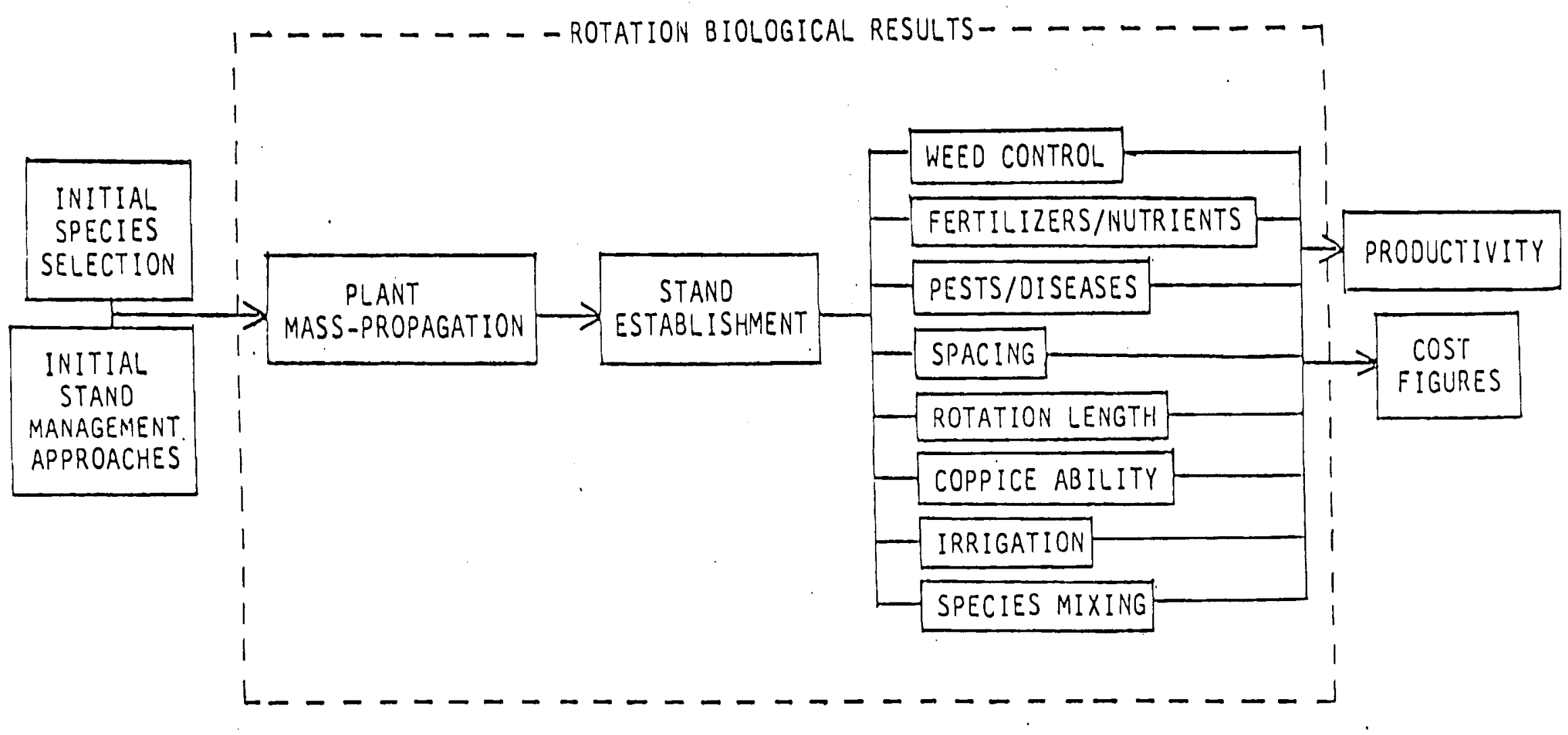

SOURCE: J.W. Ranney et al., "The Short Rotation Woody Crops Program:

A Summary of Research Sponsored by the Biomass Energy Technology Division," (Oak Ridge, TN: ORNL, March 1982), p. 9.

Flgure 1. Stand Management Compromlses the Predominant Act1vity Withln the Short Rotation Woody Crops Program 


\section{ANTICIPATED AND REALIZED PRODUCTION \\ GAINS THROUGH GENETIC SELECTION}

\begin{tabular}{|c|c|c|c|}
\hline \multicolumn{4}{|c|}{$\begin{array}{l}\text { PERCENT } \\
\text { PRODUCTION }\end{array}$} \\
\hline SPECIES & LOCATION & GAIN & VARIABLE \\
\hline SYCAMORE & MISSISSIPPI & 17 & DISEASE RESISTANCE \\
\hline SYCAMORE & MISSISSIPPI & 10 & DRY MATTER PRODUCTIVITY \\
\hline SYCAMORE & MISSISSIPPI & 25 & DRY MATTER PRODUCTIVITY \\
\hline SLASH PINE & FLORIDA & 90 & EXTRACTIVE PRODUCTIVITY \\
\hline EUCALYPTUS & FLORIDA & 50 & VOLUME \\
\hline SAND PINE & FLORIDA & 83 & ENERGY CONTENT \\
\hline BLACK COTTONWOOD & WASHINGTON & 47 & DRY MATTER PRODUCTIVITY \\
\hline BLACK COTTONWOOD & WASHINGTON & 50 & DRY MATTER PRODUCTIVITY \\
\hline MESQUITE & CALIFORNIA & 50 & DRY MATTER PRODUCTIVITY \\
\hline EUCALYPTUS & HAWAII & 15 & VOLUME \\
\hline HYBRID POPLAR & VERMONT & 100 & DRY MATTER PRODUCTIVITY \\
\hline
\end{tabular}

TABLE 1.

SOURCE: J.W. Ranney et al., p. 12. 


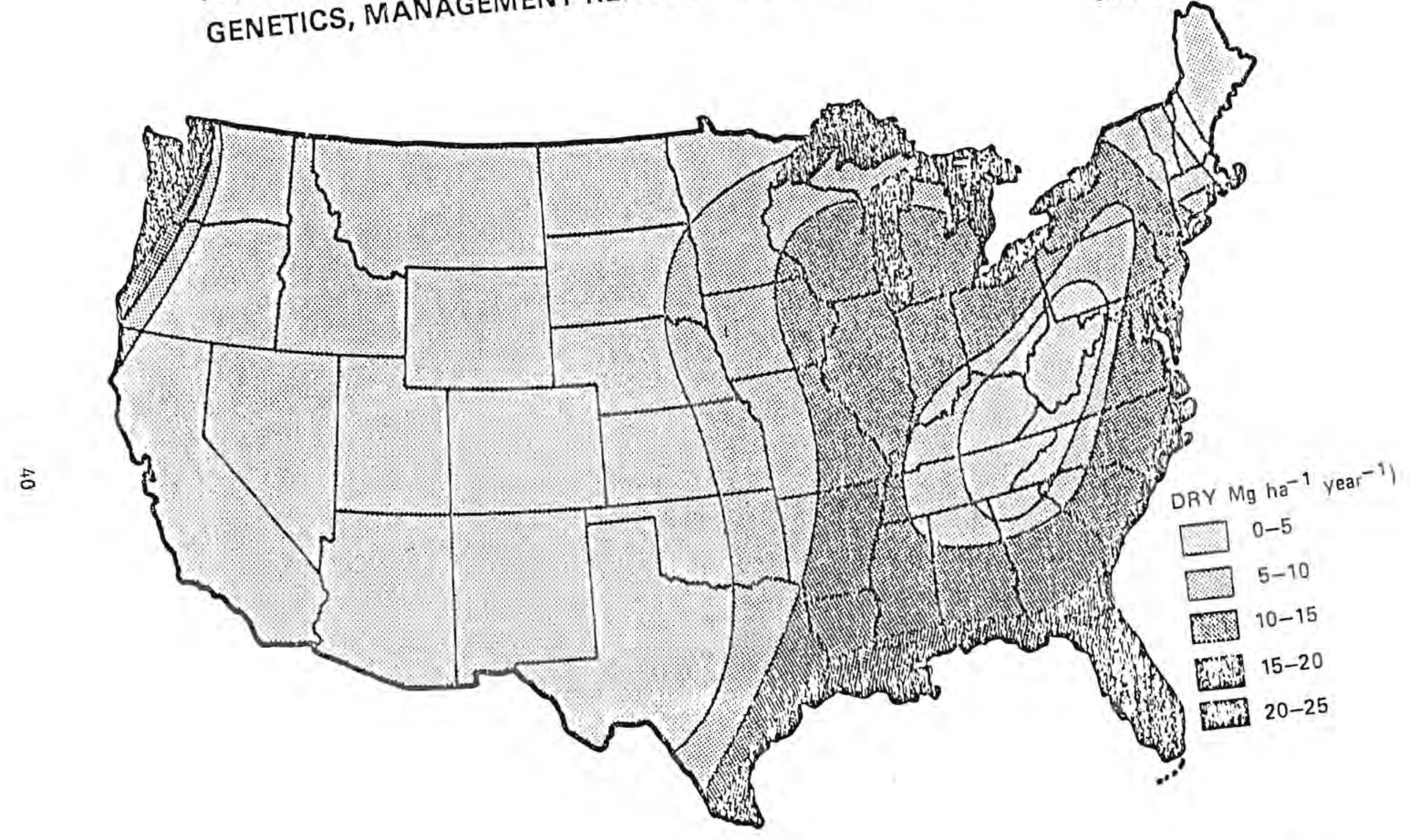
POSSIBLE LARGE SCALE PRODUCTIVITY RATES FOR SRIC.
PRODUCTIVITY ESTIMATES ASSUME IMPROVEMEINTS FROM
ORNL-DWG 82.7393 ESO 


\section{COMMONLY ACHIEVED WOODY BIOMASS PRODUCTIVITY ON SITES OF MODERATE QUALITY}

OANL.DWG 82.7392 ESD

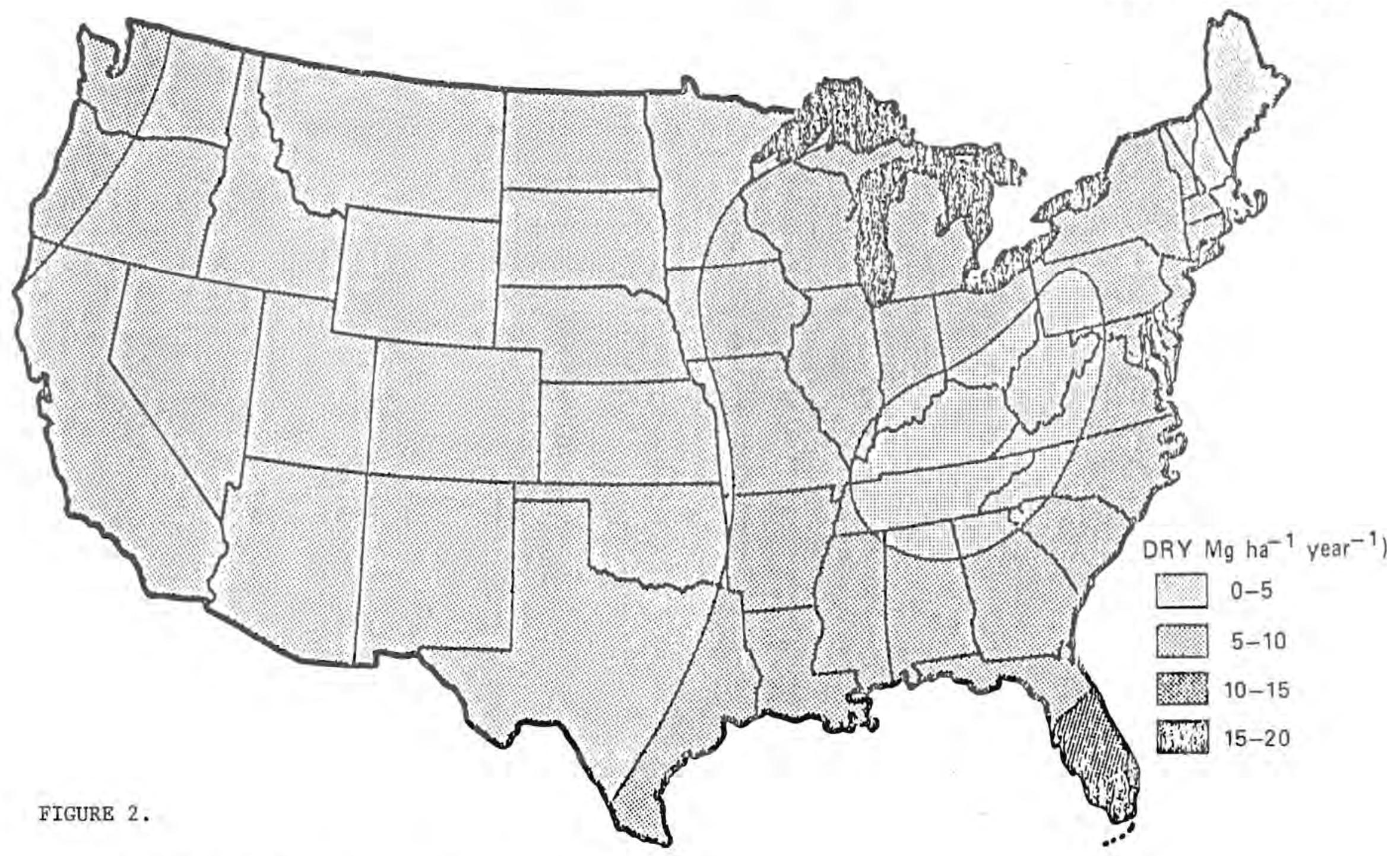

SOURCE: J.W. Ranney, et a1., p. 19. 
Technology: Whole Tree Harvesting: Impact Study on Forest Nutrient and Carbon Dynamics

Applicable Taxonomy Element(s):

\subsection{Forest Land Preparation \\ 2.3 Yield Management: \\ 3.1 Harvesting}

Laboratory: ORNL

Contact: $\quad$ D.C. West

Environmental Sciences Division

(615) $574-7367$

ORNL is conducting a long-term study on the effects of whole tree harvesting on erosion, water quality, nutrients and forest productivity. The study is being conducted at four sites which have been used extensively for research and for which a large historical data base of pertinent information exists. The forests studied differ in geographic region, size, species and totals per hectare. Data are now being analyzed from all sites on nutrient pools and amounts removed in harvest; estimates are being prepared of percent depletion of nutrients.

Reference(s):

(1) D.C. West, L.K. Mann and N.T. Edwards, "Whole-Tree Harvesting: Second Year Progress Report - Impacts on Forest Nutrient and Carbon Dynamics," ORNL/TM-7874, ORNL, December 1981. (Available from NTIS)

* Most applicable taxonomy element.

** Document contained in project file. 
Technology: Geoecology: A County-Level Data Base for the Conterminous United States

Applicable Taxonomy Element(s):

\subsection{Yield Management}

Laboratory: ORNL

Contact: $\quad$ R.J. 0lson

Environmental Sciences Division (615) $574-7819$

M. Farrel

or Environmental Sciences Div. (615) $574-7840$

ORNL has compiled and is maintaining a computerized environmental data base for research and development needs. The integrated data base contains diverse environmental research information from extant sources. Data are stored at the county level with some data available for sub-county units within larger, more diverse eastern countries. The Geoecology Data Base contains selected data on terrain and soils, water resources, forestry, vegetation, agriculture, land use, wildlife, air quality, climate, natural areas, and endangered species. A detailed listing of data is shown on Table 1 .

The data base is fully documented, and a comprehensive user's guide is available. The data base can be accessed in either batch or interactive modes. It uses the Statistical Analysis System (SAS) for data storage, retrieval and analysis. Maps and graphics are generated from the data base by using independent programs.

Uses of the data base include the study of natural vegetation and land use, wilderness area evaluation, biomass fuels and climate and water availability.

Tapes of the data base can be made available to potential users. However, the builders and maintainers of the data base solicit problems on which to work. For example, the data base could be used to monitor the gypsy moth invasion, and its recession, and anomolous areas of non-infestation. The data base could be used to depict pictorially annual acid rain fall and then study other data base items to determine the effects thereof, e.g., growth and yield by species. Forest fire history, acreage burned by county and year, could be correlated with rainfall or water table or snow cover for subsequent planning for deployment of fire fighting resources.

Reference(s):

(1) R.J. Olson, C.J. Emerson and M.K. Nungesser, "Geoecology: A Country-Level Environmental Data Base for the Conterminous United States," ORNL/TM-7351, Prepared for U.S. DOE, Environmental Sciences Division, ORNL, September 1980. (Available from NTIS) $* \frac{1}{\mathrm{~A}}$

Fi ocument contained in project file. 
TABLE 1. Data Set Number (DSN), Title, Temporal Coverage (Years), Geographic Coverage (Geocover), and Spatial Unit (Geounit)

of Data Sets within the Geoecology Data Base as of August I气81.

\begin{tabular}{|c|c|c|c|c|}
\hline os & $\operatorname{IinF}$ & reaks & chocerie & Ciounit \\
\hline \multicolumn{5}{|c|}{ a.2ira rat } \\
\hline 201 & 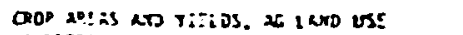 & 1969 & usi & כewit \\
\hline ㄴ) & 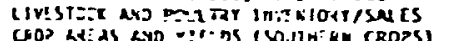 & 1969 & İis & CCMAT? \\
\hline$\infty$ & 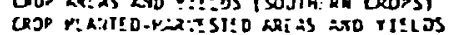 & 1975 & y. 5. & constit \\
\hline arsis & CQOP sirimilat i!siaict inOEx & ig7s & ט. 3. & canly \\
\hline 200 & 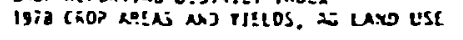 & 1978 & u. 3 . & $\cos n \pi$ \\
\hline \multicolumn{5}{|c|}{ 2asr oxin } \\
\hline 801 & 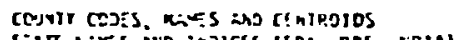 & 1970 & v. 3 . & $\operatorname{counn}$ \\
\hline $\begin{array}{l}\text { DO2 } \\
\text { DDI }\end{array}$ & 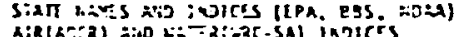 & $\begin{array}{l}1970 \\
1975\end{array}$ & U. 3. & SIRAES \\
\hline cos & 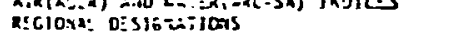 & 1970 & .. 3. & courrt \\
\hline 860 & ibs and :ijices & 1973 & sasin & $c 0=1 \mathrm{Ir}$ \\
\hline mot & 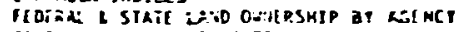 & & u. s. & Covili \\
\hline ECs & 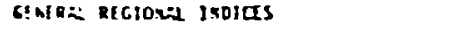 & $1970-75$ & U. $\mathbf{s .}$ & $\cos n$ \\
\hline \multicolumn{5}{|c|}{ alkin } \\
\hline cor & LiRThER SIATIOA : DEATIONS & 1970 & [AR & Dounis \\
\hline cet & 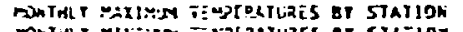 & $1911-1970$ & İis & polvis \\
\hline $\begin{array}{cc}\mathrm{cos} \\
\mathrm{mos}\end{array}$ & 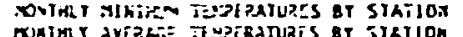 & $\begin{array}{l}1991-1970 \\
2981-1970\end{array}$ & $\begin{array}{l}\text { Lisl } \\
\text { Les: }\end{array}$ & POins \\
\hline CS: & 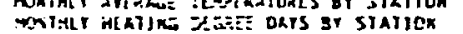 & $1941-1970$ & kisi & POllits \\
\hline iss & 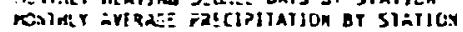 & $1041-1970$ & Wi & Points \\
\hline cor & 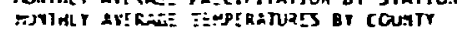 & $1961-1970$ & Wist & Coswit \\
\hline $\boldsymbol{\omega} \mathbf{a}$ & 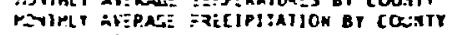 & $1961-1970$ & (x) & combit \\
\hline (C) & 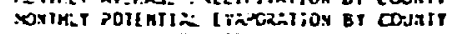 & $1961-1970$ & WI & $\cos 18$ \\
\hline c10 & 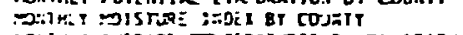 & $1001-1970$ & wisi & Countr \\
\hline (I) & 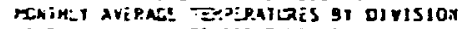 & $1941-1970$ & v. 3 . & 300 \\
\hline ci? & 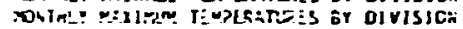 & $1981-1970$ & v. 3 . & sat \\
\hline os & reilm I MikJ & $10<1-1970$ & & 30 \\
\hline gets & 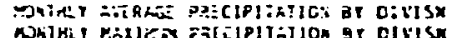 & $1941-1970$ & -5 & 500 \\
\hline as: & 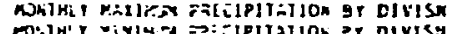 & $\begin{array}{l}2941-1970 \\
1941\end{array}$ & v. s. & $\operatorname{sen}_{0}$ \\
\hline ait & 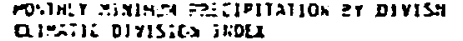 & $\begin{array}{l}1541-1970 \\
1970\end{array}$ & u. s. & $\begin{array}{l}3 c 0 \\
\cos =1 \pi\end{array}$ \\
\hline cia & 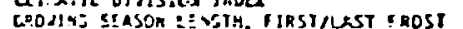 & 1978 & 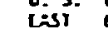 & COUNT \\
\hline (i) & 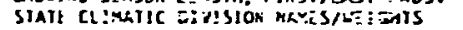 & igis & u. 5 . & sto \\
\hline $\begin{array}{ll}\text { Co } \\
\text { CI }\end{array}$ & 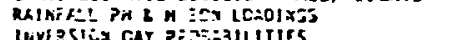 & 1974 & wi & C:M.7IT \\
\hline \multirow{2}{*}{\multicolumn{5}{|c|}{ Vegetition }} \\
\hline & & & & \\
\hline $\begin{array}{l}\text { Dol } \\
\infty\end{array}$ & 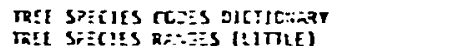 & $\begin{array}{l}1965 \\
1965\end{array}$ & $\begin{array}{l}\text { U. } 3 . \\
\text { u. S. }\end{array}$ & caurry \\
\hline Dos & 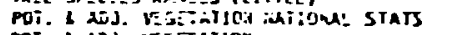 & $1906-1907$ & u. 3. & \\
\hline Dos & 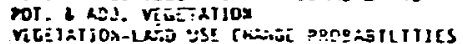 & $1965-i 957$ & u. s. & Coyil \\
\hline$\infty$ & 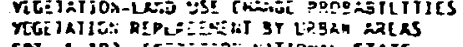 & $\begin{array}{l}1978 \\
1978\end{array}$ & visì & countr \\
\hline$\underset{0 \rightarrow 3}{D 07}$ & 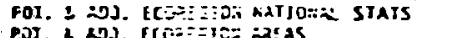 & 1976 & v. s. & 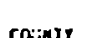 \\
\hline Do & 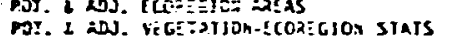 & 1976 & u. s. & Cowntt \\
\hline $\begin{array}{l}010 \\
011\end{array}$ & 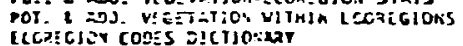 & 1998 & o. & COU:Ir \\
\hline 012 & 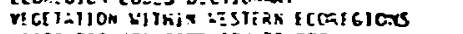 & 1976 & 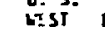 & trosts \\
\hline & Vigilatiat sihsintrity to 502 & 1979 & u. s. & \\
\hline \multicolumn{5}{|c|}{ litixay } \\
\hline 101 & Iniacenges ares (Bra) & $1970-1974$ & v. s. & countr \\
\hline $\begin{array}{l}107 \\
{[0]}\end{array}$ & 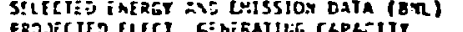 & $1979-1978$ & south & CDasist \\
\hline 100 & 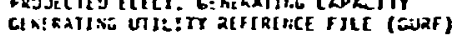 & $\begin{array}{l}1975.1995 .2000 \\
1981\end{array}$ & u. 3. & $\begin{array}{l}\text { Couint } \\
\text { poimis }\end{array}$ \\
\hline \multicolumn{5}{|c|}{ joarster } \\
\hline 101 & 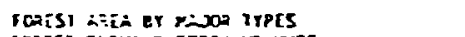 & $1955-1977$ & sonp & COUnit \\
\hline 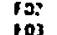 & 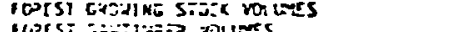 & $1955-1911$ & Sours & Counit \\
\hline 然 & 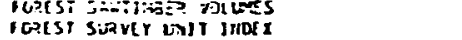 & $1995-1977$ & Sojln & $\begin{array}{l}\text { conir } \\
\text { countr }\end{array}$ \\
\hline ios & 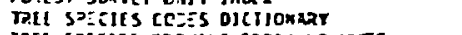 & 1979 & i. 3. & \\
\hline & 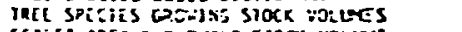 & $1055-19 ? 8$ & I $=5 I^{\circ}$ & cousir \\
\hline $\begin{array}{l}\text { (10) } \\
\text { 101 }\end{array}$ & 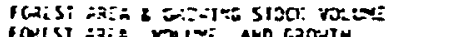 & $\begin{array}{l}1955-1978 \\
195-80\end{array}$ & [205: & cojs \\
\hline \multirow{2}{*}{\multicolumn{5}{|c|}{$c t=5, \mu$}} \\
\hline col & & & & \\
\hline 102 & 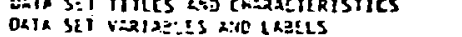 & & & \\
\hline & 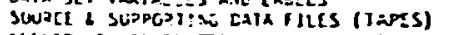 & & & \\
\hline $\cos$ & 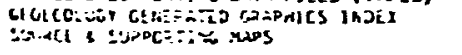 & & & \\
\hline \multicolumn{5}{|c|}{ Als a:ulis } \\
\hline 201 & $242 ! 1:: \div 180$ & $1978-1976$ & sourn & \\
\hline s.:5is & 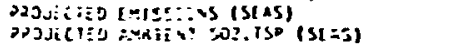 & $\begin{array}{l}75.65,70.2500 \\
75.35,50.2020\end{array}$ & $\begin{array}{l}\text { u. } 5 . \\
\text { u. 5. }\end{array}$ & $\underset{N 2 R}{N=R}$ \\
\hline $\mathrm{sot}$ & 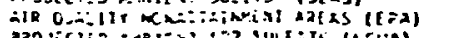 & 1979 & u. 5 . & (n) \\
\hline $\cos _{\cos }$ & 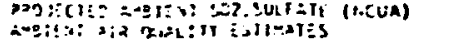 & 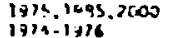 & soute & $\begin{array}{l}\text { cuinll } \\
\text { canll }\end{array}$ \\
\hline
\end{tabular}

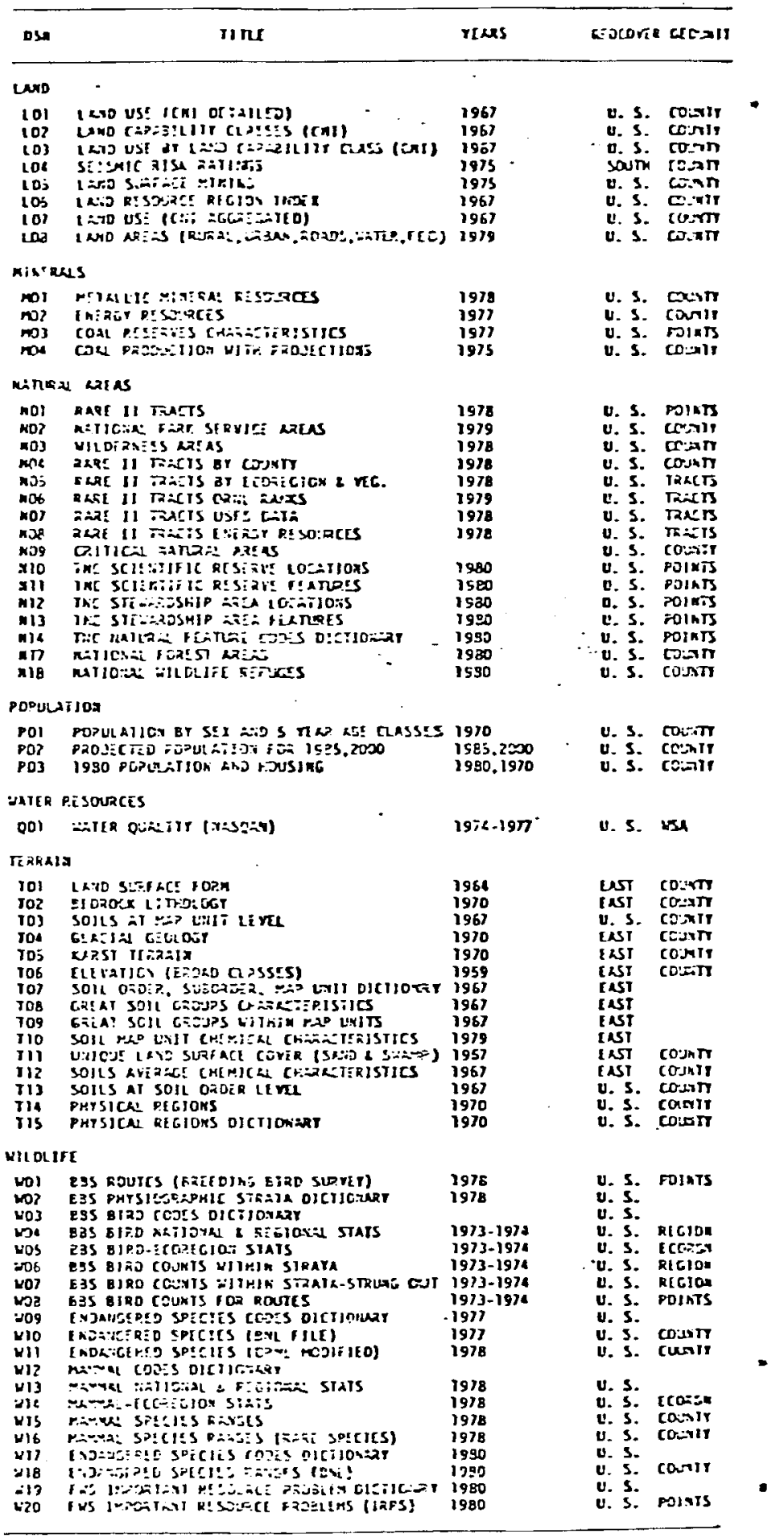


Technology: Laser Application Research

Applicable Taxonomy Element(s):

\subsection{Forest Land Preparation \\ 3.1 Harvesting* \\ 11.0 Pollution Control Systems}

Laboratory: NASA Lewis

Contact: Harvey S. Bloomfield

Program Manager

(216) $433-4000$

NASA Lewis has examined numerous novel uses for lasers, some of which have resulted, for example, in a patented laser technique for oil shale extraction and a practical technique for killing viruses in sewage plant effluent. Most of this work, carried out during the period 1971-1975, employed a portable 250 watt $\mathrm{CO}_{2}$ pulsed laser, which cost $\$ 22,000$ in 1970 . The cost of such a laser is befieved much lower at present. Two possibilities are suggested:

1. Laser Wood Cutting. Dr. Bloomfield has tested the 250 watt laser supplied by Coherent Radiation, Inc., Palo Alto, California, in cutting a range of materials including ice, coal, and oil shale. Though cutting wood has not yet been attempted at Lewis, the tests on other materials indicate that wood cutting "could work" using a commercially available portable, pulsed laser. The earlier work at Lewis in determining the feasibility and off-gases from cutting coal with laser energy is of some relevance. Dr. Bloomfield cooperated in this work with United Aircraft and the laser supplier, Coherent Radiation. There are numerous possible uses for laser wood cutting, including slash cutting, tree topping, and tree felling. A practical, safe device for tree topping, for example, would be a significant labor saving advance in the harvesting operation.

2. Laser Fluid Sterilization. Laser irradiation has been used successfully by NASA Lewis to eliminate a troublesome virus count from a municipal sewage plant effluent stream. Dr. Bloomfield's group mounted a small laser at an effluent weir for this simple, highly effective sterilization process. Laser irradiation may be an effective means to solve the pulp and paper industry's wastewater treatment problems, including the problems accompanying high biological oxygen demand effluents and the conventional secondary treatment methods producing large quantities of biological sludge.

References:

(1) H. Bloomfield, "Sterilization: A Laser Efferts and Evolution Program," July 19, 1973. 秥

* Most applicable taxonomy element.

t:- Document contained in project file. 
Technology: Ultrasonic and Eddy Current Sensors

Applicable Taxonomy Element(s):

4.1 Debarking (metal detection)*

5.2 Chemical Pulping (corrosion evaluation)

6.1 Primary Paper Mills (breakage predictor)

6.2 Paperboard Mills (breakage predictor)

Laboratory: INEL

Contact: $\quad$ J.A. Seydel

Manager, NDE Engineering Branch

(208) $526-6470$

The Nondestructive Evaluation (NDE) Branch at the INEL has considerable experience with developing ultrasonic and eddy current sensors. These may be used for metal detection in harvested logs entering a debarking machine. The eddy current sensors are the more applicable of the two for this use. Ultrasonic, nondestructive techniques are also useful in corrosion detection and monitoring. Ultrasonics and eddy current sensors may be applicable to thickness monitoring to detect and predict breaks. The former would be the better of the two in this application.

Reference(s):

(1) Seydel et al., "Spherical Ware Decomposition," Journal of NDE, April 1982.

(2) Barney Lott, "Hybrid Welding Sensor Development," NoDE Newsletter, Ames Lab., September 1981.

* Most applicable taxonomy. 
Technology: Capacitor Discharge Bark Removal

Applicable Taxonomy Element(s):

\subsection{Debarking}

Laboratory: ORNL

Contact: Eugene C. Hise

Engineering Technology Division

(615) 574-0777

Observations were made that the conductive layer lies just below the bark and that a voltage level exists that will effect debarking (as lightening does). Mr. Hise noted that ORNL has the power on-site, and the capacitor banks, to conduct an experimental evaluation of the proposed de-barking technique. 
Technology: High Temperature, High Speed Bearings and Lubricants

Applicable Taxonomy Element(s):

4.0 Debarking and Chipping/Grinding

5.1 Mechanical Pulping

5.2 Chemical Pulping

6.0 Paper and Paperboard Production

7.0 Coating and Converting

Laboratory: NASA Lewis

Contact: $\quad$ Erwin Zaretsky

Program Manager

(216) $433-4000$

Throughout a pulp and paper mill (both mechanical and chemical mills) there are numerous high-speed, high-temperature bearings whose life is critically dependent on lubrication and lubrication systems. Such problems are very similar to those encountered in the aircraft industry where engine and rotor bearings play a critical role in the reliability and hence maintenance cost of aircraft and helicopters. NASA Lewis has been a pioneer in developing bearings, lubricants and lubrication systems capable of withstanding the severe operating conditions prevailing in such systems. The results of this effort appear to be directly applicable to the pulp and paper industry. The following sections describe the results of this work.

1. Lubricant development

The objectives of the NASA Lewis Research Center effort were to study lubricant failure at high temperatures and to develop lubricants providingprolonged bearing life under adverse conditions. This work has been underway since the 1950's, and many remarkable advances have been achieved. are:

Three primary lubricant categories resulted from this effort. They

- Polyphenylethers - at $600^{\circ} \mathrm{F}$ these fluids permit about 0.4 catalogue life of typical bearings if kept in an air (oxidizing) environment. At $425 \mathrm{~F}$, the life is significantly increased to over 25 times catalogue life.

- Fluorocarbons - can achieve about three times catalogue life if run at $10 \%$ normal air oxygen level at $600 \%$. The fluorocarbons, however, seem to catalzye oxidation of the bearing surface (even at $425^{\circ} \mathrm{F}$ ) and thus were discarded as a liquid lubricant. Fluorocarbon greases, however, have been found to have extremely good qualities in sealed bearing systems. 
Parafinic lubricants - yield about 15 times catalogue bearing life at $600^{\circ} \mathrm{F}$ if run at $10 \%$ oxygen. At $425^{\circ} \mathrm{F}$, atmosphere is not a problem. It was initially observed that bearing failure occurred on start-up with these fluids, but an additive package was developed to eliminate this problem. One problem with the parafinic fluids is the low temperature pour point (a problem for military specifications). This problem, however, is not perceived to be a deterrent to the pulp and paper industry.

The parafinic fluids probably are most applicable to the pulp and paper industry.

\section{Lubricant System Development}

One of the major causes of bearing failure was observed to be the presence of particulate in the lubrication system. A 40 micron filter in the lubricant system failed to solve this problem especially at high D.N. (an empirical operating parameter obtained by multiplying the bearing diameter in millimeters times the bearing rpm). The development of a non-clogging 3 micron filter significantly improved bearing life. This filter is now commercially available from the Paul Corporation at a cost between $\$ 50$ and $\$ 500$ depending on size. Bearing lives at 3 million D.N. of up to 50,000 hours at $425^{\circ} \mathrm{F}$ are possible (when proper raceways are used).

Spallation is the normal failure mode in bearings. Above 3 million D.N. spallation causes rapid failure of the bearing race. NASA, however, has developed alloy raceways which significantly reduce this failure mode, permitting bearings to be operated for long periods of time after initial spallation is observed. At $425^{\circ} \mathrm{F}$ heavily loaded bearings have gone as much as 50,000 hours before failure.

Two detectors have been developed which have important application to bearing maintenance. The first is a piezoelectric transducer that detects the initiation of spallation. The second is a magnet spark ignition device called a chip burnoff detector which detects the amount of spallation that occurs. With these detectors it is possible to predict the point at which bearing replacement is required. Graphically this is represented in Figure 1.

\section{Bearings}

NASA, in cooperation with bearing manufacturers, is developing a bearing remanufacturing capability. Both ITI and TRW are developing this capability of regrinding bearings. Bearing refurbishment using existing housings but new raceway and balls (or rollers) also is an area of development and now has reached the commercial stage.

Tapered roller bearings for very high loads are now available on a commercial basis and may have application to high thrust devices in the Pulp and Paper industry such as chippers, refiners, and grinders. 
NASA has in place a computer capability which uses loads, D.N. and temperature as inputs and provides optimization of bearing and lubrication system design to minimize cost and maintenance and maximize life. They expressed interest in using this capability to directly analyze integrated mills.

\section{Traction Drives}

NASA has developed in cooperation with NASTEC Corporation of Cleveland a drive mechanism capable of providing speed reduction or increase in ratios ranging from $3 / 1$ to $300 / 1$. Drives have been built for transmission of 500 horsepower that are about 6 inches in diameter and 3 inches wide with life up to 47,000 hours and $97 \%$ efficiency. The drives have no gears and are lightweight and small. As such, they could be used for providing drive to Fourdrinier cans. The small size would permit hooding existing machines with ease. These drives are now commercially available.

They are also working on a hybrid traction/gear drive capable of 30,000 horsepower transmission. These drives are currently under test for helicopter application.

Recent work is directed towards variable speed drives. This effort is proceeding well and should be commercially available in the near future.

Reference(s):

(1) R.J. Parker and H.R. Singer, "Lubrication of High-Speed, Large Bore Taper-Roller Bearings," Journal of Lubrication Technology," Vo1. 100, No. 1, January 1978, pp. 31-38.

(2) E.N. Bamberger, E.V. Zaretsky, and H. Singer, "Endurance and Failure Characteristic of Main-Shaft Jet Engine Bearing at $3 \times 10^{6} \mathrm{DN}, "$ Journal of Lubrication Technology, Vol. 18, No. 4, October 1976, pp. 580-585.

(3) R.J. Parker, S.I. Pinel, and H.R. Signer, "Performance of Computer Optimized Taper-Roller Bearings to 2.4 Million DN," Journal of

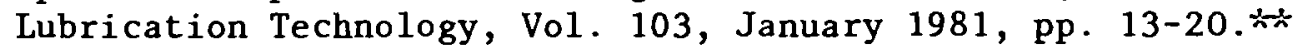

(4) E.V. Zaretsky, H. Singer, and E.N. Bamberger, "Operating Limitations of High-Speed Jet-Lubricated Ball Bearings," Journal of Lubrication Technology, January 1976, pp. 32-39.

(5) W.J. Anderson and E.V. Zaretsky, "Rolling-Element Bearings - A Review of the State of the Art," NASA Technical Memorandum, NASA TMX-71441, 1973. 
(6) R.J. Parker, "Lubrication of Rolling-Element Bearings," NASA Technical Memorandum 81449,1980 .

(7) R.J. Parker, "Rolling-Element Fatigue Lives of AISI 52100 Steel Balls with Several Synthetic Lubricants," NASA Technical Memorandum, NASA TMX-73406, 1976.

(8) R.J. Parker and R.S. Hodder, "Effects of Double Vacuum Melting and Retained Austernite on Rolling Element Fatigue Life of AMS 5749 Bearing Steel, NASA Technical Paper 1060, October 1977.

(9) H.H. Coe and E.V. Zaretsky, "Predicted and Experimental Performance of Jet Lubricated 120-Millimeter-Bore Ball Bearings to 2.5 Million DN, NASA Technical Paper 1196, April 1978.

(10) H.R. Singer and S.I. Pinel, "Endurance Test with Large-Bore Tapered-Roller Bearings to 2.2 Million DN," NASA Technical Memorandum 82669, 1981.*t

(11) S.H. Loewenthal, D.W. Moyer, and W.M. Needelman, "Effects of Ultraclean and Centrifugal Filtration on Rolling-Element Bearing Life, NASA Technical Memorandum 82660, 1981.*-'

* Most applicable taxonomy element. to Document contained in project file. 
spallation (represented by metal in lub)

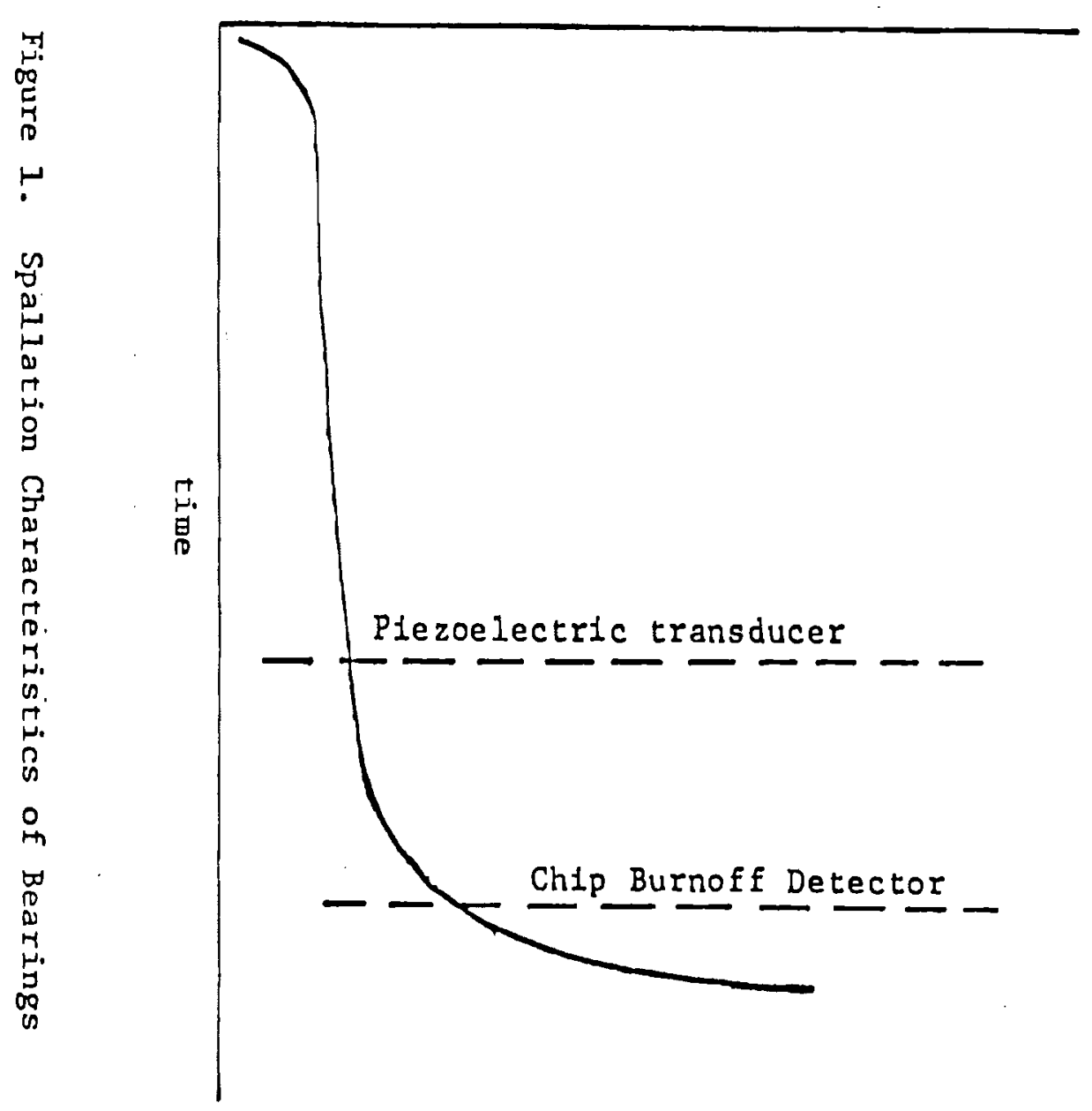


Technology: Three Laser Activated Detectors for Determining Composition of Complex Mixtures

Applicable Taxonomy Element(s):

\author{
5.1 Mechanica1 Pulping \\ 5.2 Chemical Pulping \\ 6.0 Paper and Paperboard Production \\ 10.0 Power and Chemical Recovery Systems
}

Laboratory: JPL

Contact: Dr. Rianti Liang

Energy and Materials Research Section

(216) $354-6314$

Dr. Liang described three detectors on which he is working and which may have applicability to on-line control of the pulping and papermaking processes. A brief description of each and their possible applications are discussed in the following paragraphs. A more detailed description of each of the three techniques is given in Attachments 1,2 and 3 respectively.

\title{
1. Photo-Acoustic Spectrometer
}

When a complex mixture of organic constituents is irradiated with a high-intensity laser pulse, the heat generated creates sound waves (like the pop in a flash bulb). The sound frequency and intensity are characteristic of the molecular species present and their respective concentrations. Although a significant amount of cataloging of reference spectra would be required to use such an instrument for spectrographic analysis, its applicability to the analysis of systems having relatively uniform composition is of interest.

The experimental set-up to evaluate this concept is shown in Figure 1 . Characteristic output of a two-component system is shown in Figure 2 .

It is possible that this instrument could be used to determine free alkali lignin in digestor effluent. A second application could be as an on-line consistency meter for pulp entering the head box. The system can be used for analysis of dark, optically opaque liquids and as such is potentially applicable to the analysis of numerous liquid streams not amenable to absorption spectroscopy without dilution.

\section{Laser Induced Fluorescence}

JPL is examining the exitation of molecular species using a laser. Such exitation causes electrons to bounce to higher quantum levels and upon their return to ground state give off light characteristic of the chemical groups present. This of course is the basis of emission spectroscopy. 


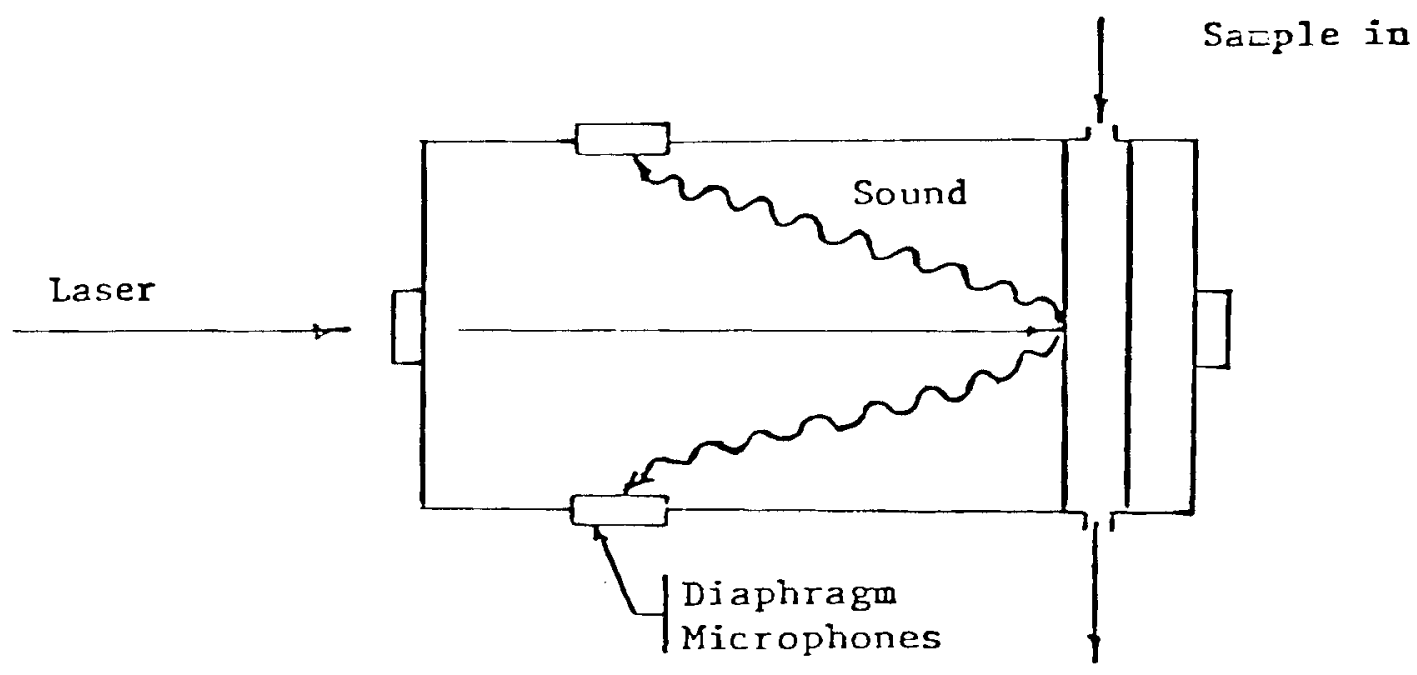

Figure 1. Experimental Set-up

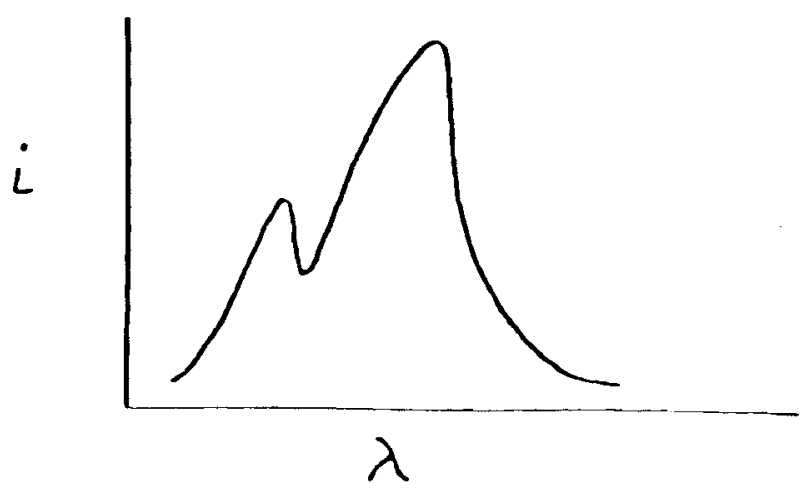

Figure 2. Characteristic Output 
It has been observed, however, that polycyclic substances and certain clays have metastable levels in which an excited electron may remain for a significant time period before returning to the ground state. Such a phenomenon is fluorescence.

Lignin has been observed to possess this characteristic. Laser irradiation of dilute black liquor exhibited fluorescent peaks at 250,330 , and 360 nanometers. JPL feels they could use this analytical technique to evaluate lignin concentration in digestor effluent and/ or recovery boiler feed without dilution by using a light pipe bundle in which one group of pipes serves as the transmitter of the excitation laser, and other groups serve as receptors for fluorescent emission. It would have to be demonstrated, however, that optical clarity of the end of the light pipe bundle were unimpaired by prolonged exposure to black liquor.

3. Transient Thermal Lensing

Pulsed laser irradiation of a liquid sample creates a region in the liquid that is instantaneously hotter than the surrounding liquid. The rate at which this energy is dissipated to the main body of liquid is a function of the viscosity and thermal conductivity of the system. The index of refraction in this "thermal lens" also is different than the surrounding liquid. Thus, by chopping the input laser beam it is possible to determine the life of the thermal lens. With a constant thermal conductivity system as would be the case with a dilute water suspension (as found in the pulp entering the head box) the only variable affecting lens life would be viscosity, which in turn is directly related to pulp concentration. Thus, this thermal lensing technique might well be used as an on-line consistency meter.

Clearly, the sensitivity of this technique will be directly dependent on the change in viscosity of pulp as a function of concentration.

‡ Most applicable taxonomy element. 
In the photoacoustic technique (PA), a sample is placed inside a specially designed cell containing a sensitive microphone. The sanple is then illuminated with chopped radiation as illustrated in Figure 1. Light absorbed by the sample is converted in part into heat by non-radiative de-excitation processes within the sample. The resulting heat flow from the sample to the surroundings creates pressure fluctuations in the cell. These pressure fluctuations are then detected by the microphone as a signal which is phase coherent at the chopping frequency. The resulting photoacoustic signal is directly related to the amount of light absorbed by the sample. This is especially the case for highly opaque and low fluorescent systems. Since only the absorbed light is converted to sound, light scattering which is a very serious problem when dealing with many systems by conventional spectroscopy, presents no difficulties in PA.

This technique, therefore, can be applied to highly opaque or highly turbid systems such as insulator, semiconductor and biological systems which cannot be studied by conventional techniques. Moreover, PA is extremely sensitive in detecting small amounts of absorption. For instance, we have obtained sensitivity improvement of 2-3 orders of magnitude by PA in detecting early polymer photooxidation as compared to conventional Fourier-Transform Infrared (FT-IR) spectroscopy. Material concentration as low as $10^{8}$ molecules $/ \mathrm{cm}^{3}$ has also be detected by PA.

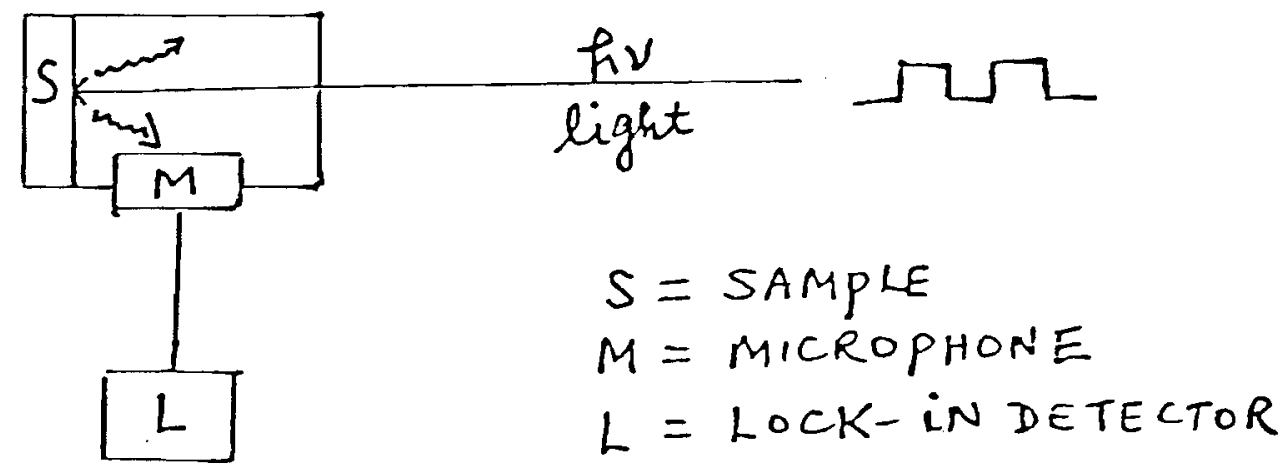




\section{Laser Induced Fluorescence (LIF)}

In LIF, a tunable narrow-band light source is aimed to a reaction zone. This light source is then swept in wavelength. Whenever the wavelength coincides with a particular molecular absorption, the sample molecules will - make a transition to an excited electronic state from which they subsequently emit (fluoresce). This emission is detected by a photomultiplier which "views" the excitation zone. The fluorescence intensity is recorded as a function of laser wavelength to produce an excitation spectrum which can be used to identify various components in the reaction zone qualitatively as well as quantitatively. Recent developments of tunable lasers have greatly enhanced the sensitivity of this technique. Molecular concentrations in the order of $10^{4}$ molecules $/ \mathrm{cm}^{3}$ has been detected by LIF. Unlike conventional chemical detectors such as a mass spectrometer, LIF is not an universal detector, but it is high specific and selective, especially when it is used to detect gaseous species. In addition, LIF has the virtue that the reaction zone can be probed directly, which is not possible with other detectors. 
ATTACHmENT 3

Thermal Lens Technique (TL)

This method is based on the temperature rise in an illuminated sample induced by the absorption of small amounts. of energy from a light beam passing through the sample. The localized temperature change brings a transverse gradient in the index of refraction, which can be probed optically as a thermal lens. A laboratory experimental set up is illustrated in Figure 2. A sample is placed in the beam of the lasers. The chopped heating laser beam forms a continuously pulsating thermal lens in the sample. This heating beam is blocked from the detection by an optical filter. The probe laser beam passes through the sample, senses the lens and expands onto a target containing a pinhole at its center. Formation of a thermal lens is followed by sampling the changing beam intensity with the pinhole-photomultiplier configuration. TL has also been carried out via a single beam configuration in which a single laser serves both as the heating as well as the probing beam. Detection sensitivity of $10^{8}$ molecules/ $\mathrm{cm}^{3}$ has been achieved. In addition to the sensitivity, TL can also be used to probe changes in thermal properties of material.

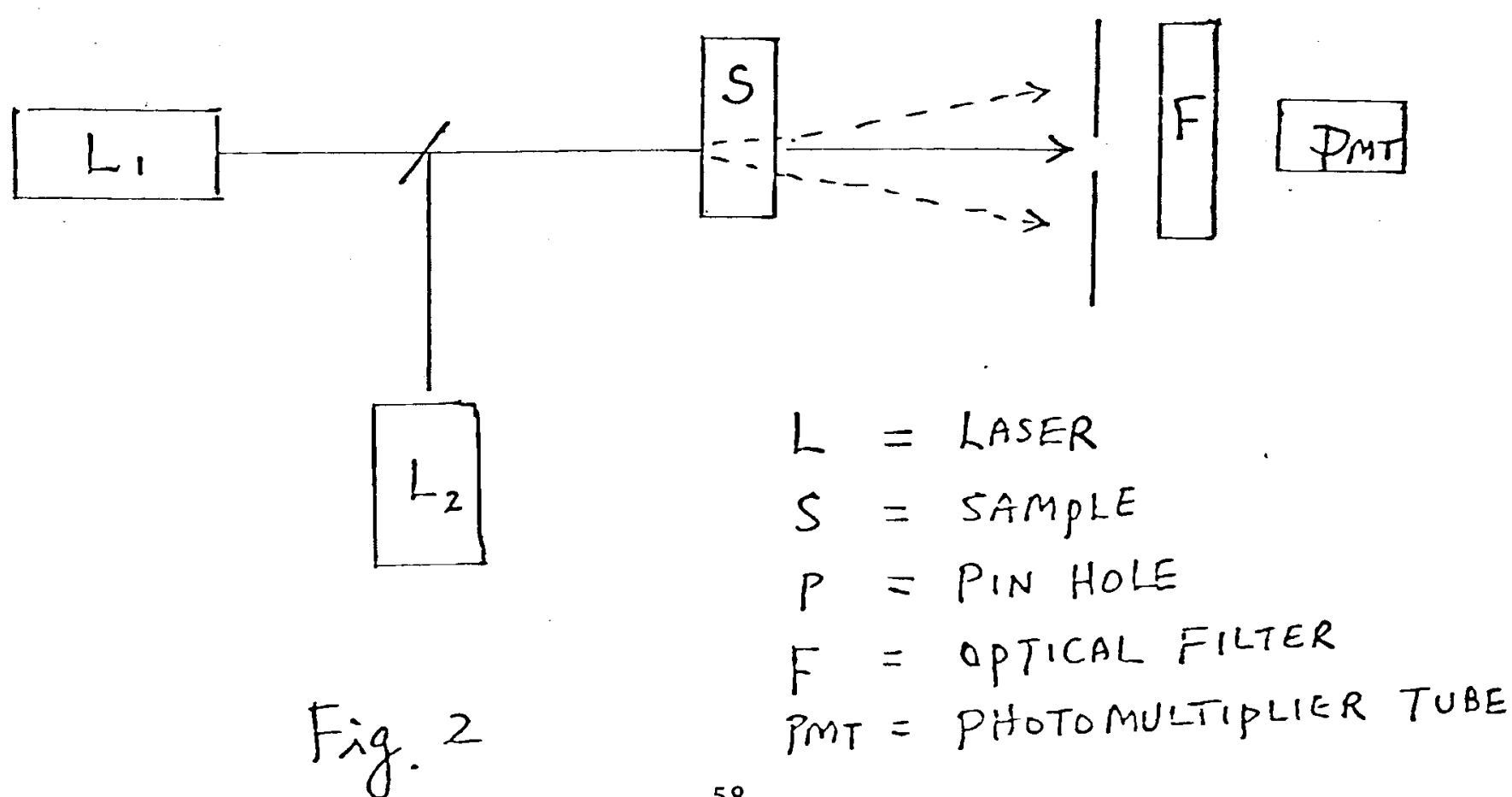

58 
Technology: Solubility Parameter Concept and Cohesive Energy Density

Applicable Taxonomy Element(s):

\author{
5.2 Chemical Pulping* \\ 7.0 Coating and Converting \\ 9.0 Waste Paper
}

Laboratory: JPL

Contact: Dave Lawson

Technical Staff, Chemical and Combustion Group

(213) $354-3615$

Mr. Lawson has extended the work of Hildebrand and Scatchard on the concept of cohesive energy density. This theory is related to the physical affinity of one substance to another, but with modification can account for weak coordinate or hydrogen bonding as well. Direct correlations have been made between the cohesive energy density of a substance and the solubility parameter of that substance. The numerical value of the solubility parameter can be derived if one knows the heat of vaporization, internal pressure, critical pressure, surface tension or refractive index of the substance. Close approximation of the solubility parameter can be made if the chemical structure of the substance is known. Once knowing the solubility parameter it is possible to select a solvent or mixture of solvents which exactly match the solubility parameter of the substance.

Mr. Lawson has developed a series of 72 sqlvents which span the solubility parameter range of 5 to $24\left(\mathrm{cal}^{\frac{2}{2}}\right.$ per $\left.\mathrm{cm}^{3 / 2}\right)$. Using this series he can experimentally determine the solubility parameter of a complex unknown structure (e.g., coal, lignin, etc.). Having made this determination it is then possible to select a pair of solvents which would be optimum for the solution of such a structure.

Such an investigation could be undertaken to determine the solubility parameter for lignin in wood. The ultimate selection of a solvent or mixture of solvents (mixtures tend to be somewhat better since by correct proportioning it is possible to exactly match the solubility parameter of the intended solute) could potentially provide a significant alternative to the alkaline kraft pulping process. The new process could be total solvent extraction of lignin or more likely the use of an optimum solvent mixture to expand the lignin cellulose matrix enabling more rapid digestion using conventional chemicals $\left(\mathrm{Na}_{2} \mathrm{~S}, \mathrm{NaOH}\right)$.

A second application would be to analyze the strength of the rosin/alum bond in coated papers. Such analysis would be beneficial in determining the optimum $\mathrm{pH}$, rosin concentration and alum concentration associated with the coating + pqocess. In addition, other ionic species could be compared with $\mathrm{Al}{ }^{+7 F^{\circ}}$ and $\mathrm{Al}(\mathrm{OH})^{++}$as the bonding agent.

Most applicable taxonomy element. 
Technology: Optical Scanners and Image Processing

Applicable Taxonomy Element(s):

5.3 Bleaching

6.1 Primary Paper Mills (breakage predictor)*

6.2 Paperboard Mills (breakage predictor)

Laboratory: INEL

Contact: $\quad$ J.0. Bolstad

(208) 526-1753

INEL's engineers are currently involved in a DOE/Honeywell/U.S. Steel program to demonstrate high-speed automatic inspection for defects in hot rolled steel. This technology is directly applicable to the detection of flows, discoloration, and potential breakage points in paper moving at high speed. INEL offers about 40 man-years of experience with laser scanning, CCD images and image processing. Another applicable project currently underway is a scanning laser radar system for the TMI Program.

* Most applicable taxonomy element. 
Technology: Polymeric Electrolytic Hygrometer

Applicable Taxonomy Element(s):

\subsection{Primary Paper Mills* \\ 6.2 Paperboard Mills}

Laboratory: JPL

Contact: Dave Laws on

Technical Staff

Chemical and Combustion Group

(213) $354-3615$

Dr. Lawson described a polymeric electrolytic hygrometer, capable of measuring moisture content in a gas stream from several parts per million to saturation. The polymer used is Nation, which acts as an ion exchange resin. The tube is contacted on both surfaces by a pair of closely-spaced, high-surface area electrodes. Moisture from humid air is absorbed into the polymer where it is electrolyzed to hydrogen and oxygen. The measured current required is directly proportional to the moisture content of the inlet air. JPL has designed a tube structure which easily and effectively filters entrained particulates from the polymer surface.

This detector is inexpensive, highly resistant to oxidation and reduction (and thus capable of operating in extremely adverse gaseous environments), and has excellent mechanical strength. These characteristics make it ideally suited to a production operation.

One can visualize the accurate monitoring of humidity in many stations along the fourdrinier dryer. In hooded dryers the make-up air could be accurately and optimally metered to minimize drying energy. Likewise, the moisture content of the nip felt can be monitored.

In light of the simplicity, low cost and ruggedness of this instruemnt, it is believed that an evaluation program in an operating mill is warranted.

* Most applicable taxonomy element. 
Technology: Precision Machining

Applicable Taxonomy Element(s):

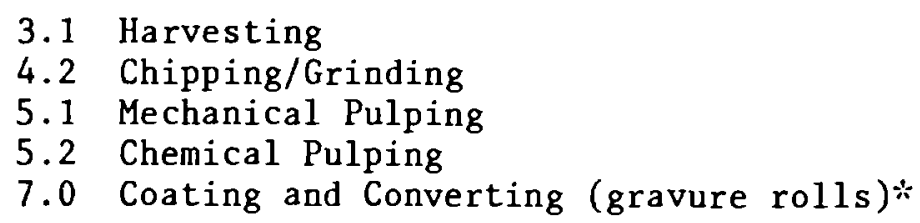

Laboratory: LLL

Contact: Jerry Cain or Ray McClure

(415) $422-4599$

LLL has developed a production technique for high precision bearings. The process involves rough turning, hardening and finish turning (as opposed to centerless grinding). The final step of finish turning is enabled by the development of cubic boron nitride as the machine tool cutting surface.

Using such techniques the "truth" in axis of rotation in even common bearings can be increased by a factor of 6 . Such bearings run quieter, have much greater endurance, and are capable of remachining. The cost, however, is considerably more than conventional bearings. It is probable that they would find application in the paper industry only in those areas where high reliability and loadings are required, e.g., chippers, refiners, etc., or where very high purity is required, e.g., gravure rolls in printing.

This latter application could represent a very significant improvement in printing characteristics.

Two firms produce cubic boron nitride commercially - GE (Worthington) and DeBeers. A distributor handling both types is:

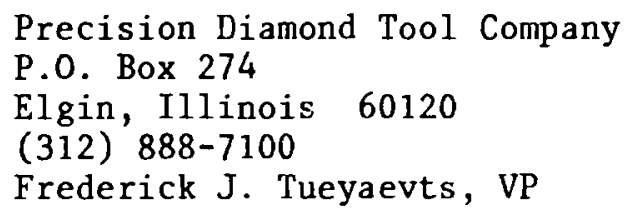

Jerry Cain offered the use of his name in making any inquiries of this firm.

* Most applicable taxonomy element. 
Technology: Pinhole Imaging Systems

Applicable Taxonomy Element(s):

5.1 Mechanical Pulping (heat exchangers)

5.2 Chemical Pulping (heat exchangers)

10.0 Power and Chemical Recovery Systems

(recovery boilers)*

Laboratory: INEL

Contact: $\quad$ J.0. Bolstad

(208) $526-1753$

INEL is developing a gas-cooled video periscope to be used at their Power Burst Facility for observation of fuel elements within the nuclear reactor core during severe loss-of-coolant testing. A simple gas-purged pinhole aperature is the only optical element exposed to the highly corrosive atmosphere and the extreme temperatures, which will range up to $3100^{\circ} \mathrm{K}$. In a paper mill, there is a need to improve combustion efficiency in the recovery boiler and this periscope technique could be used to monitor topography and uniformity of the burning solids. Another application would be for on-line monitoring of heat exchanger fouling.

Reference(s):

(1) J.0. Bolstad, "Real Time Observation of Severe Reactor Core Damage," Patent Disclosure, October 28, 1981.

* Most applicable taxonomy element.

$\therefore$ Document contained in project file. 
Technology: Microbial Conversions

Applicable Taxonomy Element(s):

10.0 Power and Chemical Recovery Systems

Laboratory: INEL

Contact: $\quad$ Larry Dawley

Scientist

(208) 526-0629

This technology involves the microbial conversion of by-products of the pulp and paper industry to produce speciality chemicals and polymer intermediates via the metabolic pathways of single cell organisms.

Reference(s):

(1) Larry Dawley, "Proposal to DOE," 1982.

(2) Dawley, Wolfram and Leeper, "MSW Assessment," 1982, In Press. 
Technology: Bottoming Cycles

Applicable Taxonomy Element(s):

5.1 Mechanical Pulping

5.2 Chemical Pulping

6.1 Primary Paper Mills

6.2 Paperboard Mills

10.0 Power and Chemical Recovery Systems*

Laboratory: INEL

Contact: Jack Demuth or Jud Whitbeck

(208) 526-9635 Manager, Geothermal Electric

Branch

(208) 526-1879

INEL is experienced in the use of low temperature organic Rankine cycles for the production of electricity. They have analyzed alternative cycle options and have built and operated several cycle configurations for use with low-temperature geothermal fluids, a 5MW plant in one configuration, and a $60 \mathrm{~kW}$ plant in several configurations. INEL also has process simulation computer codes, power cycle codes, and an availability cycle computer code. This technology may be applied to the low temperature waste heat streams which are generated in the pulp and paper process.

Reference(s):

(1) 0.J. Demuth, "Analysis of Binary Thermodynamic Cycles for a Moderately Low-Temperature Geothermal Source," TREE-1365, July 1979.

(2) 0.J. Demuth, "Analysis of Mixed Hydrocarbon Binary Thermodynamic Cycles for Moderate Temperature Geothermal Resources," PG-G-80-041, February 1981.

(3) G.L. Mines, "Prototype Geothermal Power Plant summary of Operation for Automatic-Run Test Phase," EGG-2078, February 1981.

(4) C.J. Bliem, "Performance and Operability Study of the Raft River 5MW(e) Pilot Geothermal Power Plant Steady-State Behavior," PR-6-79-017, November 1979.

(5) D.J. Wiggins and C.J. Bliem, "Operational Upset Transients in a Dual Boiling Binary Cycle Geothermal Power Plant," GRC Transactions, Vo1. 4, September 1980, p. 537.

(6) W.W. Madsen and I.J. Ingvarsson, "Analysis of the Binary Cycle for Geothermal Power Generation," prepared by Aerojet Nuclear Company for ERDA, December 1975.*-th

* Most applicable taxonomy element.

*t Document contained in project file. 
Technology: Amorphous Metals

Applicable Taxonomy Element(s):

$\begin{array}{ll}3.1 & \text { Harvesting (chain saw teeth) } \\ 4.2 & \text { Chipping/Grinding (chipper blades) } \\ 5.1 & \text { Mechanical Pulping (heat exchangers) } \\ 5.2 & \text { Chemical Pulping (heat exchangers) } \\ 6.0 & \text { Paper and Paperboard Production } \\ 10.0 & \text { Power and Chemical Recovery Systems* }\end{array}$

Laboratory: JPL

Contact: Dr. Suttish Khanna

Energy and Materials Research Section

(213) $354-4489$

One of the most exciting technologies uncovered at JPL is their work in amorphous metals. Allied Corporation developed a process for casting ferro alloys on a moving bed which quenches the metal at one million degrees centigrade per second (Trade name Metglass). Metal so cast is completely devoid of crystal structure and grain boundaries. As such it is an extremely interesting transformer core material since the thermal losses occasioned by dipole reversal mainly occur due to impedance offered by the grain structure. This application is being pursued by Allied under contract to the Electric Power Research Institute.

Amorphous metals, however, have many other characteristics which promise entirely new capabilities heretofore impossible. JPL has developed a magnetically focused sputtering technique for laying down an amorphous metal coating on a conventional substrate. Using this technique it is possible to coat conventional shapes with amorphous metals of accurately variable composition, and hence characteristics.

Having no grain boundaries such coatings have extremely high corrosion resistance. Alloys of $\mathrm{Fe}, \mathrm{Ni}, \mathrm{B}$ and $\mathrm{P}$ have been subjected to molten salt, sulfuric acid and other highly corrosive environments without any detectable effect. Boiler tubes so coated would have extremely long life in a recovery boiler (where sodium and $\mathrm{SO}_{2}$ corrosion represents a major problem). Similarly it would be possible to design a heat exchanger coated with amorphous metals, since the corrosion problems associated with subdewpoint operation would be eliminated. Such a heat exchanger not only would substantially increase economizer efficiency, but also has the potential of eliminating $\mathrm{SO}_{2}$ scrubbers in conventional large boilers.

The ferrous alloys described have a temperature limitation of about $800^{\circ} \mathrm{C}$. Above this temperature crystal growth and grain boundaries build back into the structure and the corrosion resistance is reduced.

JPL, however, is working with some unique alloy compositions which may preclude this temperature limitation and at the same time offer other unique features. An example is the use of Molybdenum Boron alloys. Such an alloy would have the characteristics of high thermal conductivity and extremely 
high hardness. Cutting tool coatings immediately loom as a possi:le application. Consider chain saw teeth, or chipper blades so coated. Successful deposition of this type of amorphous metal coating could significantly increase the life of such tools.

Titanium boron coatings would have similar characteristics to the Yoly Boron alloys. Such recipies may well be the solution to the wettable cathode problem of the aluminum industry.

It is obvious that the potential uses of amorphous metals has barely scratched the surface. This technology offers a capabilitiy for application to problems traditionally considered insoluble.

Reference(s):

(1) "Amorphous Metals: Cutting Losses in the Core," EPRI Journa1, Vol. 7, No. 1, January/Febraury 1982, p.14. *t

* Most applicable taxonomy element. $* *$ Document contained in project file. 
Technology: Acoustic Characterization of the Efficiency of Combustion and Flames

Applicable Taxonomy Element(s):

\subsection{Power and Chemical Recovery Systems}

Laboratory: JPL

Contact: Richard M. Clayton

Supervisor, Chemical and Combustion Group

(213) 354-6659

Or his employees:

1) K. Ramoha11i

2) W. Dokko

A considerable amount of wood product and purchased fossil fuels are consumed on site in paper/pulp plants. The sum is about $2.1-2.2$ quad/year with about half being self generated in 1982. The trend is very definitely towards more self-generated Btu's and less purchased. The ratio of self-generated to purchased Btu's was projected to be 1.0 in 1982 and growing at the rate of 0.03 /year since 1972 . About 98 percent of the increase in self-generated Btu's is coming from increasing Btu recovery in bark and liquor burning - where boiler combustion efficiency is likely never higher than $80-86$ percent with $60-65$ percent more typical. Clearly, a diagnostic to disclose low boiler combustion efficiency might prove quite useful.

JPL offers the results of some work started under Dr. Karl Bastress of DOE. Simply stated, the diagnostic is the presence of purely turbulent noise, exclusive of boiler geometry, above $25 \mathrm{kHz}$. An ellipsoidal mirror is used to catch sound waves.

This acoustic signature changes when the burner is operated under less than optimum efficiency. Empirical determination of the spectrum at optimum efficiency and at off-optimum points permits an on-line efficiency monitor and control system.

Since much more of the purchased Btu's in this industry is now coal, it is worth noting that this same JPL group has been successfully using potassium acetate as the catalyst in a 75 micron coal burner to reduce burning time by 25 percent.

Reference(s):

(1) K. Ramohalli, "Some Fundamental Acoustic Observations in Combusting Turbulent Jets," Combustion in Reactive Systems, J.R. Bowen, N. Manson, A.K. Oppenheim and R.I. Soloukhim, eds., 1981 .

Document contained in project file. 
Technology: Explosive Forming, Bonding and Welding

Applicable Taxonomy Element(s):

5.1 Mechanical Pulping (heat exchangers)

5.2 Chemical Pulping (heat exchangers, recovery boilers)

10.0 Power and Chemical Recovery Systems (boiler tubes)*

Laboratory: LLL

Contact: $\quad$ Richard L. Landringham

Material Scientist

(415) 422-8022

Dr. Landringham is a material scientist at LLL active in explosive joining techniques, techniques which use shaped explosive charges enabling the forming of a complex shape from metal power, "welding" of similar or dissimilar metals with joints indistinguishable from basemetal, and the forming of composite structures such as laminated tubes. LLL has worked to some degree with amorphous metals using these techniques.

With these techniques it is feasible to fabricate laminated boiler or heat exchanger tubes. For example, it is possible to wrap a boiler tube with an amorphous metal strip, e.g., Allied Corporation's 2" wide ribbon, and bond the amorphous metal to the tube substrate, forming a composite tube structure. This type of forming would avoid any heat treatment (welding) which could destroy the glass-like structure of the amorphous metal. Such a tube would possess the extremely high corrosion resistance of amorphous metals on the side exposed to flue gases and as such could be used in recovery boilers or other heat exchangers subject to a highly corrosive environment. One could hypothesize an economizer operating below the dew point for recovering the latent heat of water of combustion. This concept, if successful, would have great significance to all industrial and utility boilers enabling the utilization of all the energy available in the high heating value of fuel, while at the same time eliminating the need for $\mathrm{SO}_{2}$ scrubbers.

$\star$ Most applicable taxonomy element. 
Technology: Photovoltaic Remote Power Applications

Applicable Taxonomy Element(s):

1.1 Tree Seedling Nurseries

2.0 Forest Land Preparation, Stocking and Yield

Management

3.1 Harvesting

10.0 Power and Chemical Recovery Systems*

Laboratory: NASA Lewis

Contact: Anthony F. Ratajczak

Program Manager

(216) $433-4000$

NASA Lewis has designed photovoltaic (PV) power systems for many field applications. The cost of PV solar cell arrays continues to decline with growing production experience and is about $\$ 20$ per peak watt. Complete systems generally consist of a PV array, battery storage, charge controller, and status instrumentation. Several of these NASA designed systems could be used immediately in the pulp and paper industry:

1. PV Powered Insect Survey/Kill Traps. NASA Lewis has designed power systems for field insect traps operated by the Agricultural Research Service near Texas A\&M University. PV power supplies permit great flexibility in siting traps for insect survey or control purposes. The PV power system itself has no moving parts and is considered highly reliable for remote siting. (See attachments 1 and 2. )

2. PV Powered Forest Lookouts. NASA Lewis has installed PV power systems in two remote forest lookout towers in northern California. These 300 watt solar cell arrays, with ancillary storage/control components, have delivered 100 percent availability for a period of years. They save the U.S. Forest Service the costs related to liquid fuel use. (See attachments 3 and 4 .)

3. Portable PV Supply for Remote Field Crews. NASA Lewis, in work funded by ERDA (1977), in cooperation with the National Park Service, designed, built, and demonstrated a PV-powered refrigerator at a remote location. The refrigerator operated satisfactorily over the 84-day test. The PV system was comprised of a 220 watt PV array, 600 ampere-hours of (Delco car type) battery capacity, a 4 cubic foot recreational type refrigerator and associated instrumentation and controls. The Park Service was extremely pleased with the system. (See attachments 5 and 6.) 
4. PV Powered Greenhouse Temperature Control. Dr. Ratajczak observed that a solar PV-powered greenhouse fan could be designed around the direct relationship between PV power output and greenhouse insolation heat gain.

Clearly, the economics of all of these PV-powered systems are key to their adoption by the industry. The systems appear to be very simple, highly reliable, easy to maintain, etc., but still rather expensive. NASA Lewis has the capability and practical design experience to be of great assistance to the industry in evaluating particular PV applications.

Reference(s):

(1) A.F. Ratajczak, "Photovoltaic-Powered Refrigerator Experiment at Isle Royale National Park, ERDA/NASA 1022/77/15, NASA TM 73703, June 1977.

(2) "Description and Status of NASA-LeRC PV Application System Experiments," DOE/NASA/1022-78/38, NASA TM-78936, June 1978.

* Most applicable taxonomy element.

**: Document contained in project file. 

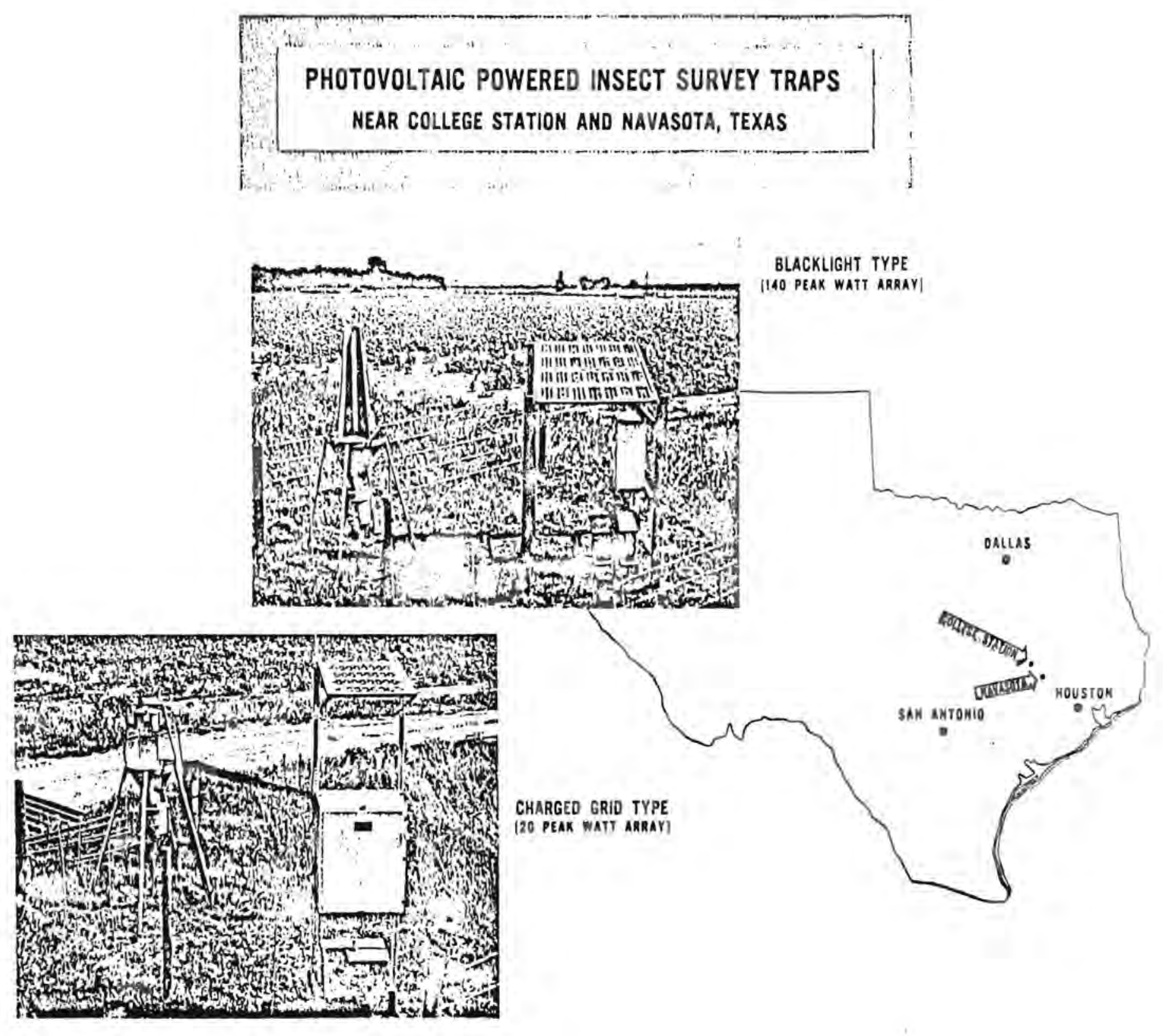
Solar cell arrays are now providing electric power for four insect survey traps near Texas A\&M University in College Station, Texas. The traps were designed and built by the Agricultural Research Service (ARS-Cotton Pest Control Equipment and Methods Research Unit) of the U. S. Department of Agriculture at College Station. The photovoltaic power systems for this joint ARS-NASA-ERDA experiment were designed by engineers at the NASA Lewis Research Center as part of the ERDA sponsored Photovoltaic Tests and Applications Project.

Insect survey traps are used to determine population patterns of harmful insects so that effective pest control programs can be initiated thereby reducing damage to crops. One type of trap utilizes a fluorescent blacklight to attract insects; another kills the insects on an electric grid after they have been attracted by a synthetic pheromone (sex attractant). To date, a network of these types of traps have been utility-powered by means of long extension cords; consequently, flexibility of siting was greatly limited. Now, ARS scientists are not constrained in the conduct of insect studies; traps can be placed in the most advantageous and effective locations.

The data gathered on insects collected by the network of traps is used in computer programs which allows ARS scientists to predict future insect populations.

Although the insect survey trap network near Texas A\&M is concerned particularly with the cotton boll weevil, similar traps are also used in many other locations for survey and / or control of other crop-destroying pests; consequently, the overall potential market for solar-powered units is believed to be significant. 


\section{PHOTOVOLTAIC POWERED FOREST LOOKOUTS}

LASSEN AND PLUMAS NATIONAL FORESTS, CALIFORNIA

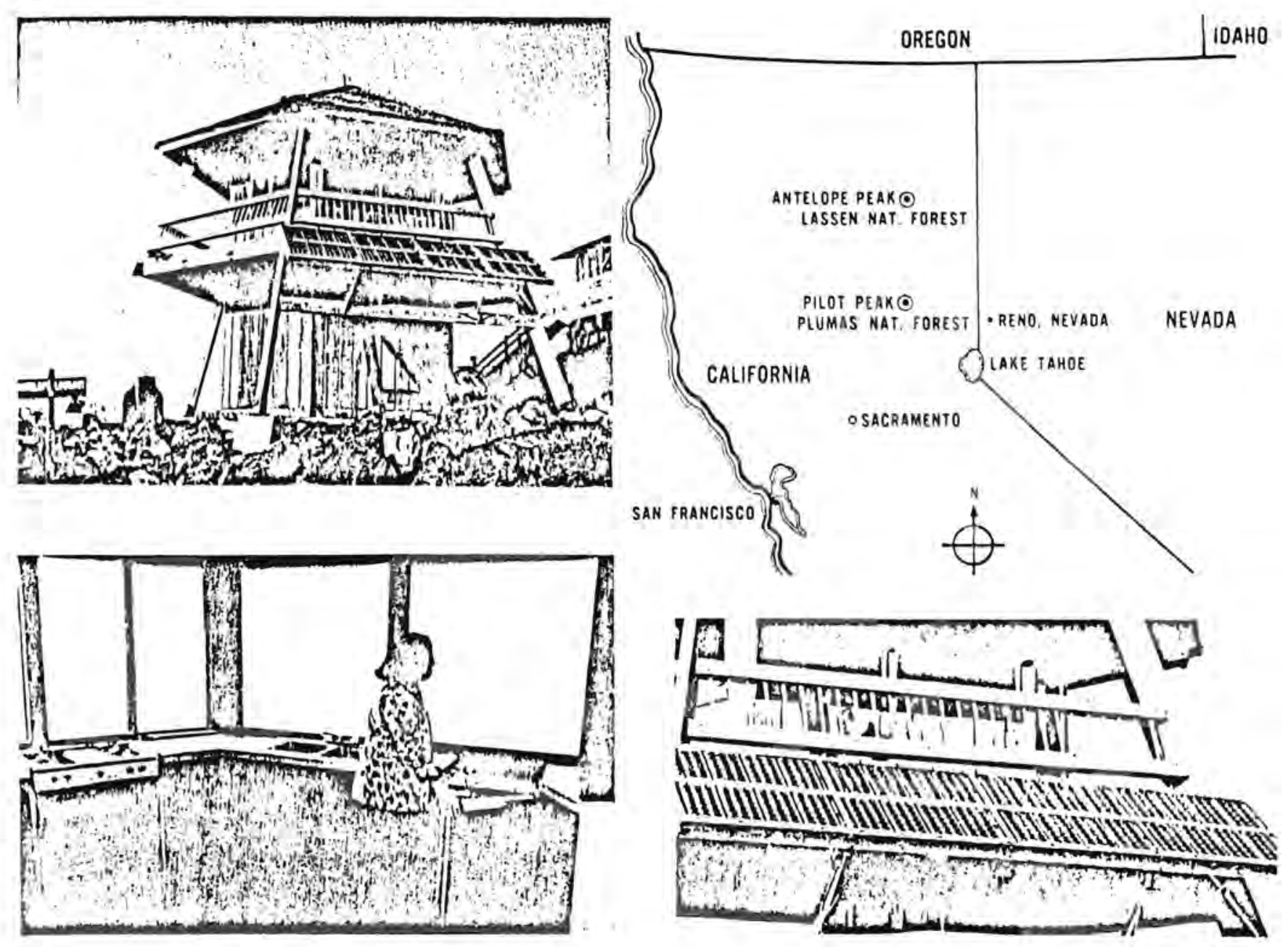




\section{Photovoltaic Powered U. S. Forest Service Forest Lookouts}

Three-hundred watt solar cell arrays are providing complete electrical power for each of two newly designed U. S. Forest Service forest lookout towers. The systems were installed in early October 1976 by NASA-LeRC personnel and are another of the applications being sponsored by the ERDA/NASA Tests and Applications Project.

Located on Antelope Peak in the Lassen National Forest and Pilot Peak in the Plumas National Forest (both in northern California), the towers are among the first of a new design which will eventually replace many old towers. The solar cell array was designed to blend harmoniously with the architecture of the building and provides power for a refrigerator, lights, water pump and Forest Service radio.

Each complete photovoltaic power system consists of a 300 watt solar cell array, 3000 ampere-hours of battery storage, a battery charge controller and instrumentation to indicate the status of the power system.

Photovoltaic power for forest lookouts will not only make living conditions considerably more pleasant for lookout personnel, but will also save the Forest Service the considerable time, trouble and expense of procuring, storing and transporting fuels to these remote locations for other types of electrical generators. 
PHOTOVOLTAIC POWERED REFRIGERATOR

AT WILDERNESS tRAIL CONSTRUCTION CAMP - ISLE ROYALE NATIONAL PARK - MICHIGAN

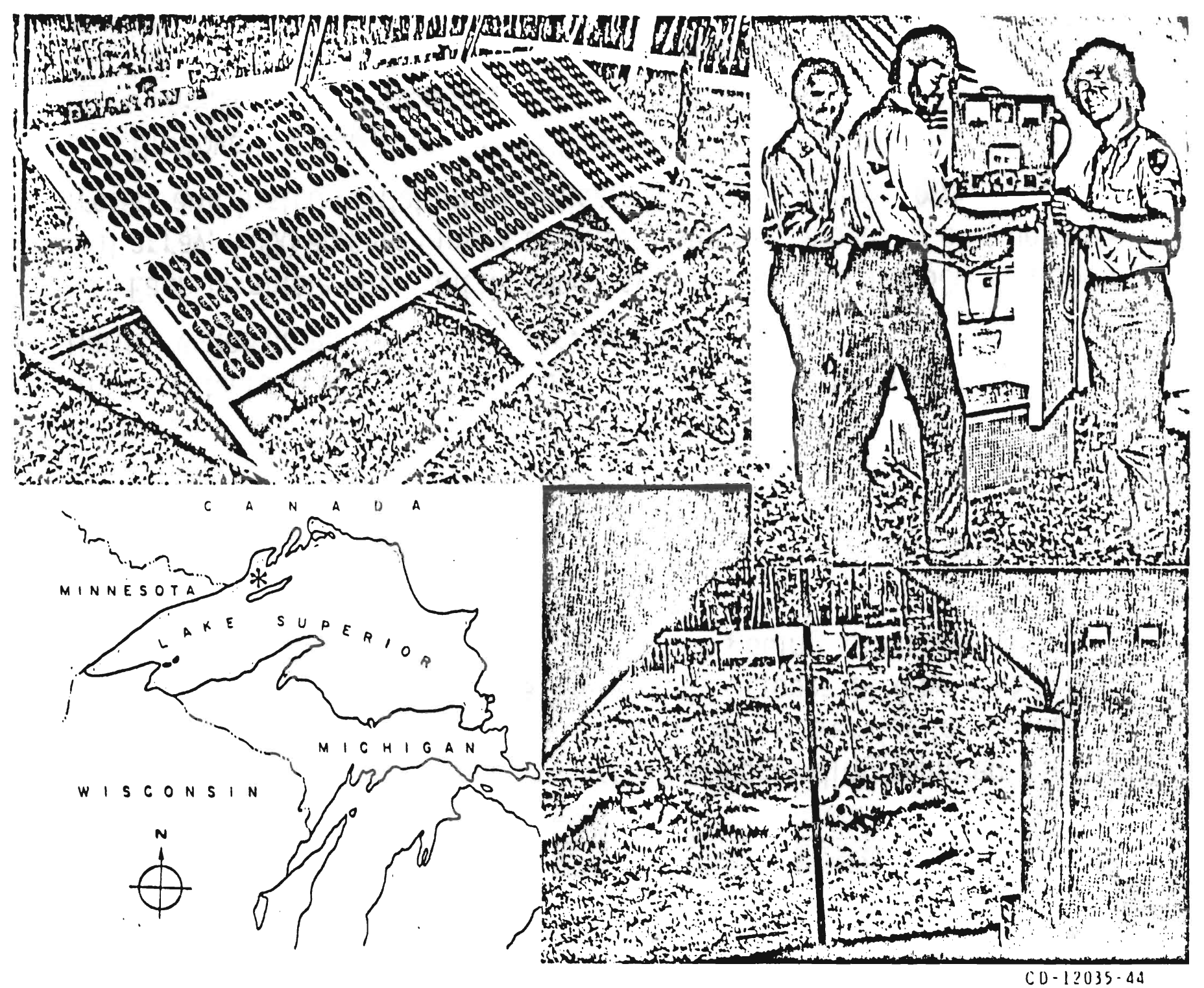




\section{Solar Cell Powered Refrigerator \\ Operating at Isle Royale National Park}

A 200 watt solar cell array is in operation powering a portable refrigerator, at a trail construction camp in Isle Royale National Park, Michigan.

This system, installed May 20, 1976, by LeRC Test and Demonstration Project personnel, is one of several tests planned by ERDA to demonstrate the versatility and timeliness of photovoltaic power.

Isle Royale National Park is a wilderness island in northern Lake Superior. Electrical power, generated on site, is available only at the Park Headquarters, the visitor center, and the lodge area.

Each year the island is visited by many thousands of visitors, $90 \%$ of whom hike and camp in the back country. Wilderness trails are constructed and maintained by trail crews working out of camps like the one at which the refrigerator is now located.

The remoteness of the camps allows for food resupply only once a week. With refrigeration, the crew can now enjoy a more varied and nutritious diet, including perishable foods.

Such photovoltaically powered refrigeration systems are ideal and cost effective for preserving not only food stuff but also medicines, for people living in out-of-the-way places or underdeveloped parts of the world. 
Technology: Bi-Phase Engine Application for Liquid Concentration

Applicable Taxonomy Element(s):

5.2 Chemical Pulping

10.0 Power and Chemical Recovery Systems $\star$

Laboratory: NASA Lewis

Contact: Harvey Bloomfield

Program Manager

(216) 433-4000

NASA Lewis has tested a Bi-phase engine for use as a brine separator. It appears that the $B i$-phase engine could be useful as a replacement for the first ( $f l a s h$ ) drying stage of black liquor concentration before the liquor enters a multiple effect evaporator. If feasible, significant drying energy could be saved. INEL (William Toth (208) 526-1801) is also technically informed in $\mathrm{Bi}$-phase engine applications; it has contractually supported such developments.

* Most applicable taxonomy element. 
Technology: Spray Nozzle Particle Size Control

Applicable Taxonomy Element(s):

5.2 Chemical Pulping (black liquor recovery boiler)

10.0 Power and Chemical Recovery Systems*

Laboratory: NASA Lewis

Contact: $\quad$ Robert W. Bercaw

Head, Advanced Energetics and Power Systems Section (216) 433-4000

The optimum black liquor droplet size as it enters the combustion zone of a recovery boiler is $\frac{1}{4} "$. Droplet size control is a key parameter for operation of the Tomlinson boiler. Recent sensor proposals, for example, have suggested means to monitor droplet size as the droplets leave the liquor gun and travel a distance of about 20 feet to the boiler wall. NASA Lewis, with a grant to the University of Washington, developed a technique for small (200 micron) droplet size control using an ultrasonic transducer at a nozzle. The periodic pressure imposed by the transducer forces a fixed fluid flow pulsation which becomes uniform size droplets as it leaves the nozzle. This technology has been used by IBM for its Ink Jet Printer. If the sonic approach could be extended to the $\frac{1}{4} "$ black liquor droplet spray gun, it appears that its application would be immediate.

* Most applicable taxonomy element. 
Technology: Multicomponent Liquid Separations Using a Continuous Annular Chromatograph

Applicable Taxonomy Element(s):

9.0 Waste Paper (decoating, deinking)

10.0 Power and Chemical Recovery Systems**

Laboratory: $\quad$ ORNL

Contact: J.R. Hightower or Chemical Technology Div.

or J.S. Watson

(615) 574-6777

Chemical Technology Div. (615) $574-6794$

Multicomponent liquid chromatographic separations have been achieved by using a slowly rotating annular bed of sorbent material. By continuously introducing the "to-be-separated" feed material at a stationary point at the top of the bed, and the eluent everywhere else around the annulus, elution chromatography occurs. The rotation of the sorbent bed causes the separated components to appear as helical bands, each of which has a characteristic and stationary exit point; hence, the separation process is truly continuous.

Chromatography is a method of separating various components from a mixture of chemical substances. It is particularly useful with mixtures of compounds whose chemical or physical properties are so nearly identical as to make other separation techniques difficult or impractical. In a chromatographic separation, a mixture is resolved into its individual components by the selective retardation of the components as they are transported through a bed of sorptive material by a moving fluid. The degree of retardation is determined by the relative affinity of each substance for the sorbent. Thus, in elution chromatography, the moving phase, referred to as the eluent, passes through a sorbent bed, upon which a mixture has been loaded, until all sample components have been eluted from the bed. The components move through the bed at rates depending upon the partition or distribution coefficient and are separated into zones which elute at characteristic times.

With its near universal applicability, versatility, and high resolution capabilities, chromatography lacks only throughput capacity to make it the ultimate separation technique. Typical chromatographic separations are made in fixed columns and, as such, are inherently batch in nature. Various attempts have been made to increase the capacity of chromatographic devices either through cyclic operations of large diameter columns, or through continuous feeding of a mixture and continuous removal of the components in moving-bed systems.

Three metal recovery systems, all using cation exchange resin as the sorbent, have been explored: (i) the separation of iron and aluminum, as obtained by an acid leach of coal fly ash, using a step gradient of ammonium sulfate in sulfuric acid as eluent; (ii) the isocratic separation of hafnium from zirconium, important to the nuclear industry; and (iii) the 
isocratic and gradient elution separations of copper nickel, and cobalt in ammonium carbonate solutions. The last system simulates the leach liquor of the Caron process for recovering nickel and cobalt from laterite oxide ores. The different colors formed by each of the metals allow visual observations of the progress of a separation and quantification of the separation using an in-line spectrophotometer.

In the pulp and paper industry the technique might find use in chemical recovery operations, e.g., from decoating and de-inking streams. Another possible application would be to recover formic, acetic, lactic, glycolic oxolic and saccharinic acids from the black liquor stream as potential coproducts. A simpler separation would recovery sodium saccharinate from the mixture of other products in alkali lignin. Sodium saccharinate has been shown to be a useful sacrificial adsorbant when used in enhanced oil recovery.

Reference (s):

(1) J.M. Begovich and W.G. Sisson, Chemical Tech. Div., ORNL, "A Rotating Annular Chromatograph for Continuous Metal Separations and Recovery," presented at Symposium on Resource Recovery and Environmental Issues of Industrial Solid Wastes, Gatlinburg, TN, October 28-30, 1981.

(2) J.M. Begovich and W.G. Sisson, Chemical Tech. Div., ORNL, "Continuous Ion Exchange Separation of Zirconium and Hafnium," for presentation at American Institute of Mining, Metallurgical and Petroleum Engineers Annual Meeting, Chicago, IL, February 22-26, 1981.

(3) R.M. Cannon, J.M. Begovich and W.G. Sisson, ORNL, "Pressurized Continuous Chromatography," Separation Science and Technology, 15 (3), 1980, pp. 655-678.*t

(4) R.M. Cannon, and W.G. Sisson, ORNL, "Operation of an Improved, Continuous Annular Chromatograph," Journal of Liquid Chromatogrpahy, 1 (4), 1980, pp. 427-441.tte

(5) C.D. Scott, R.D. Spence, and W.G. Sisson, ORNL, "Pressurized, Annular Chromatograph for Continuous Separations," Journal of Chromatography, 126, 1976, pp. 381-400.tot

* Most applicable taxonomy element.

** Document contained in project file. 
Technology: Combustion Research Facility

Applicable Taxonomy Element(s):

10.0 Power and Chemical Recovery Systems

Laboratory: Sandia National Laboratories, Livermore

Contact: William J. McLean

(505) $844-8170$

Current combustion research at Sandia includes major experimental and analytical studies of flame processes, both laminar and turbulent; detailed investigation of combustion processes in engines and power systems; and studies of the combustion characteristics of pulverized coal.

The experimental aspects of the Sandia combustion program emphasize developing and using advanced laser-optical diagnostic methods. These techniques, under development over the past decade, are proving capable of making detailed chemical and kinetic measurements in combustion environments previously inaccessible. Using lasers in conjunction with sophisticated optics and detectors, time-resolved species concentrations, temperatures, and velocities are measured within flames without disturbing the process. Detailed measurements such as these are seen by many as keys to understanding the combustion process.

In recent years Sandia research has demonstrated that these methods can measure major species, and in some cases minor species, along with important combustion intermediates. However, access to the details of trace species concentrations requires that higher-powered, speciallydesigned lasers and diagnostics equipment be developed, and it is toward these ends that a major portion of the program is aimed. Figure 1 shows how the specially-designed lasers are made available to all labs.

To support this work, the Department of Energy, through its Office of Energy Research, has established a Combustion Research Facility at Sandia National Laboratories, Livermore. Here the resident research staff develops the advanced diagnostic methods needed, applies them to combustion studies, and makes the technology available to other researchers. To promote this transfer, the facility is open for use by qualified visiting researchers.

of particular interest to prospective outside users of the facility are its unique complement of sophisticated diagnostics equipment, its broad continuing program of combustion research, and the opportunity to interact with an extensive resident research staff representing relevant disciplines. A current industrial user of the facility is Weyerhaeuser. An open invitation exists to others to conduct non-proprietary research 


\section{Beam Distribution System Allows Use of Each Major Laser in All Labs}

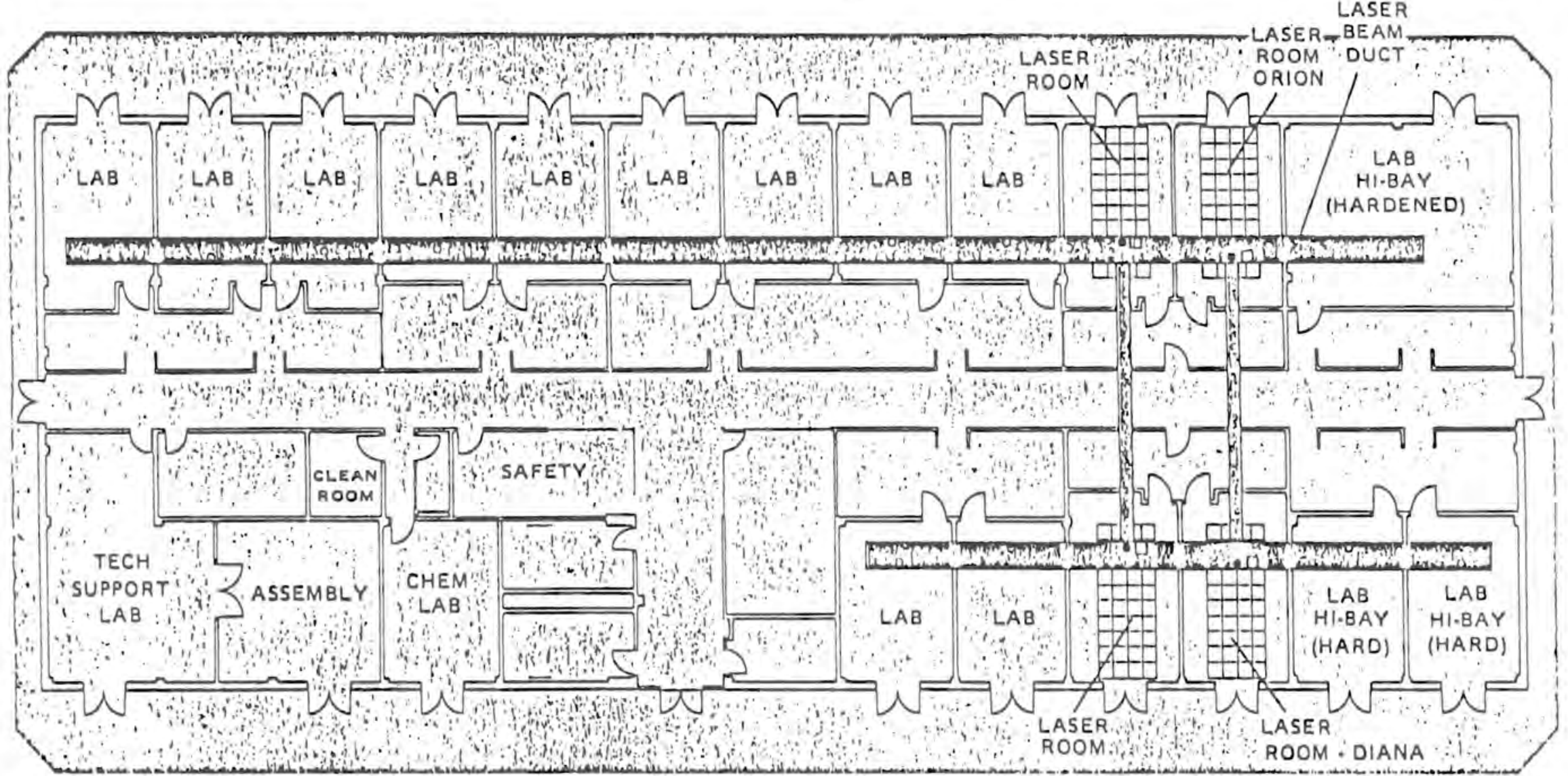

THROUGH A COMPLEX SYSTEM OF PERISCOPES AND DUCTS, THE OUTPUT OF EACH OF THE FACILITY LASERS CAN BE DELIVERED TO ANY LAB EXPERIMENT AREA DESIRED
- RECEIVING PERISCOPES \& MIRRORS

- tRANSMITTING PERISCOPES \& MIRRORS

- RELAY MIRRORS 
in the facilities on a no-cost recovery basis. The laboratory will provide lab space and technician and researcher assistance to the visiting researcher(s). It is probable that research tasks on black liquor and wood combustion could each be conducted here.

Reference(s):

(1) Sandia National Laboratory, Livermore, "Combustion Research Facility, n.d.

(2) W.J. McLean, "Ignition of Pulverized Fuels," SNLL, n.d.

(3) W.J. McLean, D.R. Hardesty and J.H. Pohl, "Direct Observations of Devolatizing Pulverized Coal Particles In a Combustion Environment," SNLL, n.d. 
Technology: Management Oversight and Risk Tree (MORT) System for Evaluating and Managing Environment, Safety and Health Information

Applicable Taxonomy Element(s):

11.0 Health, Safety, and Pollution Control Systems

Laboratory: INEL

Contact: $\quad$ J.L. Clark

Manager, Systems Safety Division

(208) 526-1357

Idaho National Engineering Laboratory has been designated the lead Federal Center for developing, implementing and coordinating all safety programs. In this role they have developed over the years an outstanding capability not only in industrial safety per se, but rather the entire subject of plant management that minimizes oversights, errors and omissions in evaluating risks, and properly allocates resources to permit only acceptable hazards to exist. The expenditure of an infinite amount of capital can bring the level of risk to zero. Any lesser expenditure permits some level of risk - hence hazard to exist. The Management Oversight and Risk Tree (MORT) MORT system permits the systematic analysis of risks and consequences which in turn permits the proper allocation of resources to maintain an acceptable hazard level.

The system has reached a level of sophistication such that it is far more than another management tool, it is indeed an extremely comprehensive management system that considers all aspects of plant operation.

The System Safety Development Center at INEL has now shared the MORT Concept with many private corporations and foreign countries. They hold seminars each year on the MORT program and its detailed implementation. A list of the scheduled 1982 seminars follows:

FY-1982

\section{SEMINAR-WORKSHOP SCHEDULE}

\section{Activity}

Operational Readiness (Pilot)

MORT Seminar

A/I Refresher

A/I Workshop

Appraisal Workshop

Risk Analysis Workshop

Operational Readiness

MORT Seminar
Location

Idaho Falls, ID

Knoxville, TN

Knoxville, TN

Knoxville, TN

Dublin, CA

Las Vega, NV

Rockville, MD

New Orleans, LA $\underline{\text { Dates }}$

March 9-11, 1982

March 8-12, 1982

March 9-11, 1982

March 30-April 8, 1982

April 5-9, 1982

April 19-23, 1982

May 4-6, 1982

May 17-21, 1982 
A/I Workshop Appraisal Workshop MORT Seminar A/I Refresher Operational Readiness Operational Readiness Appraisal Workshop

Risk Analys is Workshop A/I Workshop
Richland, WA Las Vega, NV

Albuquerque, NM

Albuquerque, NM Boise, ID Cincinatti, $\mathrm{OH}$ Idaho Falls, ID Albuquerque, NM New Orleans, LA
June 8-17, 1982

June 28-July 2, 1982

July $12-16,1982$

July 13-15, 1982

July 20-22, 1982

August 3-5, 1982

August 9-13, 1982

August 23-27, 1982

September 14-24, 1982 
Technology: Enzymatic Hydrolysis of Celluslose $\left(\mathrm{C}_{6}\right)$ and Hemicellulose $\left(C_{5}\right)$

Applicable Taxonomy Element(s):

10.0 Power and Chemical Recovery Systems

11.0 Pollution Control Systems*

Laboratory: JPL

Contact: Minoo Dastoor

Chemical and Biological Processes Section

(213) $354-7429$

JPL has been engaged in evaluating enzymatic hydrolysis of both cellulose and hemicellulose. They have evaluated anaerobs that convert $C_{6}$ cellulose to methane and/or methanol and $\mathrm{C}_{5}$ hemicellulose to furfurol alcohol. This work has been primarily directed towards the production of useful fuels or feedstock from cellulosic materials.

It was recommended, however, that the waste streams from both groundwood and Kraft processes have high fiber content and as such represent a potential feedstock for such reactions. The relative uniformity of the waste stream (compared to municipal waste for example) would greatly simplify the conversion of the cellulosic fractions to useful products. Were such an application successful it would provide another product from the mill, while simultaneously reducing the quantity of waste requiring disposal.

JPL has also investigated a technique for quantitative recovery of lignin from waste streams using quaternary ammonium compounds and methanol. This technology coupled with enzymatic hydrolysis could be very effective for total recovery of waste streams.

Reference(s):

(1) W.P. Buttler, "Technical Support Package on Extracting Lignin from Mill Wastes," for NASA Tech. Brief Winter 1976, Item 46 from JPL Invention Report 30-3572/NPO-13847 (Pasadena, CA: Jet Propulsion Laboratory, March 1977).

* Most applicable taxonomy element. $*$ Document contained in project file. 
Technology: Estimating Environmental Movement of Toxicants with Multi-media Models

Applicable Taxonomy Element(s):

\subsection{Health, Safety and Pollution Control Systems}

Laboratory: ORNL

Contact: Charles C. Coutant

Environmental Sciences Division

(615) $574-7386$

ORNL has developed a family of multi-media models to estimate the environmental movement of toxicants. The problem is to estimate likely exposure for new chemicals or for new processes using existing chemicals prior to initiation of the activity so that potential risks can be managed. Numerous mechanisms operate to move toxic materials away from their point of origin to locations where organisms are exposed directly or through the food chain.

ORNL's family of submodels, called Unified Transport Model for Toxicants (UTM-TOX) combine physical-chemical data on toxicants, mechanisms of dispersal and accummulation, and environmental data for typical or specific sites.

Some models are simplistic and provide rough worst-case approximations, while other models go to great length to incorporate more realistic mechanisms and the environmental factors which influence them.

The ability to estimate toxicant exposure to humans and their environment generally means decreased cost of treatment or cleanup due to decreased need for high margins of error in planning facilities or activities to meet acceptable risk levels.

These models are under continuous development and are available for use in the current version at any time. The UTM-TOX is funded by the National Science Foundation and the Environmental Protection Agency. It could be appropriate to planning of new pulping facilities, integrated mills, or the making of significant process changes in existing facilities, e.g., to bleaching operations or coating operations.

Reference(s):

(1) C.C. Coutant, "Technical Highlight: Estimating Environmental Movement of Toxicants with Multi-Media Models," ORNL, n.d. $\neq-1$

相 Document contained in project file. 
Technology: Waste Water Treatment (Anaerobic Digestion)

Applicable Taxonomy Element(s):

\subsection{Pollution Control Systems}

Laboratory: ORNL

Contact: $\quad$ T. Donaldson

Chemical Technology Division

(615) $576-4853$

Pilot plant is a 16 feet diameter by 10 feet high column; it uses fixed film bacteria on the packed bed (packing fraction $70 \%$ ); pilot plant rating is 50,000 gallons per day ( $\mathrm{gpd}$ ), but it is operating at 15,000 gpd. Methane is vented to the air; sufficient is generated that if captured it would sustain required generation of power. Analysis indicates that on plant sizes below $10^{6} \mathrm{gpd}$ there is cost advantage versus activated sludge, in both operating and capital costs. Feed to the packed bed is via a rough filter and it comes after the primary settling basin; $\mathrm{pH}$ into the packed bed is 7 , and the $\mathrm{pH}$ out is 5.5 . Bed reduces BOD by 55 percent and TSS by 65 percent; bed has operated two years without plugging. 
Technology: Enhanced Oil Recovery Using Weak Black Liquor or Bleach Plant Effluent

Applicable Taxonomy Element(s):

\subsection{Pollution Control Systems}

Laboratory: ORNL

Contact: James S. Johnson, Jr.

Chemistry Division

(615) $574-4982$

When an oil reservoir can no longer be produced by primary means (the use of pumps and natural reservoir pressures), resort is made to secondary means such as chemical flooding of the formation using an injection of a surfactant emulsion, permitting additional oil to be removed from rock pores and pumped to the surface. As the flood of emulsion and oil proceeds through the formation from the injection well to the recovery well, surfactant is adsorbed from the emulsion onto sandstone surfaces in the formation with the result that the efficiency of pore scrubbing is reduced as a function of distance from the injection well. To reduce surfactant loss it is possible to include in the emulsion a sacrificial adsorbate which is adsorbed by sandstone in preference to the surfactant.

Research is reported on manufacture of surfactants from tall oils recovered in softwood pulping and, in the use of weak black liquor and bleach plant effluents as sacrifical adsorbants. The tall oil is very effective in reducing interfacial tensions; effectiveness is not strongly correlated with tall oil concentration, a favorable observation. Research is also reported on the effectiveness as sacrificial adsorbants of several substances generated in the pulping of wood; specifically results were:

- ligno sulfonate - sharp reduction of adsorption

o caustic extract - same as ligno sulfonate

o weak black liquor - substantial effect but not sharp

- sodium saccharinate - same as weak black liquor

- acid bleach - relatively ineffective

- kraft liquor - relatively ineffective (can be made very effective by sulfonation to ligno sulfonate)

Reference(s):

(1) A.L. Compere et al., "Chemicals for Enhanced Oil Recovery Biennial Report for the Period April 1978-March 1980," DOE/BETC/ OR-11, prepared by ORNL for U.S. DOE, March 1981. (Available from NTIS) $\cdots+\dot{*}$ 
Reference(s) (Continued):

(2) A.L. Compere et al., "Chemicals for Enhanced Oil Recovery Semiannual Report for the Period April 1-September 30, 1980," DOE/BETC/OR-18, prepared by ORNL for U.S. DOE, November 1981. (Available from NTIS)

(3) United States Patent 4,313,500, "Sacrificial Adsorbate for Surfactants Utilized in Chemical Floods of Enhanced Oil Recovery Operations," Johnson, Jr., et al., February 2, 1982.

* - Document contained in project file. 
Technology: Real Time Dust Mass Monitoring System

Applicable Taxonomy Element(s):

\subsection{Pollution Control Systems}

Laboratory: Sandia National Laboratories, Livermore

Contact: James C.F. Wang

(505) $844-8170$

The mass loading and size distribution of particulate emissions from industrial stacks are critical parameters which the EPA uses for air pollution monitoring and control. Presently, commercial particle detectors are either optical devices which do not measure particle mass directly, or physical sampling devices which do not provide real-time measurements. Futhermore, the accuracy of these measurements suffers from many inherent shortcomings in the instruments when they are adapted from the laboratory bench to an industrial stack. For example, the optical properties of the particulate matter are required for optical techniques, but in a stack exhaust, these properties are generally not known a priori and many also change in time. Maintaining a clean window for optical access is also a very difficult task.

Physical sampling techniques, on the other hand, involve sample withdrawal by a probe, with consequent dilution or cooling of the sample, or both. Also, the particle size in the sample may change because of agglomeration and condensation of gaseous species during dilution or cooling. Futhermore, the particle analysis is usually performed off-line and may be biased or dubious because of difficulties associated with redispersion of the particles in the analyzer.

Recently, at Sandia National Laboratories the feasibility of using a tapered-element oscillating microbalance (TEOM) for real-time particle mass measurements at room temperature has been demonstrated. This mass monitor measures the actual weight of the particles collected from a sampled gas stream in real time. Thus, measurement biases of the type encountered in conventional physical sampling techniques are minimized.

To improve the measurement accuracy of the physical sampling technique further, a new TEOM for high-temperature applications (up to $300^{\circ} \mathrm{C}$ ) is being developed in which the sampled gas can be kept at the stack gas temperature during measurements. Furthermore the new TEOM is designed to be interfaced to a multi-staged cyclone train (one TEOM/cyclone) for real-time aerodynamic particle size fraction measurements. This new TEOM/cyclone system has been designed; laboratory tests on various components have been conducted, and preliminary results on these tests are available.

The new TEOM detector operates as follows: Briefly, the tapered fiber element is clamped rigidly at the wide end with high-temperature cement. A dust collection cup is mounted rigidly on top of the narrow end of the 
tapered element; together, the parts are set in oscillation between a set of electrically-charged plates. The oscillation of the fiber element is monitored by a light emitting diode (LED) and a photo-transistor at $90^{\circ}$ to the direction of the oscillation. Because of the temperatures encountered, the LED and photo-transistor are placed in a box outside the detector assembly. Two high-temperature optical fibers are used to transmit the LED signal and to carry the oscillation signal to the photo-transistor, respectively. The oscillation signal from the photo-transistor is then amplified and fed to the conductive surface of the TEOM fiber. This feedback arrangement maintains the fiber oscillation, whose natural frequency will change in relation to the mass deposited on the dust collection cup; in a typical configuration collection of $300 \mathrm{mg}$ in the cup causes the natural frequency to shift by 25 percent, from $200 \mathrm{cps}$ to $150 \mathrm{cps}$. The sensitivity and frequency are chosen by proper dimensioning of the oscillating tapered element.

An in-the-field test of the TEOM will take place in a stack at the Willows Creek, TN TVA power station in late summer; results will be compared with those acquired in EPA Method Five testing. The device may have application in monitoring and control of mass and size distribution of particulate emitted at integrated mill sites.

Reference(s):

(1) J.C.F. Wang, H. Pataschnick and G. Rupprecht, "Recent Developments on a Real Time Particulate Mass Monitor for Stack Emission Application," Journal of the Air Pollution Control Association, Vol. 31, No. 11, November 1981.

(2) J.C.F.Wang, H. Pataschnick and G. Rupprecht, "A New Real-Time Iso-Kinetic Dust Mass Monitoring System," Journal of the Air Pollution Control Association, Vol. 30, No. 9, September 1980. 
Technology: Economic Evaluation and Sensitivity Analysis

Applicable Taxonomy Element(s):

\subsection{Process Control Systems}

Laboratory: INEL

Contact: Steve Metzger

Manager, Engineering Economics

(208) $526-1884$

The Engineering Economics Branch of INEL has experience evaluating alternative energy technologies to determine the financial feasibility of implementing new systems or process changes. Computer models are available which allow parametric sensitivity analysis of individual components in the economic model and which perform Monte Carlo simulation of projects to determine profitability risk profiles. The resulting financial data can be used by executives to evaluate the expected return from a project or by advocates of a technology to market new processes. (The models are referenced in the reports below.)

Reference(s):

(1) Alternate Energy Technical Development Project No. 907 Task Force, "Assessment of Biomass as an Alternative Energy Source," Internal Technical Report No. PGA-81-049, EG\&G Idaho, Inc., September $1981 . *$ *

(2) Energy Programs Division, INEL, "Title X Sunset Provisions Institute of Conservation Programs Division, "Internal Report BRC 非F0104000.

the Document contained in project file. 
Technology: $\cdots$ Sensors and Controls Signal Validation

Applicable Taxonomy Element(s):

\subsection{Process Control Systems}

Laboratory: INEL

Contact: Ronne W. Brower

Data Integrity Section

(208) 526-9503

INEL, through its nuclear programs, has developed real time capability in process control systems. With the necessary and complicated control systems in nuclear reactors, appreciation for adequate system sensors and the analysis of data from such sensors has gained a magnitude in the prediction of instrumentation failures. Data validation techniques allow interpretation of sensor signals as real systems data or as spurious signals from potentially malfunctioning sensors. The Automated Data Qualification (ADQ) program uses statistical techniques to qualify information from sensors. These statistical techniques serve as the basis for systematic evaluation of measurement information. The functions used are called information quality functions (IQF) and estimated data quality (EDQ).

IQFs are basically algorithms which test some detectable attribute of time series data against known system parameters. At times, manipulations on the data stream (for example, transformation from time to frequency domain or separation of signal and noise) are required before the test is applied. IQFs have been defined so as to produce a binary (pass condition/fail condition) result. Data are inspected using the moving window.

A hierarchy of IQFs can be defined for data qualification that is independent of particular physical systems. Classes within the hierarchy represent increasing information requirements. The lowest level requires only the original data stream. Somewhat more advanced qualification is possible with two or more original data streams. Further sophistication can be achieved using a single stream and historical factors including calibrations, known environmental stresses, and operating characteristics such as range and uncertainty. The highest level of $I Q F$ requires multiple data streams as well as historical data. The classes within the hierarchy indicate the computer resources needed for implementation and also establish whether single- or multiple-channel analyses are applicable. Each class of IQF can have various implementations, and the list of functions found useful to data can be extended on alternative statistical procedures. This offers a broad choice of functions depending on desired level of confidence, information available about the physical system, and computational resources at hand. 
After IQFs have been chosen and implemented, the task remains to use them to produce a single EDQ function; current practice has been to normalize EDQs. Weighted averages of IQFs have been employed and allow users to specify the relative importance of each IQF. Weighted products have also been used and are especially sensitive to low level IQFs. The weights chosen in either case are situation dependent. For instance, IQF redundancy could be given more emphasis than IQF noise in systems where both factors are present.

ADQ produces estimates of data quality based on known measurement system performance characteristics augmented with knowledge of the physical processes underlying the plant or equipment under observation. The technique can provide quantitative estimates of measurement integrity to reduce the probability that decisions will be based on false data. It can also be employed to develop information about the present and probable future health of the measurement system for use in reducing down time through preventive maintenance. $A D Q$, however, cannot produce good data from bad or improve the signal-to-noise ratio.

The choice among IQFs and EDQs depends on need for data quality assurance. If the only concern is the possibility of measurements going out of range, the IQF might simply be a limit check and no EDQ may be necessary. If it is desired to have continual estimates of overall measurement system health, data channel quality, and time to failure, the functions will be complex and will involve substantial resources beyond the basic instrumentation.

A natural function of $A D Q$ is the ability to predict instrument failure, that is, certain IQFs will indicate imminent instrument failure. In addition to failure prediction, calibration coefficient correction is possible for degraded instruments.

\section{Reference(s):}

(1) Ronnie W. Brower and Lorenzo D. Goodrich Jr., "A Summary of Automated Data Qualification Development at the INEL," EGGLOFT-5737. Prepared for U.S. NRC, EG\&G Idaho, Inc., January 1982. ㄴ.t

(2) Richard R. Good, Ronnie W. Brower and Lorenzo D. Goodrich Jr., "Automated Data Qualification," INTECH, October 1981. the

th Document contained in project file. 
Technology: Failure Modes and Effects Analysis and Statistical Analysis

Applicable Taxonomy Element(s):

\subsection{Paper and Paperboard Production (statistical analysis of breakage locations) \\ 12.0 Process Control Systems}

Laboratory: INEL

Contact: $\quad$ J.A. Close

Decision Analysis Supervisor

(208) 526-1233

INEL has developed for DOE powerful reliability methods for assessment of reactor systems. Design Optimization has been developed to allocate redundancy in an optimal manner to reduce cost and maximize plant availability. Another technology is the analysis of fault trees on the Computer Aided Design (CADS) System increasing the analyst's productivity. These methods are generic and can be applied to any system when incorporated early in the design stage of the system to improve availability and reduce cost in any plant operation. Software implementing these methods has been developed and is used in the nuclear industry. In particular, these methods provide a useful way of assessing common cause failures and are applicable in identifying instrument failures in process control systems making a system more efficient in the production phase. INEL also has expertise in all areas of statistical analysis.

Reference(s):

(1) D.M. Rasmuson, "Integrating Reliability Analysis and Design," ALO-131, EGG-IS-5187, prepared for U.S. DOE, EG\&G Idaho, Inc., July $1980 . *+1$

(2) A.J. Nelson, "Research Engineering and Construction Report," RE-A-77-101, September 1977.

* Most applicable taxonomy element.

$\stackrel{*}{*}$ Document contained in project file. 
Technology: Fiber Optic Information Network

Applicable Taxonomy Element(s):

\subsection{Process Control Systems}

Laboratory: LLL

Contact: John Severyn or Thomas B. Hirschfeld

(415) 422-4599

Lawrence Livermore has a Local Area Network, Camac, for rapid transmission of experiment and control data within the laboratory; the system is fiber optics based. It was designed by Ethernet, Palo Alto, CA, and built by Intel, DEC and Xerox; interfaces and chips by Intel, software by $\mathrm{DEC}$, consoles and readouts by Xerox.

Fiber optic fluorimetric analysis is also LLL capability; laser pulses generated far from the "to-be-analyzed" material (up to a km) fluoresces the material and the light emitted returns via fiber optics to a fluorescence spectroscope for identification and quantification of the material.

The lab is also a leader in design and manufacture of fiber optic connectors (contact R. Reedy). All of the foregoing may have application in interconnection of heirarchial automatic control systems within an integrated pulp and paper mill. 
Technology: Complex, Multivariable Real Time Simulation and Control

Applicable Taxonomy Element(s):

\author{
2.3 Yield Management \\ 12.0 Process Control Systems*
}

\author{
Laboratory: NASA Lewis \\ Contact: John Szuch \\ Head, System Dynamics Section, \\ Physics and Electronics Division \\ (216) $433-4000$
}

In the pulp and paper mill there are many opportunities for process monitoring, analysis, and control using computer-aided systems. In addition to the need for improved sensors, there is a need for large and rapid computational facilities to approach real time simulation of the complex processes involved. Examples are in chemical pulping, bleaching, paper making, and black liquor recovery in the Tomlinson boiler. Real time process simulations would enable the evaluation of new process control laws and the verification of control software prior to building control hardware and operating it in expensive inplant tests.

Pulp and paper processes are ideal candiates for sophisticated, on-line computer control. A significant barrier to the development and use of such systems, however, is the size and complexity of the processes to be controlled, and the risk of production loss accompanying control testing in the mill. In addition, the forest products industry would be served by the development of computer-aided command control systems to simulate and predict the behavior of forest fires. This type of system should be highly portable and yet requires a large and rapid computing capability.

NASA Lewis has developed hybrid (analog and digital) computer models to successfully simulate the real time operation of aircraft turbine engines. The major purpose of this work was to support the development of advanced engine controls. The hybrid computer allowed the achievement of high steady-state and dynamic accuracies with reasonable solution times for engine simulation. Hybrid computer simulation is often viewed as an art requiring specialists in dynamic system modeling, computer programming, and computer operations.

The NASA Lewis capability in hybrid computer simulation is possibly superior to any analogous capability within the pulp and paper industry or its control equipment suppliers. The Center, funded by an industry association or by another agency such as the Department of Energy, could conceivably apply its experience in hybrid computer simulation to pulp and paper industry processes in a focused, directed effort. An analogous program is that for sensor development being performed for the Department of Energy by the National Bureau of Standards, guided by a steering committee from the pulp and paper 
industry. Such a direct industrial application of the NASA Lewis capability would require a top level policy change and probably Congressional action. However, the likelihood of major advances in U.S. process control technology in the industry, which now lags far behind that of other nations, appears high. The pulp and paper industry's positive experience with the NBS Sensor Program has provided recent proof that a highly specialized research group from outside the industry can make an important, otherwise lost technical contribution through directed $R \& D$.

\section{Reference(s):}

(1) John R. Szuch, Susan M. Krosel, and William M. Burton, "An Automated Procedure for Developing Hybrid Computer Simulations of Turbofan Engines," NASA Technical Memorandum 81604, prepared for Fourteenth Annual Simulation Symposium, Tampa, Florida, March 18-20, 1981.:-

(2) John R. Szuch, James F. Soeder, Kurt Seldner and David S. Cwynar, "F100 Multivariable Control Synthesis Program - Evaluation of a Multivariable Control Using a Real Time Engine Simulation," NASA Technical Paper 1056, October 1977.

(3) R.A. Blech and D.J. Arpasi, "An Approach to Real Time Simulation Using Parallel Processing," NASA Technical Memorandum 81731, prepared for 1981 Summer Computer Simulation Conference, July 15-17, 1981.

* Most applicable taxonomy element.

is Document contained in project file. 
Technology: Process Control Engineering and Software Development

Applicable Taxonomy Element(s):

12.0 Process Control Systems

Laboratory: ORNL

Contact: $\quad$ Eugene C. Hise

Engineering Technology Division

(615) 574-0777

Few locations exist which: (1) house engineers familiar with so many diverse processes (2) retain sophisticated research tools to analyze and describe processes and the parameters of their control (3) have specialists in instrument design and manufacture (4) are staffed with mathematicians to prepare the alogrithms for process control, and (5) have software and hardware specialists broadly experienced in implementation of automatic control systems.

Oak Ridge National Laboratory is such a location and is prepared to engineer automatic control systems for unit processes and multi-level systems for the PPI and other industries. 


\section{DISTRIBUTION}

No. of

Copies

OFFSITE

5 William B. Williams

Department of Energy

Office of Industrial Programs

Forrestal Building

1000 Independence Avenue, S.W.

Washington, D.C. 20585

$30 \mathrm{Jim}$ Reed

Energetics, Inc.

2000 Century Plaza

Suite 447

Columbia, MD 21044

Yuk io Nakamura

Energy Conservation Technology

Jet Propulsion Laboratories

4800 Oak Grove Lane

Pasadena, CA 91103

Thomas J. Wilbank

Energy Division

Oak Ridge National

Laboratory

P. 0. Box $X$

Oak Ridge, TN 37830

Donald Jarad

Technology Utilization

Oak Ridge National

Laboratory

P. 0. Box $X$

Oak Ridge, TN 37830

Roger Batzel

Lawrence Livermore National

Laboratory

P. 0. Box 808

Livermore, CA 94550

125 S. F. Sobczynski

Office of Industrial Progress

Department of Energy

Forestal Bldg.

Washington, DC 20585
No. of

Copies

\section{OFFSITE}

Gerald Richards

Research Technology Utilization Lawrence Livermore National

Laboratory

P. 0. Box 808

Livermore, CA 94550

Robert Toth

EG\&G Idaho

Idaho National Engineering

Laboratory

P. 0. Box 1625

Idaho Fal ls, ID 83401

Lloyd I. Shure

Planning Analysis and Systems

NASA Lewis Research Center

21000 Brookpark Road

Cleveland, $\mathrm{OH} 44135$

Harrison Allen, Jr.

NASA Lewis Research Center

21000 Brookpark Road

Cleveland, $\mathrm{OH} 44135$

Donald A. Beatty

NASA

600 Independence Avenue, S.W.

Washington D.C. 20546

William Thielbahr

Department of Energy

Idaho Operations Office

550 2nd Street

Idaho Falls, ID 83401

Nallan C. S. Chari

Process Engineering \& Control

Owens-Illinois, Inc.

P. 0. Box 1035

Toledo, $\mathrm{OH} 43666$ 


\section{DISTRIBUTION (Contd)}

No. of

Copies

OFFSITE

J. Keith Davy

10928 Longmeadow Drive

Damascus, MD 20750

William L. Adams

Accuray Corporation

650 Ackerman Road

Columbus, $\mathrm{OH} 43202$

Heinz Walbaum

Proces Instruments Development

International Paper Company

Corporate Resource Center

P. 0. Box 797

Tuxedo Park, NY 10987

John D. Higham

Engineering

Impact Systems

1821 Zanker Road

San Jose, CA 95112

Dale Raymond

Union Campe, P. 0. Box 412

R\&D Development Division

Princeton, NJ 08540

Del R. Raymond

Energy Department

Fiber Products R\&D

Weyerhaeuser Company

Tacoma, WA 98477

Peter Ariessohn

WTC 1830

Weyerhaeuser Company

Tacoma, WA 98477

C. R.:O'Bannon

Fiber Process Control

WTC-1K2

Weyerhaeuser Company

Tacoma, WA 98477
No. of

Copies

OFFSITE

Ole K. Fadum

The Foxboro Company

Foxboro, MA 02035

Peter F. McCrea

Corporate Research

The Foxboro Company

Foxboro, MA 02035

John Janssen

Technology Strategy Center

Honeywel1 Control Systems

1700 West Highway 36

Roseville, MN 55113

C. P. Donofrio

Technical Planning and

Surveillance

Champion Papers

Knoghtsbridge

Hamilton, $\mathrm{OH} 45020$

W. Cy Rut ledge

Central Research

Mead Corporation

8th \& Hickory Streets

Chillicothe, $\mathrm{OH} \quad 45601$

Craig Stansbury

American Paper Institute, Inc.

260 Madison Avenue

New York, NY 10016

Dudley F. Church

Crown Zellerbach

P. 0. Box 5035

Vancouver, WA 98663

Maxcy C. Rivk in

Director of Research

Westvaco Research Laboratory

Johns Hopk ins Road

Laure 1, MD 20810 


\section{DISTRIBUTION (Contd)}

No. of

Copies

OFFSITE

Gary A. Baum

Paper Physics Section

The Institute of Paper Chemistry

P. 0. Box 1039

Appleton, WI 54912

Robert A. Bareiss

St. Regis Paper Company

Technical Center

West Nyack Road

West Nyack, NY 10994

Robert J. Pfeifer

Accuray Corporation

650 Ackerman Road

P. 0. Box 02248

Columbus, $\mathrm{OH} 43202$

Keith Hardacker

The Institute of Paper Chemistry

P. 0. Box 498

Appleton, WI 54912

Stanley Sobczynski

Department of Energy

Office of Industrial Programs

Forrestal Building

Room 6E-034

1000 Independence Avenue, S.W.

Washington, D.C. 20585

James Whetstone

Fluid Engineering Division

Building 230, Room B-120

National Bureau of Standards

Washington, D.C. 20234

27 DOE Technical Information

Center

DOE Richland Operations Office

H. E. Ransom
No. of

Copies

ONSITE

35 Pacific Northwest Laboratory

C. H. B Toomster

M. Clement

D. E. Deonigi

L. L. Fassbender

B. A. Garrett-Price

N. L. Moore (21)

L. D. Williams

Technical Information Files (5)

Publishing Coordination (2)

Distr. 3 
, 